\title{
Water Integration Project Science Strategies White Paper
}

\author{
A. K. Yonk
}

September 2003

Idaho National Engineering and Environmental Laboratory Bechtel BWXT Idaho, LLC 
INEEL/EXT-03-00734

\title{
Water Integration Project Science Strategies White Paper
}

\author{
A. K. Yonk
}

September 2003

Idaho National Engineering and Environmental Laboratory Idaho Completion Project Idaho Falls, Idaho 83415

Prepared for the U.S. Department of Energy Assistant Secretary for Environmental Management Under DOE Idaho Operations Office

Contract DE-AC07-99ID13727 


\begin{abstract}
This white paper has been prepared to document the approach to develop strategies to address Idaho National Engineering and Environmental Laboratory (INEEL) science and technology needs/uncertainties to support completion of INEEL Idaho Completion Project (Environmental Management [EM]) projects against the 2012 plan. Important Idaho Completion Project remediation and clean-up projects include the 2008 OU 10-08 Record of Decision, completion of EM by 2012, Idaho Nuclear Technology and Engineering Center Tanks, INEEL CERCLA Disposal Facility, and the Radioactive Waste Management Complex. The objective of this effort was to develop prioritized operational needs and uncertainties that would assist Operations in remediation and clean-up efforts at the INEEL and develop a proposed path forward for the development of science strategies to address these prioritized needs.

Fifteen needs/uncertainties were selected to develop an initial approach to science strategies. For each of the 15 needs/uncertainties, a detailed definition was developed. This included extracting information from the past interviews with Operations personnel to provide a detailed description of the need/uncertainty.

For each of the 15 prioritized research and development needs, a search was performed to identify the state of the associated knowledge. The knowledge search was performed primarily evaluating ongoing research. The ongoing research reviewed included Environmental Systems Research Analysis, Environmental Management Science Program, Laboratory Directed Research and Development, Inland Northwest Research Alliance, United States Geological Survey, and ongoing Operations supported projects. Results of the knowledge search are documented as part of this document.
\end{abstract}




\section{CONTENTS}

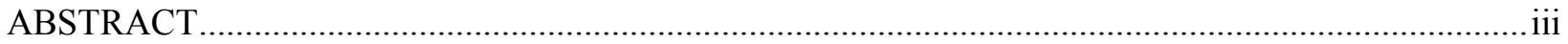

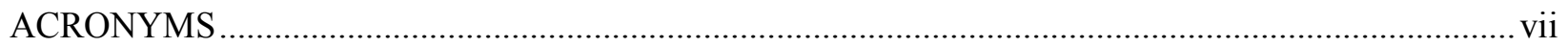

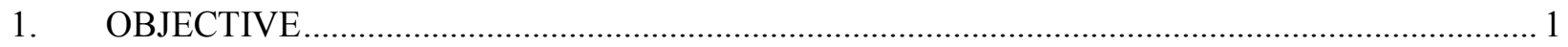

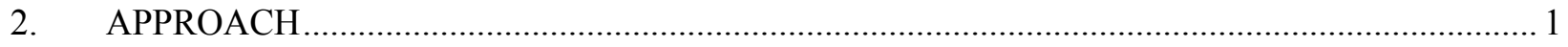

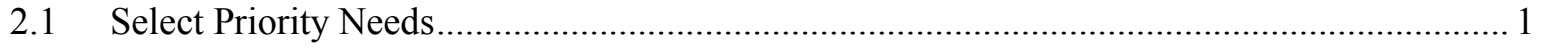

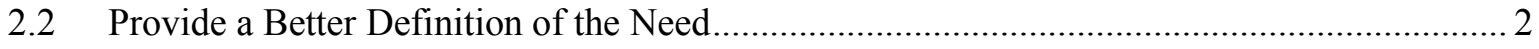

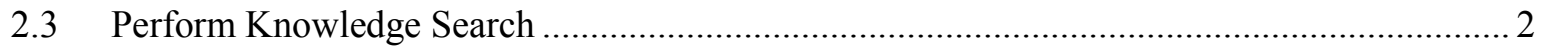

2.4 Develop Research Strategy for Potential Solutions ...................................................... 2

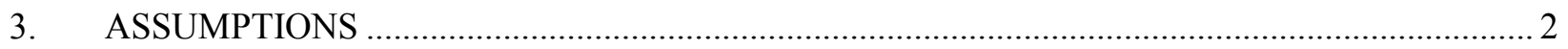

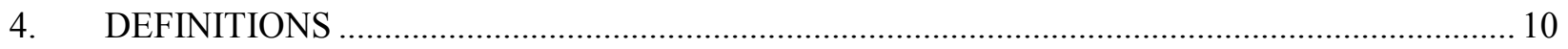

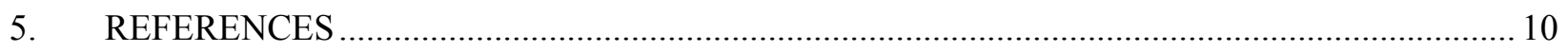

Appendix A-Top 15 Prioritized R\&D Needs ............................................................................. A-1

Appendix B-Ongoing and Recently Completed Research Projects ................................................. B-1

\section{TABLES}

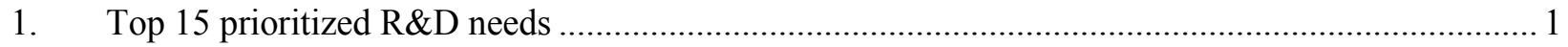

2. Top 15 prioritized needs matched to ongoing research ....................................................... 3

3. Top 15 R\&D projects compared to number of ongoing research projects from Appendix B ........... 8 


\section{ACRONYMS}

ANL Argonne National Laboratory

BRA Baseline Risk Assessment

CERCLA Comprehensive Environmental Response, Compensation, and Liability Act

CST crystalline silicotitinate

D\&D decontamination and decommissioning

DCE 1,2-dichloroethane

DNAPL dense nonaqueous phase liquid

DOE U.S. Department of Energy

DOE-EM U.S. Department of Energy Office of Environmental Management

Eh redox potential

EM electromagnetic

EM Environmental Management

EMC electromagnetic coupling

EMSP Environmental Management Science Program

ERIS Environmental Restoration Information System

ERL Earth Resources Laboratory

ERT electrical resistivity tomography

ESP Environmental Simulations Program

ESRA Environmental Systems Research Analysis

GPR ground-penetrating radar

HFI high-frequency impedance

HHGIT Hybrid Hydrologic-Geophysical Inverse Technique

HLW high-level waste

ICDF INEEL CERCLA Disposal Facility

ICP Idaho Completion Project 


\begin{tabular}{|c|c|}
\hline ICP-MS & inductively coupled plasma-mass spectrometry \\
\hline INEEL & Idaho National Engineering and Environmental Laboratory \\
\hline INTEC & Idaho Nuclear Technology and Engineering Center \\
\hline IP & induced polarization \\
\hline IP & Integration Project \\
\hline ISCO & in situ chemical oxidation \\
\hline LBNL & Lawrence Berkeley National Lab \\
\hline LDRD & Laboratory Directed Research and Development \\
\hline MCL & maximum contaminant level \\
\hline MD & molecular dynamics \\
\hline MIC & microbially-influenced corrosion \\
\hline MIP & Modified Invasion Percolation \\
\hline MRF & migration-resistant fraction \\
\hline MT & magnetotelluric \\
\hline NIST & National Institute of Standards and Technology \\
\hline NMR & nuclear magnetic resonance \\
\hline NTS & Nevada Test Site \\
\hline NWIS & National Water Information System \\
\hline NWQL & National Water Quality Laboratory \\
\hline O\&M & operation and maintenance \\
\hline ORP & oxidation reduction potential \\
\hline PCE & tetrachloroethylene \\
\hline PI & Principal Investigator \\
\hline PNNL & Pacific Northwest National Lab \\
\hline $\mathrm{QA} / \mathrm{QC}$ & quality assurance/quality control \\
\hline QM & quantum mechanics \\
\hline
\end{tabular}




\begin{tabular}{|c|c|}
\hline $\mathrm{R} \& \mathrm{D}$ & Research and Development \\
\hline RESL & Radiological and Environmental Sciences Laboratory \\
\hline RFETS & Rocky Flats Environmental Technology Site \\
\hline ROD & record of decision \\
\hline RWMC & Radioactive Waste Management Complex \\
\hline SASW & spectral analysis of surface waves \\
\hline SDA & Subsurface Disposal Area \\
\hline SGL & Subsurface Geoscience Laboratory \\
\hline SIMS & secondary ion mass spectrometry \\
\hline SIP & spectral induced polarization \\
\hline SNF & Spent Nuclear Fuel \\
\hline SRPA & Snake River Plain Aquifer \\
\hline SSP & Subsurface Science Program \\
\hline SSR & shallow seismic reflection \\
\hline SSRL & Stanford Synchrotron Radiation Laboratory \\
\hline STVZ & Sandia/Tech Vadose Zone \\
\hline TCE & trichloroethene \\
\hline TEM & transmission electron microscopy \\
\hline TFA & Tanks Focus Area \\
\hline TIMS & thermal ionization mass spectrometry \\
\hline TRA & Test Reactor Area \\
\hline UI & University of Idaho \\
\hline USGS & United States Geological Survey \\
\hline $\mathrm{VZ}$ & vadose zone \\
\hline VZRP & Vadose Zone Research Park \\
\hline WAG & waste area group \\
\hline
\end{tabular}




$\begin{array}{ll}\text { WSU } & \text { Washington State University } \\ \text { XAFS } & \text { x-ray absorption fine structure } \\ \text { XBGPR } & \text { cross borehole ground penetrating radar } \\ \text { XPS } & \text { x-ray photoelectron spectroscopy } \\ \text { VETEM } & \text { very early time electromagnetics } \\ \text { YMP } & \text { Yucca Mountain Project }\end{array}$




\section{Water Integration Project Science Strategies White Paper}

\section{OBJECTIVE}

The objective of this effort is to define an approach to develop research strategies to address the prioritized operational needs and uncertainties that have been identified by the Water Integration Project.

\section{APPROACH}

This task defines an approach for the development of strategies to address Idaho National Engineering and Environmental Laboratory (INEEL) science and technology needs/uncertainties to support completion of INEEL Idaho Completion Project (ICP) (Environmental Management [EM]) projects against the 2012 plan. Important remediation and clean-up projects include the 2008 OU 10-08 Record of Decision (ROD), completion of EM by 2012, Idaho Nuclear Technology and Engineering Center (INTEC) Tanks, INEEL CERCLA Disposition Facility (ICDF), and the Radioactive Waste Management Complex (RWMC).

\subsection{Select Priority Needs}

Fifteen needs/uncertainties were selected to develop an initial set of research strategies. To do this a technical committee performed a review of each of the needs/uncertainties. The outcome of both the April and September 2002 value-engineering sessions provided input into the process (INEEL 2002a, 2000b). The top 15 prioritized Research and Development (R\&D) needs are presented in Table 1.

Table 1. Top 15 prioritized R\&D needs.

1. Need to determine preferred flow zones in the aquifer for characterization at the regional and subregional scale.

2. Need methods for delineation of flow direction in the aquifer at a facility scale.

3. Need to improve the use of 3D tomography and other cross-hole geophysics for selected facilities to show changes in moisture.

4. Need to better define the porosity and permeability in selected areas.

5. Need to analyze existing data and collect temperature logs on all aquifer and vadose zone wells to evaluate flow regimes.

6. Need to know the geochemical characteristics (e.g., oxidation states) of the near field environment for actinides.

7. Need measurement technique to monitor ambient water travel time through the VZ to the SRPA at selected facilities.

8. Need to develop better methods for correction factors of measurement of water levels in a flat gradient environment.

9. Need research on contaminant release from treated waste forms (grout and vitrified waste).

10. Need to perform vertical profiling of contaminant plume geometry to determine layering effects (Such as $\mathrm{Cr}^{6}$ at the Test Reactor Area).

11. Need development and testing of the in situ geochemical probe to measure Eh, $\mathrm{pH}$, and ORP for selected ions in vadose zone studies.

12. Need studies of physical waste form of contaminants in the Subsurface Disposal Area and other sites. 
Table 1. (continued).

13. Need studies of chemical state of the waste form in the Subsurface Disposal Area and other sites

14. Need to determine what from the standpoint of geochemistry is influencing transport and retardation.

15. Need to develop better tracer tests to track flow through the interbeds in selected areas.

\subsection{Provide a Better Definition of the Need}

For each of the 15 needs/uncertainties, a detailed definition was developed. This included extracting information from the past interviews to provide a detailed description of the need/uncertainty. Appendix A presents the 15 prioritized R\&D needs grouped into need categories with a detailed description of the need and a listing of which uncertainty the need assists in solving.

\subsection{Perform Knowledge Search}

For each of the 15 prioritized R\&D needs, a search was performed to identify the state of the associated knowledge. The knowledge search was performed primarily by reviewing literature and evaluating ongoing research. The ongoing research reviewed included Environmental Systems Research Analysis (ESRA), Environmental Management Science Program (EMSP), Laboratory Directed Research and Development (LDRD), Inland Northwest Research Alliance (INRA), United States Geological Survey (USGS), and ongoing Operations (ICP) supported projects. Table 2 presents the top 15 prioritized needs matched to the ongoing research projects. A summary sheet of the state of the knowledge for each ongoing research project that provided information for each of the 15 prioritized needs was prepared and is presented in Appendix B.

\subsection{Develop Research Strategy for Potential Solutions}

Table 3 was prepared to evaluate the number of associated research projects from the state of the knowledge search discussed above and to provide a suggestion for research needs for the development of the research strategy necessary to solve the 15 prioritized R\&D needs. It should be noted that for some of the 15 prioritized needs, there were a large number of ongoing research projects identified. Status of the ongoing research, as well as applicability of the research to the INEEL, needs to be evaluated by ICP managers. Using Table 3, the next step in the process is to meet with the ICP project managers and the INEEL technical staff to determine if a need is a priority to the ICP managers, if a need is already being addressed, or if there is sufficient evidence of research existing from the knowledge search to answer specific needs from the list of 15 prioritized needs. Also, using this white paper and the knowledge gained from the Science Strategy Stakeholder meetings, those R\&D needs still existing after the meeting with the ICP managers and the INEEL research staff, a path forward will be defined for those needs still requiring further research. The research may be addressed by directed INEEL research (LDRD), through ESRA projects, through standard testing, or through an open call such as EMSP.

\section{ASSUMPTIONS}

The following assumptions have been made:

- $\quad$ Defined needs that will assist in meeting the INEEL revised 2012 plan have been agreed to by ICP managers.

- $\quad$ ICP and INEEL personnel are available to support development of the detailed research strategy. 


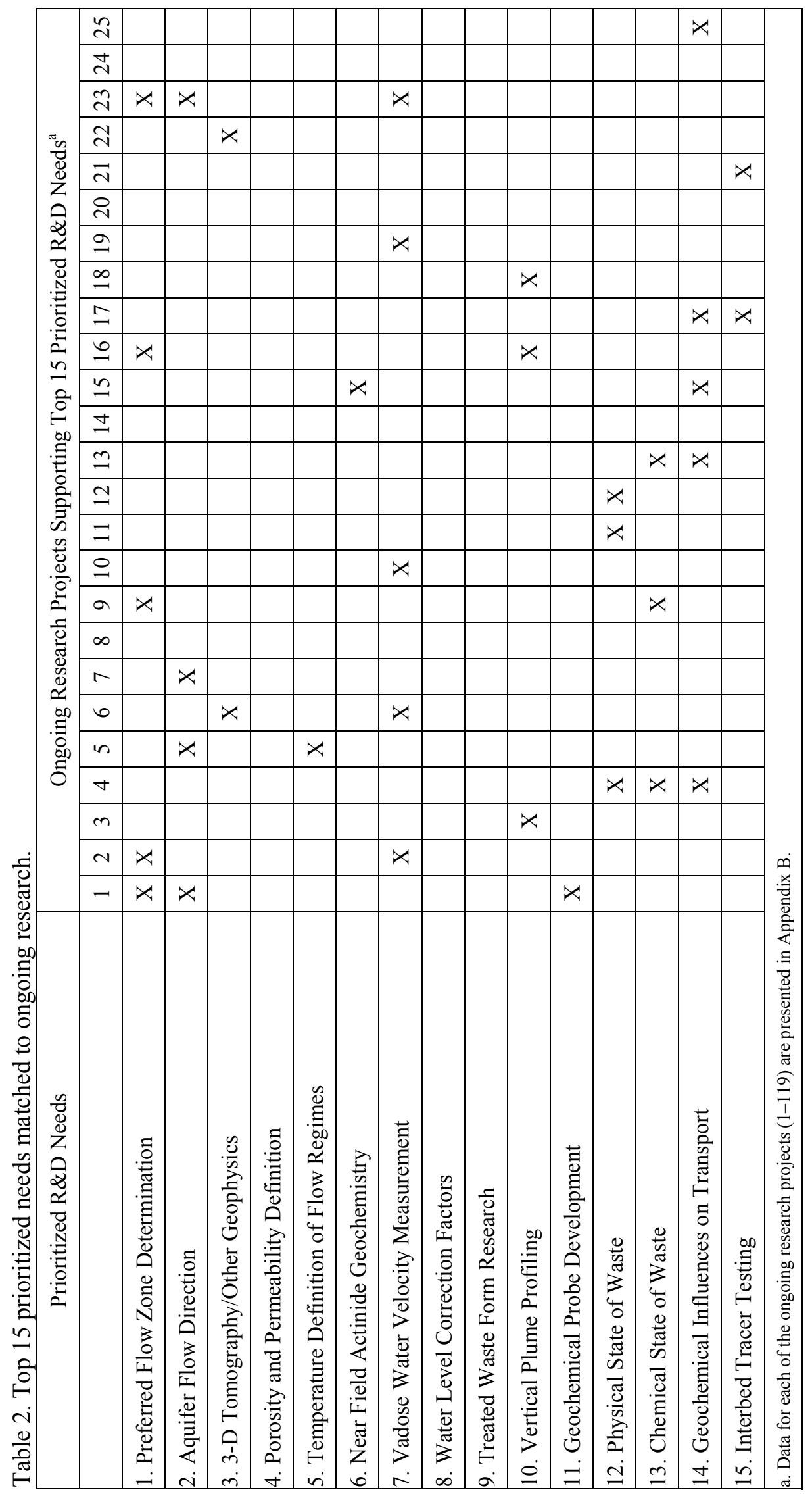




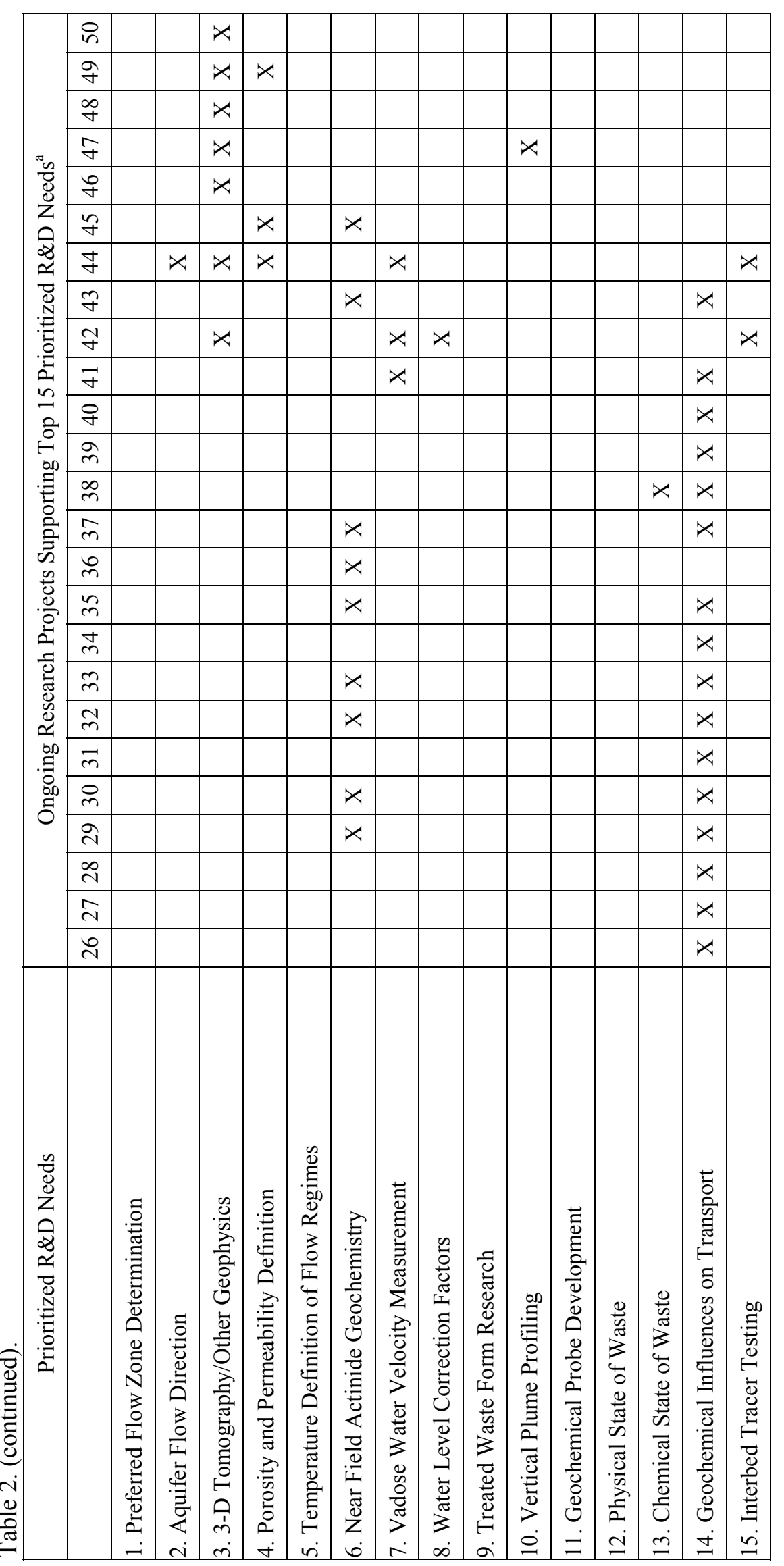




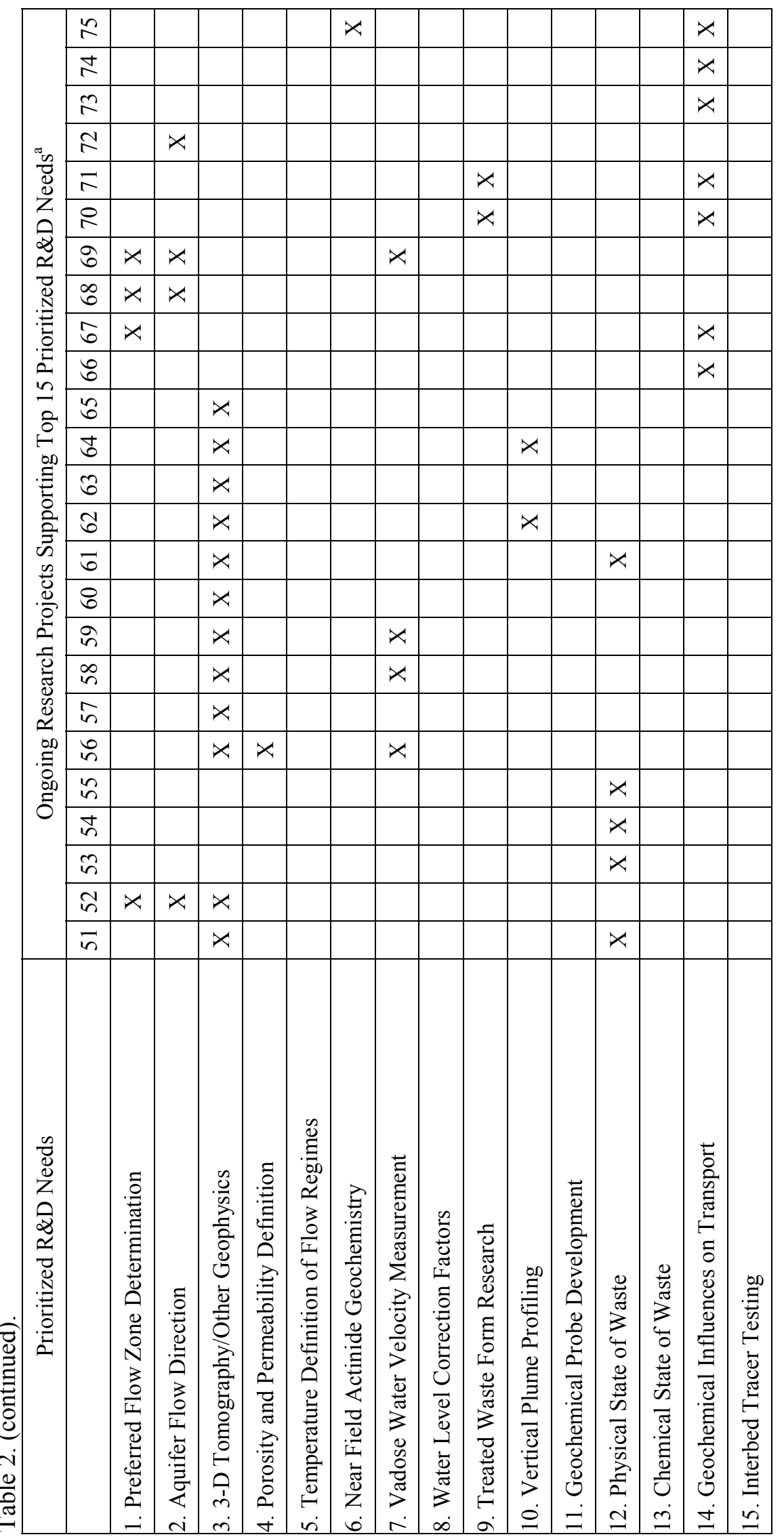




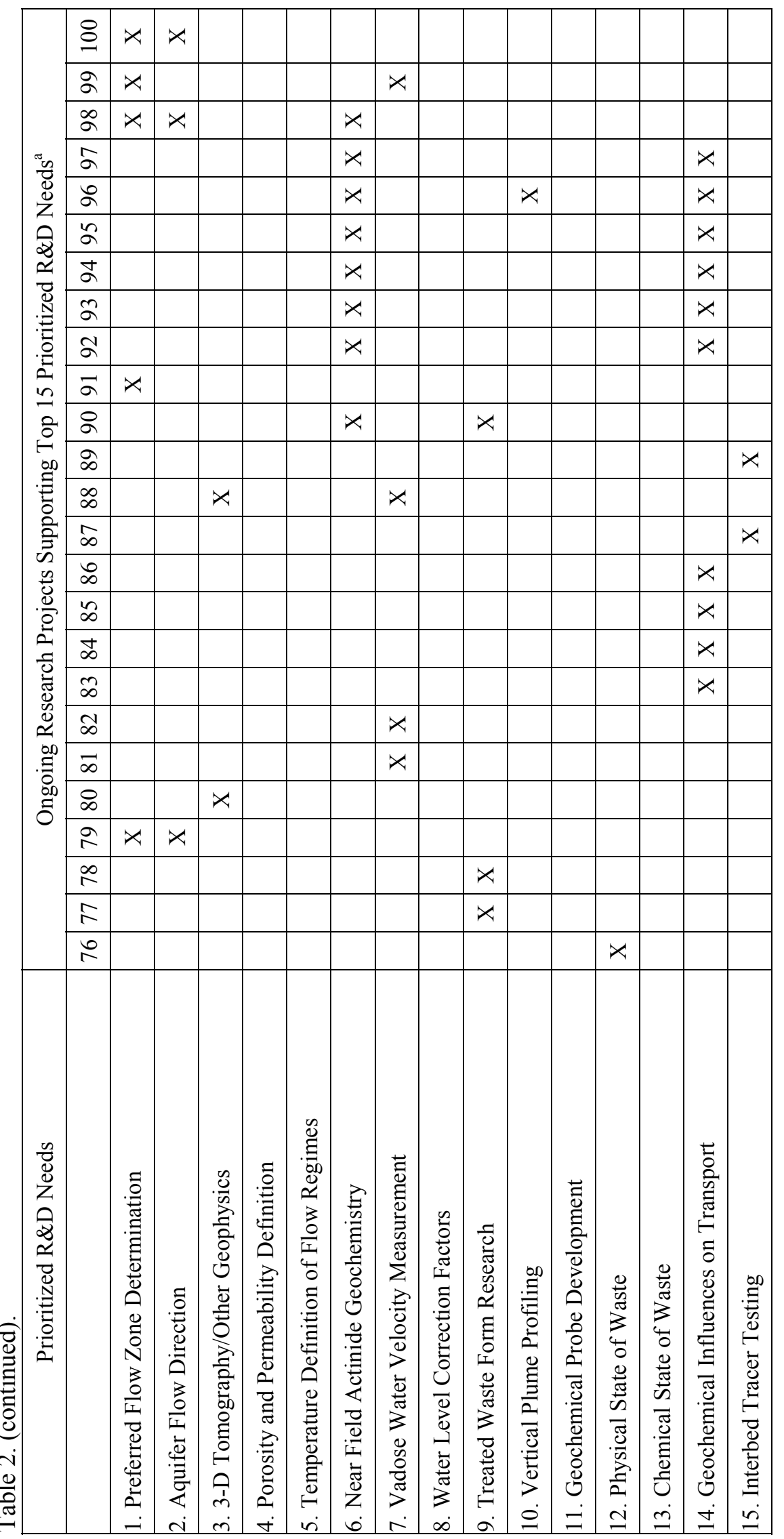




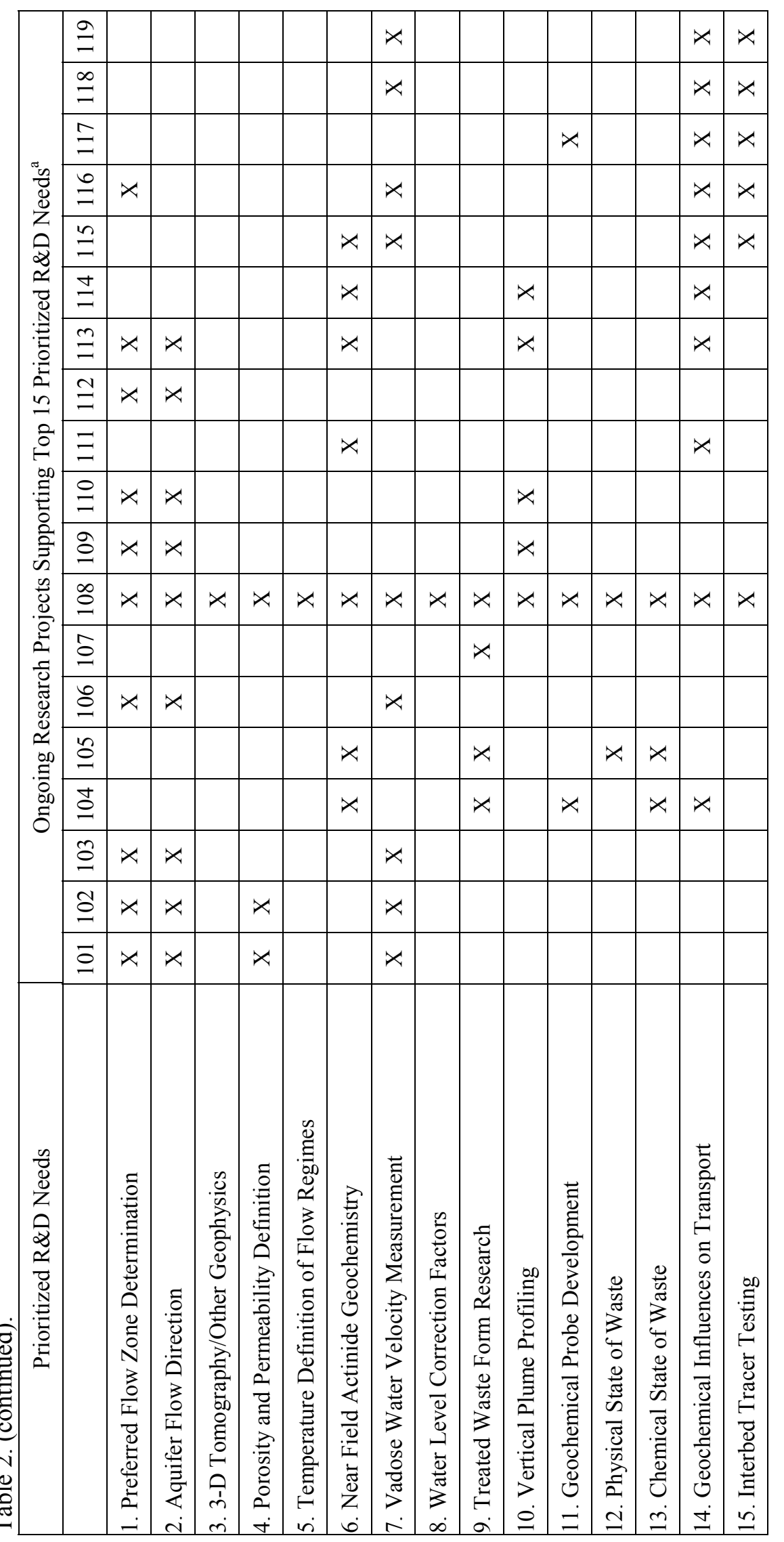


Table 3. Top $15 \mathrm{R} \& \mathrm{D}$ projects compared to number of ongoing research projects from Appendix B.

\begin{tabular}{|c|c|c|c|}
\hline & R\&D Need & $\begin{array}{l}\text { Number of Ongoing } \\
\text { Research Projects }\end{array}$ & Comments \\
\hline 1. & $\begin{array}{l}\text { Need to determine } \\
\text { preferred flow zones in } \\
\text { the aquifer for } \\
\text { characterization at the } \\
\text { regional and subregional } \\
\text { scale. }\end{array}$ & 23 & $\begin{array}{l}\text { This is an area were further research is } \\
\text { necessary for long-term modeling and } \\
\text { preparation of Baseline Risk Assessments } \\
\text { (BRAs). Further research into noninvasive } \\
\text { methods and tracer tests for delineation of } \\
\text { preferential flow paths is necessary. }\end{array}$ \\
\hline 2. & $\begin{array}{l}\text { Need methods for } \\
\text { delineation of flow } \\
\text { direction in the aquifer at } \\
\text { a facility scale. }\end{array}$ & 20 & $\begin{array}{l}\text { Flow direction at a facility scale may be } \\
\text { quite variable in relation to the regional scale } \\
\text { modeling of flow. Need to perform } R \& D \text { on } \\
\text { flow perturbations on a facility level to be } \\
\text { able to predict long term risk from each } \\
\text { facility with regard to cumulative risk. }\end{array}$ \\
\hline 3. & $\begin{array}{l}\text { Need to improve the use } \\
\text { of 3D tomography and } \\
\text { other cross-hole } \\
\text { geophysics for selected }\end{array}$ & 21 & $\begin{array}{l}\text { A number of the projects reviewed were not } \\
\text { exclusively 3D Tomography but do give a } \\
\text { 3D picture of the area being surveyed and } \\
\text { were included in this category. }\end{array}$ \\
\hline
\end{tabular}

facilities to sho

4. Need to better define the porosity and permeability in selected areas.

5. Need to analyze existing

$\mathrm{R} \& \mathrm{D}$ to assist with this may be difficult as distribution of porosity and permeability is controlled by the complexities of fracture flow. Research needs to be performed to develop a realistic lump sum estimate for the site to be used in risk assessment calculations.

data and collect temperature logs on all aquifer and vadose zone wells to evaluate flow regimes.

6. Need to know the geochemical characteristics (e.g., oxidation states) of the near field environment for actinides.

7. Need measurement

This is an area that needs further research both in the aquifer and the vadose zone. These data can be utilized to assist with the knowledge of stratigraphy, structural elements, flow characteristics, and geophysical differences in the aquifer and vadose zone.

technique to monitor ambient water travel time through the VZ to the SRPA at selected facilities.

Numerous geochemical studies exist both in ongoing research for the INEEL and on a complex wide basis that would provide valuable information on the $R \& D$ need.

A number of these studies are specific to the INEEL, others are specific to another site in the complex but with methodologies that can be adapted for use at the INEEL. 
Table 3. (continued).

\begin{tabular}{|c|c|c|c|}
\hline & R\&D Need & $\begin{array}{l}\text { Number of Ongoing } \\
\text { Research Projects }\end{array}$ & Comments \\
\hline 8. & $\begin{array}{l}\text { Need to develop better } \\
\text { methods for correction } \\
\text { factors of measurement of } \\
\text { water levels in a flat } \\
\text { gradient environment. }\end{array}$ & 2 & $\begin{array}{l}\text { Further research needs to be performed on } \\
\text { the effects of barometric level changes that } \\
\text { may mask actual water level changes. }\end{array}$ \\
\hline 9. & $\begin{array}{l}\text { Need research on } \\
\text { contaminant release from } \\
\text { treated waste forms (grout } \\
\text { and vitrified waste). }\end{array}$ & 9 & $\begin{array}{l}\text { The ongoing research identified in } \\
\text { Appendix B is work from other sites. Need } \\
\text { further R\&D on any planned, treated waste } \\
\text { forms at the INEEL. }\end{array}$ \\
\hline 10. & $\begin{array}{l}\text { Need to perform vertical } \\
\text { profiling of contaminant } \\
\text { plume geometry to } \\
\text { determine layering effects } \\
\text { (Such as Cr6 at the Test } \\
\text { Reactor Area). }\end{array}$ & 12 & $\begin{array}{l}\text { Further R\&D needs to be performed specific } \\
\text { to the plumes existing on the INEEL. }\end{array}$ \\
\hline 11. & $\begin{array}{l}\text { Need development and } \\
\text { testing of the in situ } \\
\text { geochemical probe to } \\
\text { measure } \mathrm{Eh}, \mathrm{pH} \text {, and ORP } \\
\text { for selected ions in vadose } \\
\text { zone studies. }\end{array}$ & 4 & $\begin{array}{l}\text { Further research needs to be performed on } \\
\text { the probe. This could be performed at the } \\
\text { INEEL or at other sites in the complex to } \\
\text { develop baseline data. }\end{array}$ \\
\hline 12. & $\begin{array}{l}\text { Need studies of physical } \\
\text { waste form of } \\
\text { contaminants in the } \\
\text { Subsurface Disposal Area } \\
\text { and other sites. }\end{array}$ & 11 & $\begin{array}{l}\text { One of the studies actually deals with waste } \\
\text { forms in the Subsurface Disposal Area } \\
\text { (SDA). The others are studies that could be } \\
\text { applied to assist in determining the physical } \\
\text { waste form in the SDA. Further R\&D is } \\
\text { needed for determining the physical waste } \\
\text { form at the SDA. }\end{array}$ \\
\hline 13. & $\begin{array}{l}\text { Need studies of chemical } \\
\text { state of the waste form in } \\
\text { the Subsurface Disposal } \\
\text { Area and other sites. }\end{array}$ & 6 & $\begin{array}{l}\text { This is an area where further R\&D is needed } \\
\text { to assist with remediation of the SDA. }\end{array}$ \\
\hline 14. & $\begin{array}{l}\text { Need to determine what } \\
\text { from the standpoint of } \\
\text { geochemistry is } \\
\text { influencing transport and } \\
\text { retardation. }\end{array}$ & 48 & $\begin{array}{l}\text { The ongoing research projects deal with } \\
\text { some aspects of geochemistry and how the } \\
\text { geochemistry may influence fate and } \\
\text { transport. Many of the studies are from other } \\
\text { sites in the complex but could be applied to } \\
\text { the INEEL. Analysis of the ongoing research } \\
\text { projects, as well as the applicability to the } \\
\text { ICP remediation and clean-up projects, needs } \\
\text { to performed. }\end{array}$ \\
\hline 15. & $\begin{array}{l}\text { Need to develop better } \\
\text { tracer tests to track flow } \\
\text { through the interbeds in } \\
\text { selected areas. }\end{array}$ & 12 & $\begin{array}{l}\text { The research studies identified in Appendix } \\
\mathrm{B} \text { only discuss tracer tests in a peripheral } \\
\text { manner. Further research is needed. }\end{array}$ \\
\hline
\end{tabular}




\section{DEFINITIONS}

Scientific Need: Scientific understanding to assist in the completion of a project. Knowledge gap. Associated with high project risk.

Technology Need: A technology to assist in the completion of a project. Technology gap. Associated with high project risk.

Uncertainties: Gap in knowledge or understanding of a parameter(s).

\section{REFERENCES}

INEEL, 2000a, Raw Data Report and Meeting Record from the Vadose Zone/Groundwater Uncertainties Prioritization Meeting, April 2 \& 3, INEEL/EXT-02-00529, April 2002.

INEEL. 2000b, Development of the FY-02 Supplement of the INEEL Site-wide Vadose Zone/Groundwater Roadmap, INEEL/EXT-02-01038, September 2002. 


\section{Appendix A \\ Top 15 Prioritized R\&D Needs}


A-2 


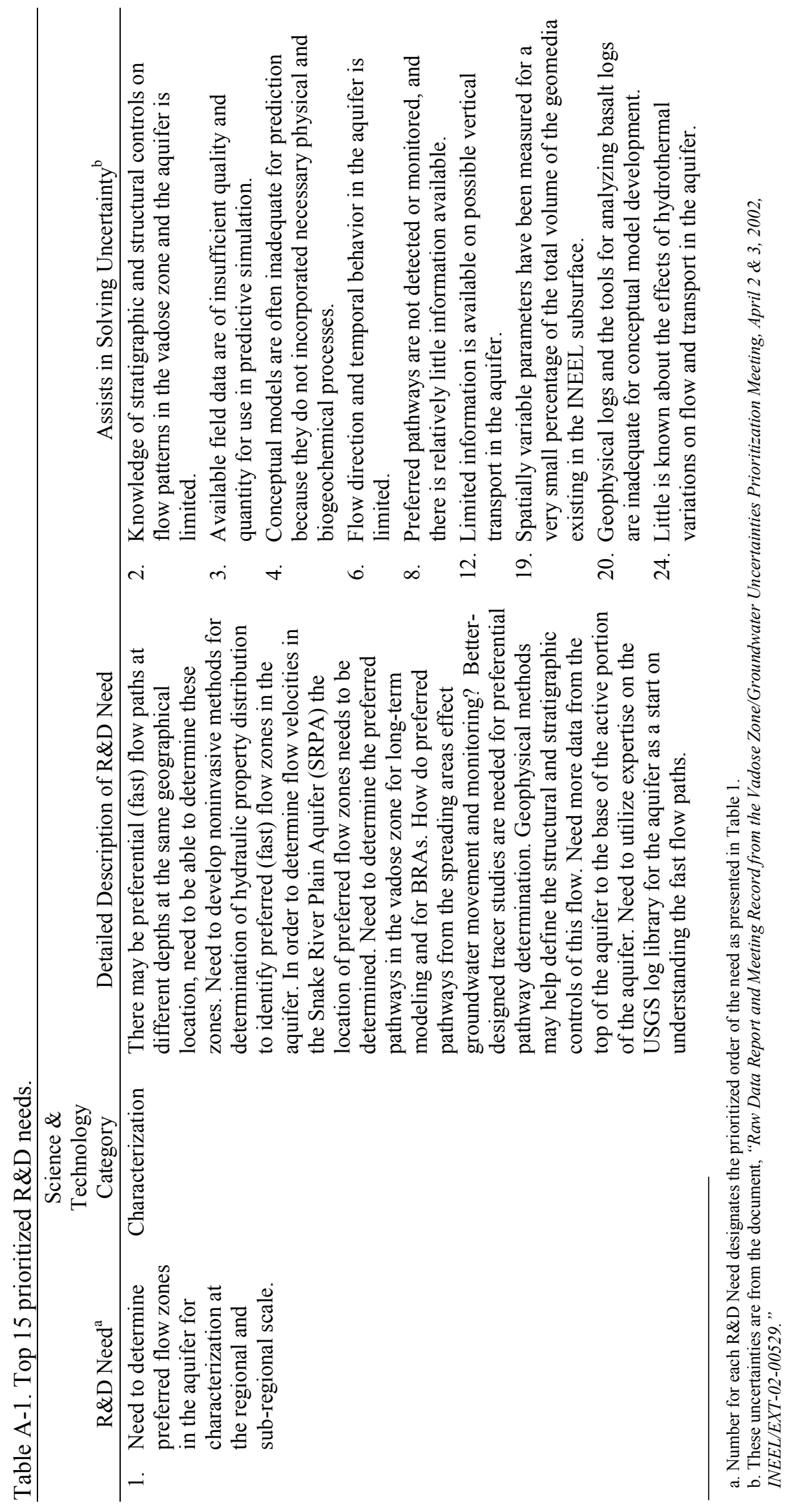




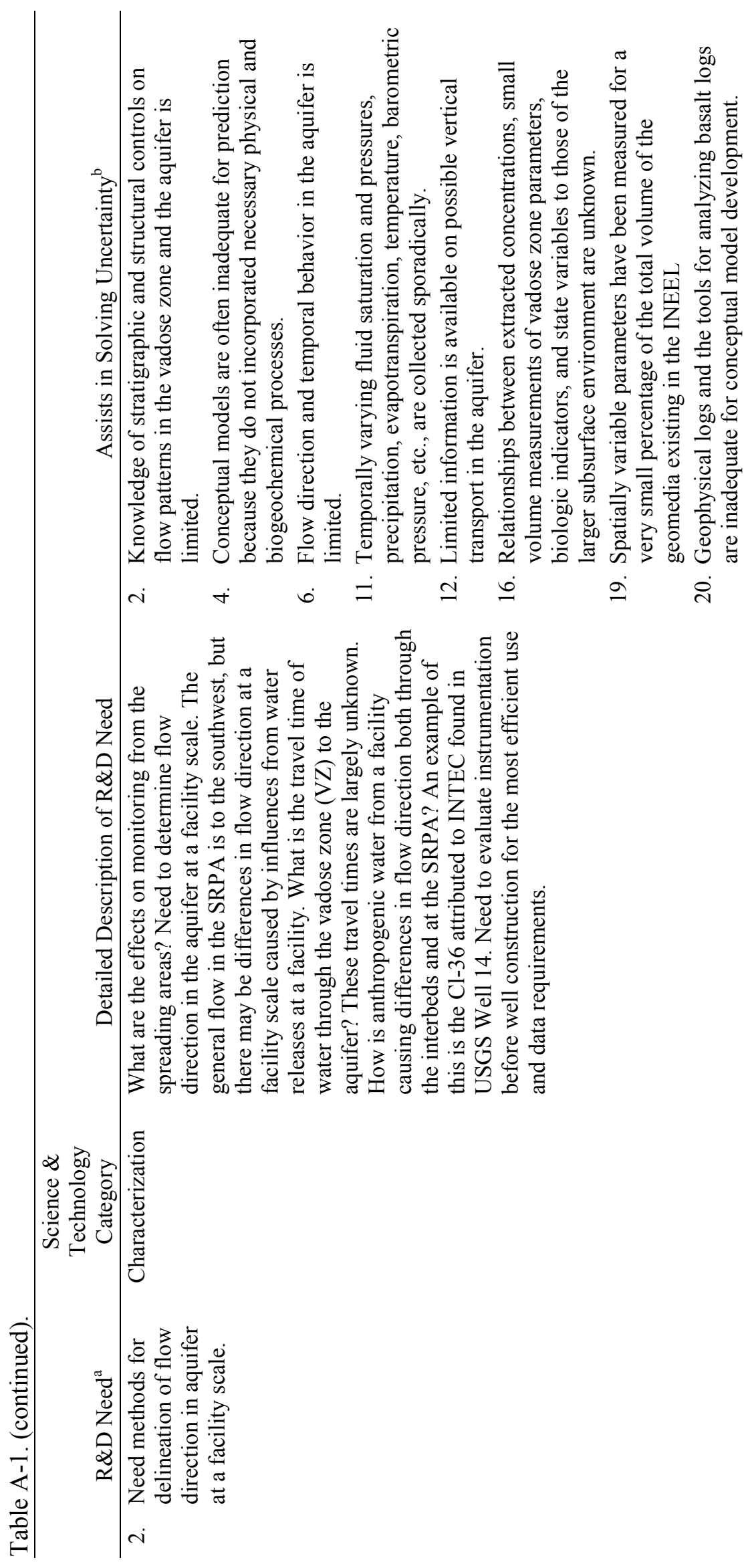




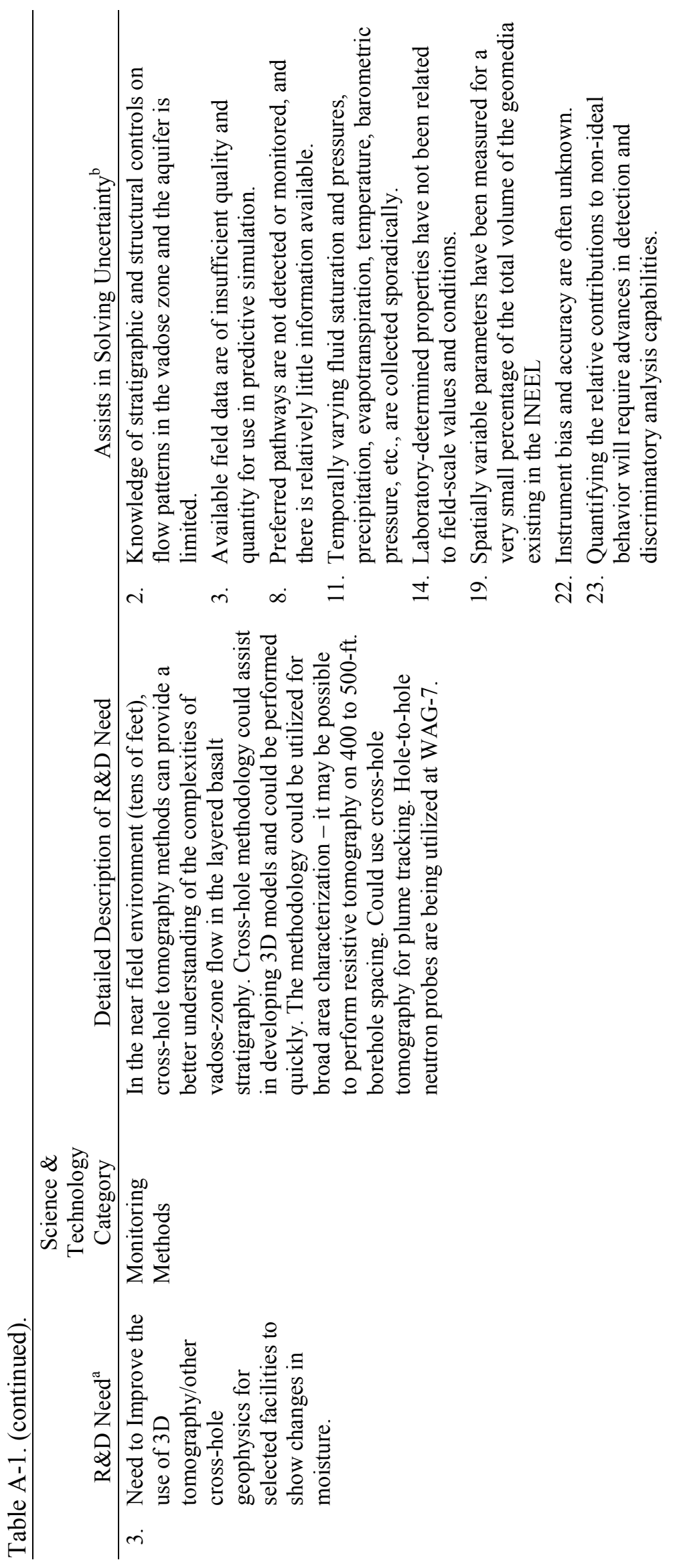




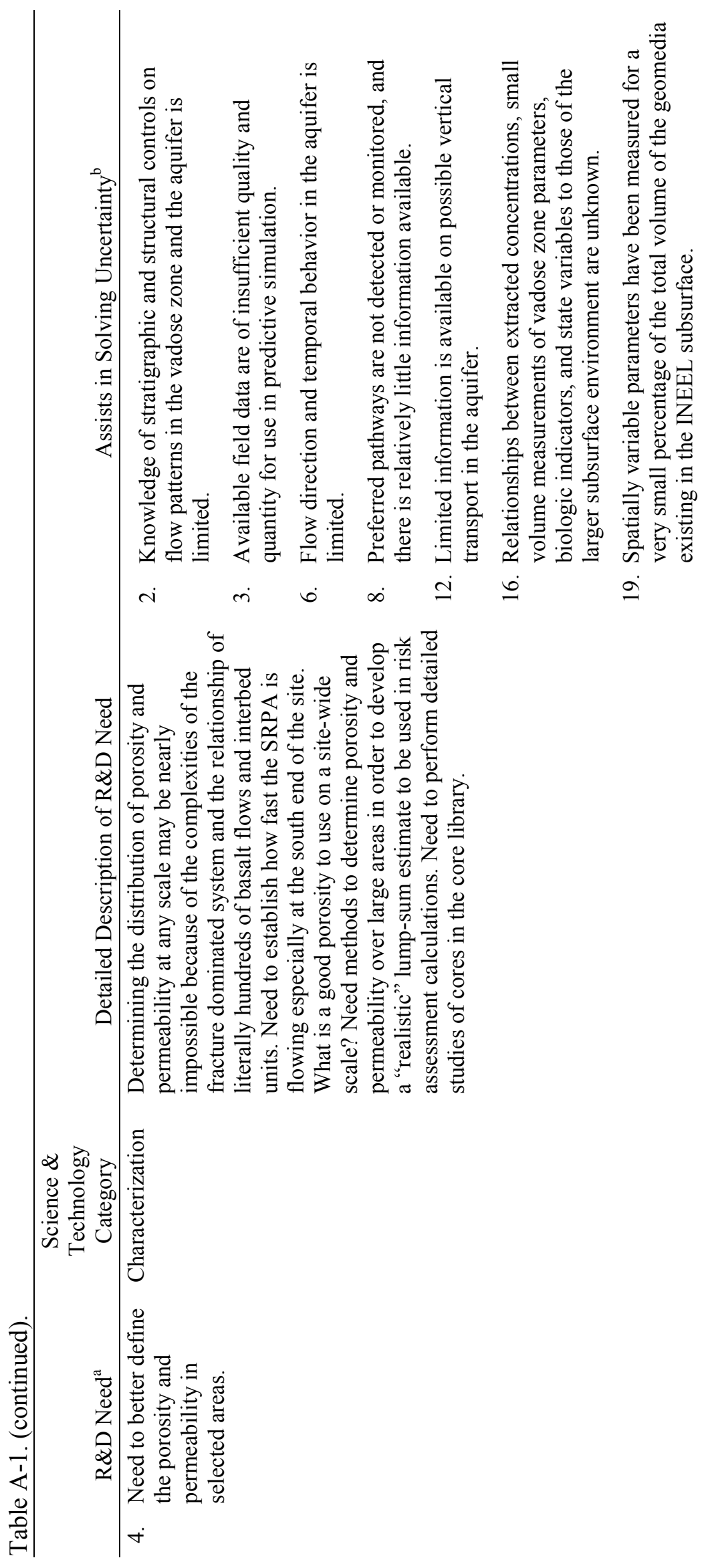




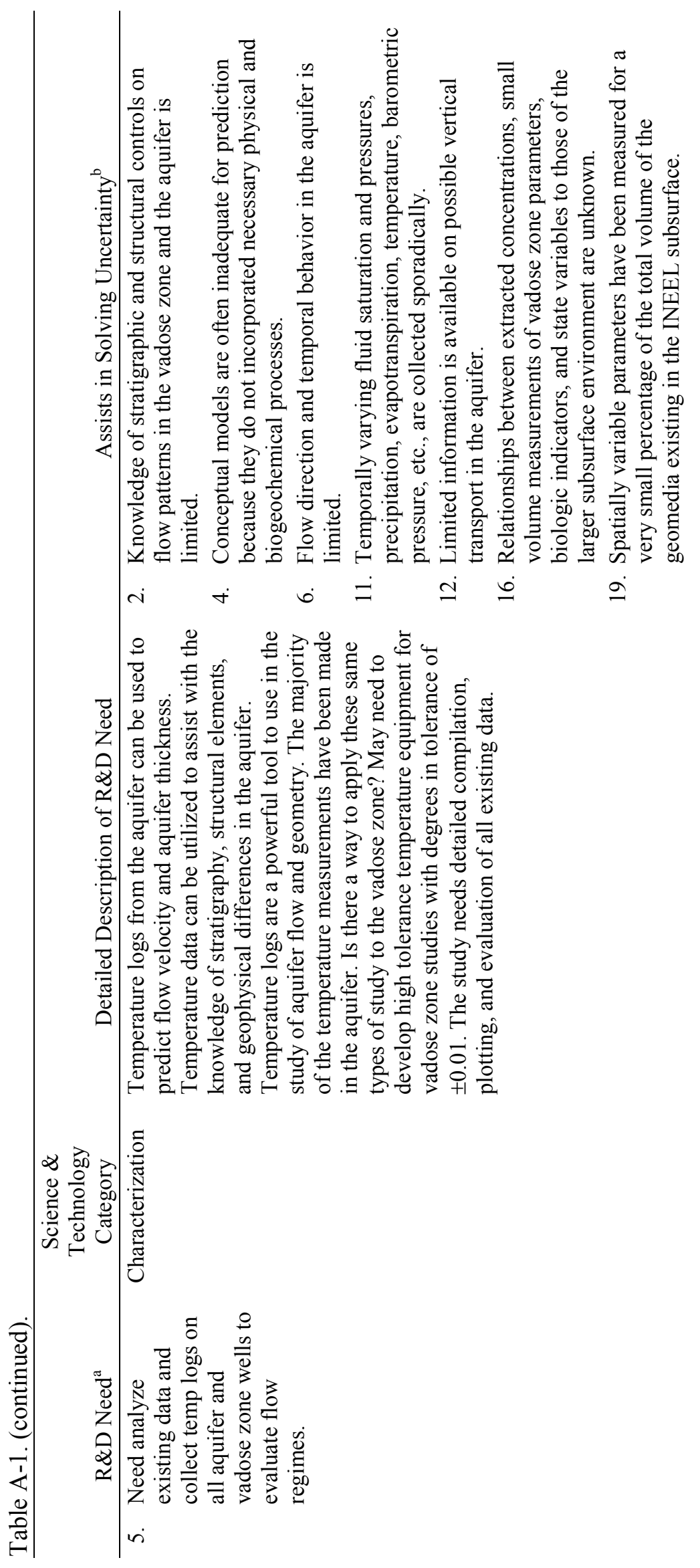




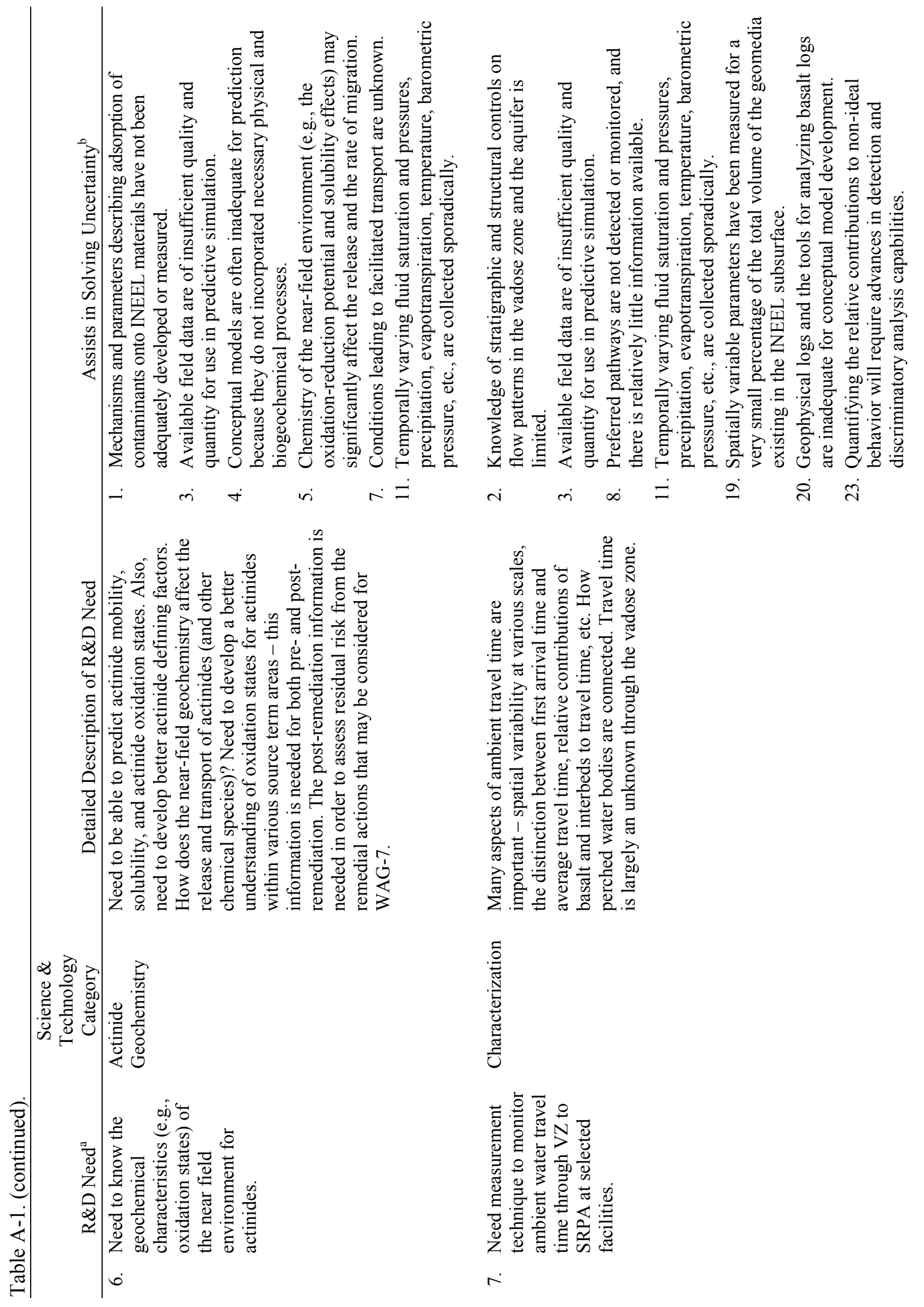




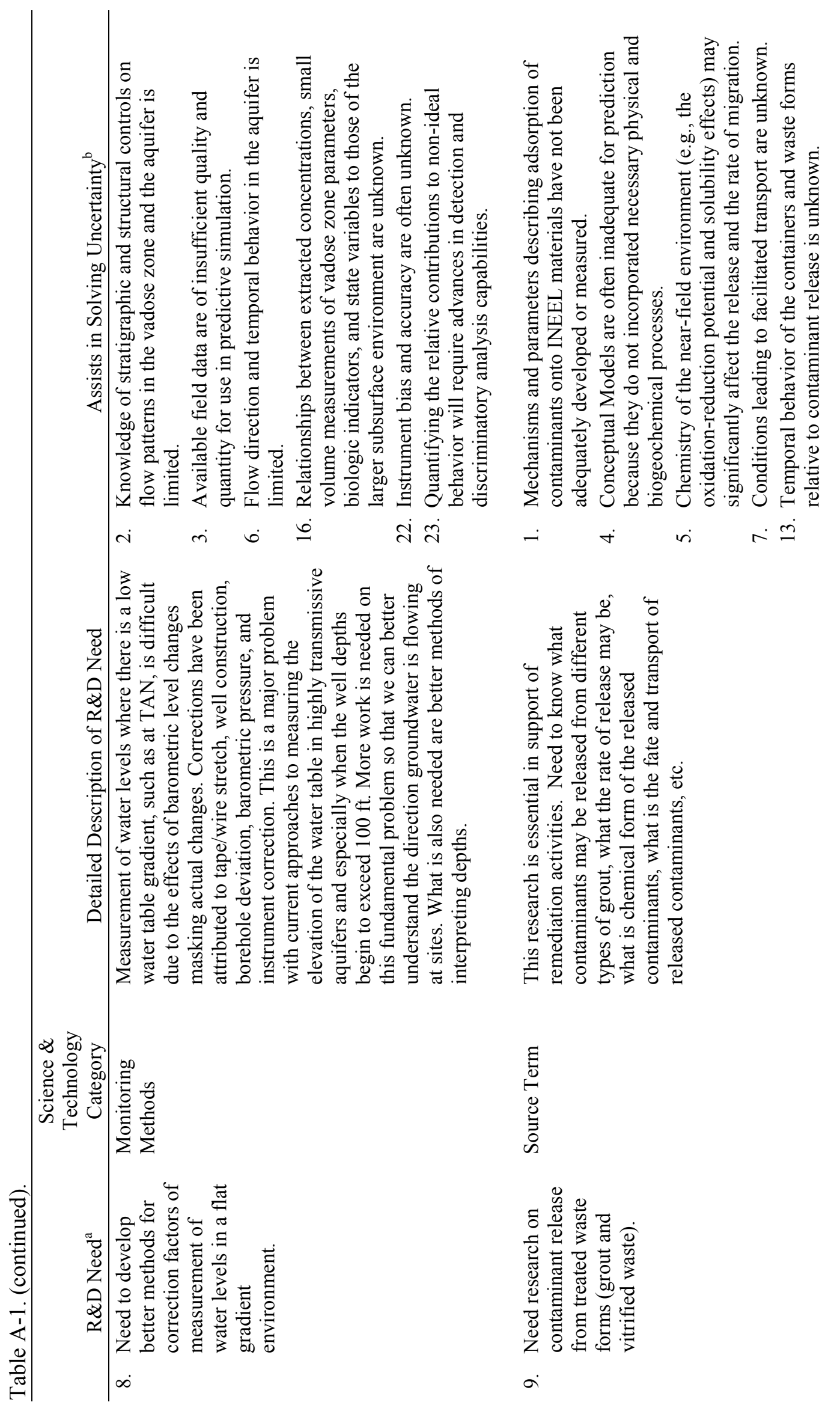




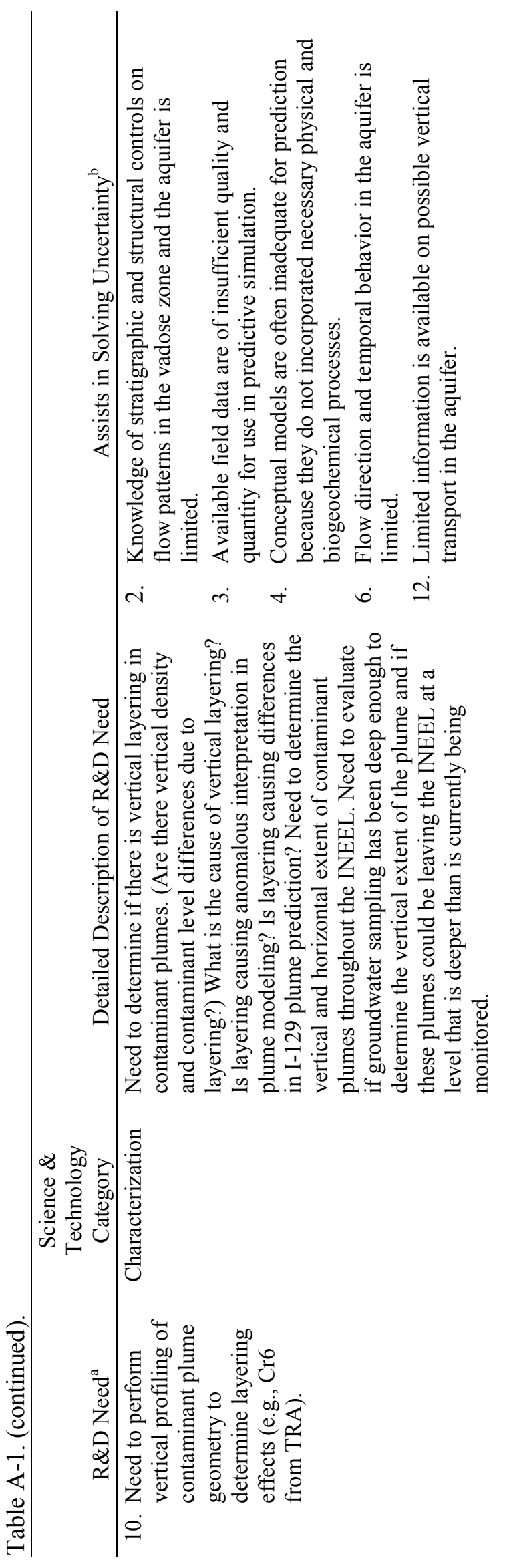




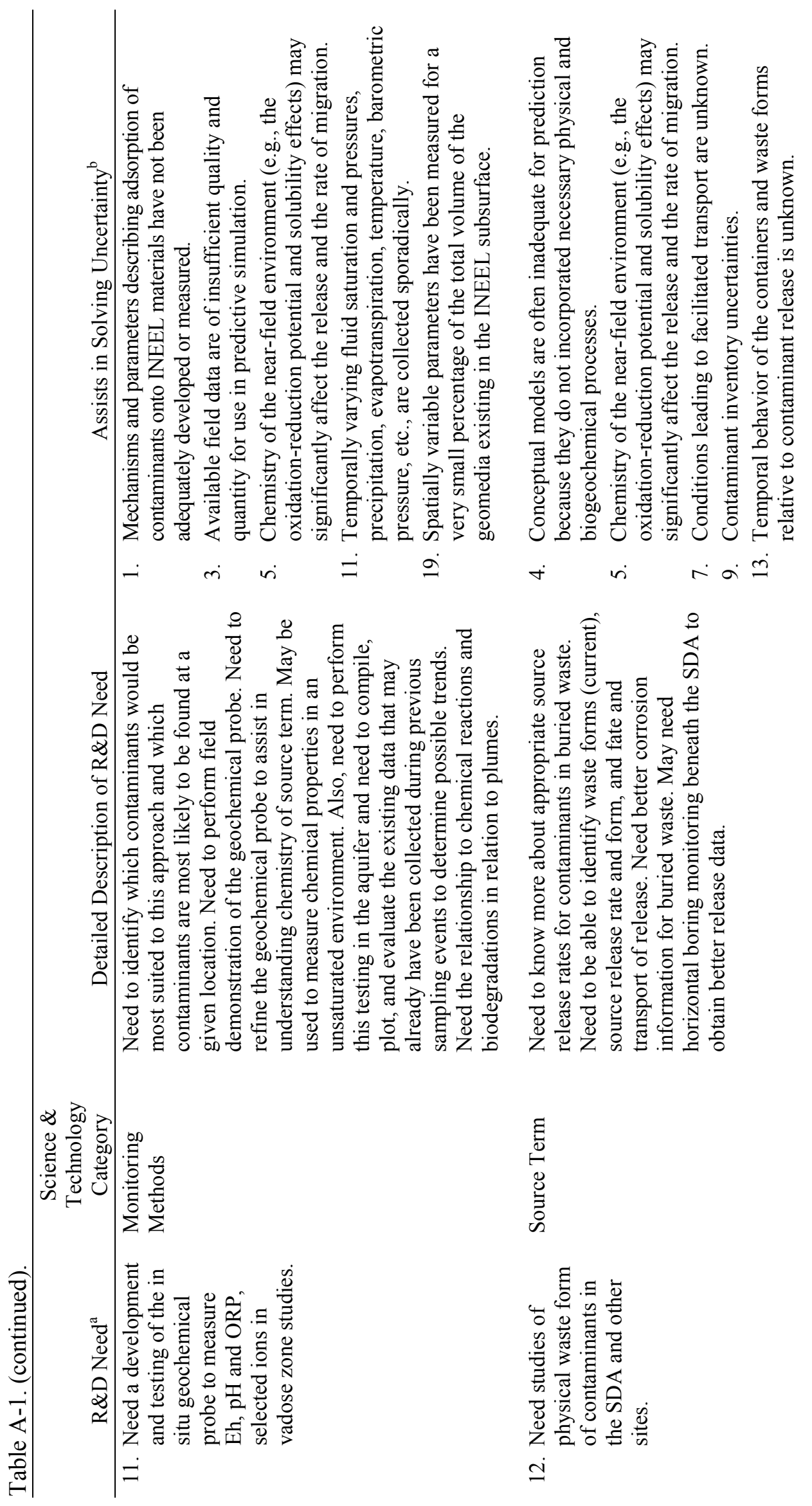




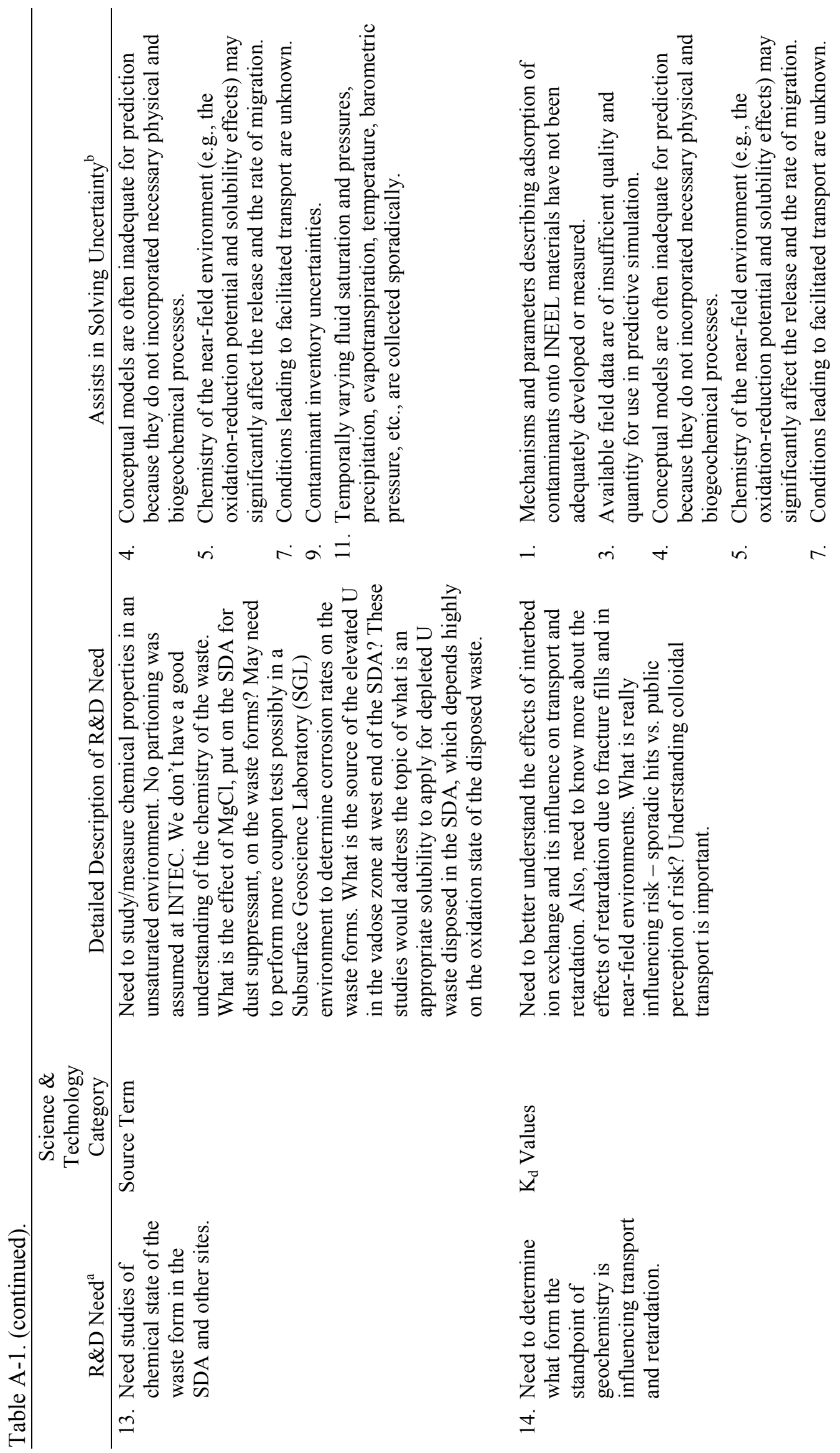




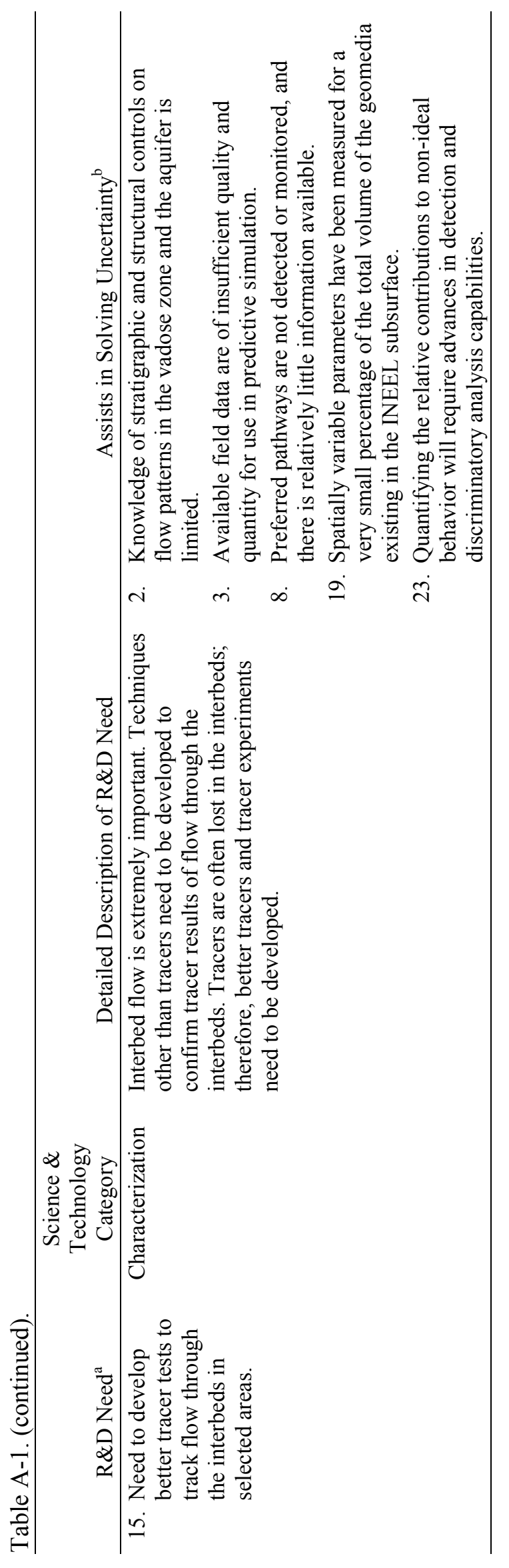


A-14 


\section{Appendix B}

\section{Ongoing and Recently Completed Research Projects}


B-2 


\title{
Appendix B
}

\section{Ongoing and Recently Completed Research Projects}

Research Project Number: 1

\author{
Spatial and Temporal Characterization of the Vadose Zone
}

Conceptual Model Input: Aquifer and Vadose Zone

Addresses Need: 1 . Need to determine preferred flow zones in the aquifer for characterization at the regional and subregional scale.

2. Need methods for delineation of flow direction in the aquifer at a facility scale.

11. Need development and testing of the in situ geochemical probe to measure Eh, $\mathrm{pH}$, and ORP for selected ions in vadose zone studies.

Principal Investigators: Earl D. Mattson, Gail Heath, Joel Hubbell, Mitch Plummer, Annette Schafer, Clark Scott, and James Sisson (INEEL); Eric Miller and Mohamed Khames Miled (Northeastern University); and Robert Holt (University of Mississippi)

Purpose: Methodologies for determining fluid pathways, quantifying chemical transport fluxes, and describing subsurface heterogeneities are needed to ultimately describe spatial and temporal chemical transport in subsurface liquids and gases. Three major tasks in this project will examine cross-cutting methodologies for integrating point measurements of soil physics with spatial measurements of geophysics, and to integrate those into a quantitative description using numerical techniques. Task 1 examines physical techniques for examining temporal changes in the vadose zone; Task 2 examines spatial distribution of geologic properties; and Task 3 develops methodologies to incorporate the first two tasks into a more holistic approach.

Project Description: An incomplete understanding of contaminant fate and transport mechanisms and an inadequate description of geologic heterogeneity have resulted in uncertain predictions of contaminant behavior in the vadose zone. This project focuses on the following three research areas identified to reduce this uncertainty:

- $\quad$ Developing innovative measurement tools

- $\quad$ Developing integrated approaches between temporal and spatial characterization

- Developing appropriate data interpretation techniques to provide a more holistic understanding of contaminant fate and transport.

Soil physical characterization tools have the advantage of providing continuous temporal data, but suffer from the fact that the measurement volume is small in comparison to the problem of interest. Alternatively, measurement techniques such as geophysics measure large volumes but do not provide direct measurements of state variables or parameters of interest, and are typically acquired at discrete points in time. The two measurement techniques are complementary and must be integrated and evaluated together to develop better conceptual and numerical models of contaminant fate and transport. The three 
focus areas will require innovative experiments at suitable spatial and time scales to develop data sets that can be integrated and evaluated to reduce uncertainty in predictions.

Understanding and predicting water movement and chemical transport at waste disposal sites requires measurement of four vadose zone variables: water content, water pressure, temperature, and chemical concentration. Richard's equation requires these variables as initial conditions in predictive models and to develop modeling transport parameters. Despite the apparent simplicity of the concept of four state variables, obtaining a complete data set that adequately describes the temporal and spatial distribution has not been achieved. Parameters required by the numerical models are nonlinear and require temporal evaluation. In addition, appropriate measurement techniques are not available to provide the spatial distribution of these variables in a heterogeneous subsurface. As a result, contaminant transport modeling with these nonlinear effects has resulted in an unacceptable degree of uncertainty. We need a methodology for the temporal and spatial measurement of state variables, and to develop appropriate techniques to interpret and integrate the data with flow and transport models. 
Research Project Number: 2

\section{Next Generation of Predictive Models of Vadose Zone Flow and Transport}

Conceptual Model Input: Vadose Zone

Addresses Need: $\quad$ 7. Need measurement techniques to monitor ambient water travel time through the VZ to the SRPA at selected facilitates.

Principal Investigators: T. R. Wood, et al (INEEL); D. Peak (Utah State University); R. J. Glass (Sandia National Laboratories); J. Fairley and M. J. Nicholl (University of Idaho); R. D. Stedtfeld and T. L. Tyler (Idaho State University); D. Lebreque (MultiPhase Technologies, LLC); and P. Chiappini (Ziccardi Productions)

Purpose: The development and application of methodologies that account for the full dynamics in unsaturated flow and transport processes will lead us to improved numerical simulations for fractured rock vadose zones. Scientifically sound and integrated experimental, theoretical, and mathematical studies will be necessary to describe the impacts of complex system behavior on contaminant fate and transport. The development of appropriate mathematical tools to diagnose the existence of complexity is an important aspect of this effort. The fusion of mathematics with traditional characterization technologies, such as chemistry, geology, hydrology, microbiology, and with new mathematical tools is essential for the development of a new conceptual framework for the mechanisms that underlie liquid flow and contaminant transport.

Project Description: The ability to predict the transport of radionuclides, chlorinated hydrocarbons, metals, and other pollutants in the subsurface, particularly in fractured rock vadose zones, is both a requirement and a challenge for subsurface environmental policy. Recent monitoring efforts at a number of locations suggest that fractures can accelerate contaminant transport in the subsurface. Not only did contaminant transport rates exceed predicted rates by several orders of magnitude, but also the contaminant detection events were episodic in nature. Subsequent field and laboratory experiments have verified that variable or episodic fluid flow and contaminant transport does occur. Based on what is already known about fluid flow and contaminant transport, we propose that fractured rock vadose zones are complex and dynamic systems. It is also suggested that the variable flow of water observed in fractured rock systems is due to the dynamical interaction of the physical, chemical, and biological properties of the system. A paradigm shift is required to account for the effects that the interacting parameters have in producing the dynamic behavior of water flow and contaminant transport in subsurface environments. This project is investigating the role of complex, interacting hydrological, geochemical, and biological parameters in producing the dynamic behavior of contaminants in subsurface environments. Mesoscale test beds are the unifying experimental framework upon which system identification tools, sensing methods, and conceptual models are developed. The mathematical tools under development are to be used for the diagnosis of system characteristics, and will provide the basis for predictive modeling. 
Research Project Number: 3

\section{Borehole Probe Development}

Conceptual Model Input: Aquifer and Vadose Zone

Addresses Need: 10 . Need to perform vertical profiling of contaminant plume geometry to determine layering effects (such as $\mathrm{Cr}^{6}$ at the Test Reactor Area)

Principal Investigators: C. A. McGrath, R. P. Keegan, J. D. Baker, C. L. Riddle, J. E. Lee, R. Hertzog, and W. Yoon (INEEL)

Purpose: This project was established to develop two proto-type neutron-generator-based boreholelogging instruments. This project also includes the construction of calibration facilities and instrument modeling. The ultimate goal is to transfer this technology to the Environmental Restoration operations units.

Project Description: In situ subsurface characterization data that describes the location and concentration of radionuclides and RCRA contaminants is difficult to obtain. The main goal of this project is the construction and characterization of two prototype neutron-generator-based boreholelogging instruments that will generate these types of data. To date, this has involved building the probes, constructing calibration facilities, and developing a full program of instrument modeling. Two probe designs have been chosen to fill needs present at the INEEL. The pulsed fission neutron (PFN) probe is designed to detect fissile material in the subsurface. The neutron gamma (NG) probe is designed to detect many different elements in the environment surrounding the tool. Alone, these probes are technologically interesting, but provide little useful information. It is only when combined with a comprehensive calibration and characterization program that these tools begin to provide useful data. This calibration program requires both a calibration facility and a comprehensive modeling program.

The calibration facility constructed for this program was once the critical facility for the Engineering Test Reactor at the INEEL. Surrogates, which are described in more detail later, have been prepared for use in the facility. Filled with carefully chosen materials, these surrogates can be used to mimic the subsurface environment. With ports that allow the insertion of sources or other target materials, the surrogates will allow for mockups of many different environments.

Computer modeling is the final important component of the borehole probe program. Still in the early stages, the modeling will bridge the gap between the actual measurements and the calibrated results. Though it would be impossible to exactly simulate all the environments that may be encountered, computer models will be used to allow extrapolation to what may be found in the field. The second year of this 3-year project was recently concluded. The probes, facility, and modeling have been the focus of the work for the past year. The prototypes are basically completed and need only be characterized and calibrated, which will be the focus of future work on the project. 
Research Project Number: 4

\section{Interfacial Processes Controlling Fate and Mobility of Actinides, Fission Products, and Other Contaminants}

Conceptual Model Input: Aquifer, Vadose Zone, and Source Term

Addresses Need: 12 . Need studies of physical waste form of contaminants in the Subsurface Disposal Area and other sites.

13. Need studies of chemical state of the waste form in the Subsurface Disposal Area and other sites.

14. Need to determine what from the standpoint of geochemistry is influencing transport and retardation.

Principal Investigators: Gary S. Groenewold and George D. Redden (INEEL)

Purpose: This project will provide a defendable assessment of whether transport-perturbing factors could significantly augment radionuclide transport in the subsurface. In some cases, radionuclide solubilization may be inhibited, which may suggest approaches for manipulation of contaminated zones such that risk from mobilization is decreased. The project is also pursuing characterization approaches for identifying radionuclide surface speciation.

Project Description: Radionuclide contamination in mixed waste burial grounds poses a long-term threat to the underlying groundwater because the contamination is susceptible to hydrological, chemical, and biological perturbations that could significantly alter its stability and enhance its transport within the subsurface. However, the majority of the interred contamination is stable over the near-term with respect to subsurface transport. Specific factors with a higher probability for perturbing radionuclide transport behavior are (a) extended radionuclide-mineral contact time, (b) periodic wetting and drying cycles, (c) colloids, and (d) microbial ligands. This task was initiated in 2001 with the goals of evaluating these transport-perturbing factors and understanding their behavior in terms of radionuclide speciation on relevant mineral surfaces. 
Research Project Number: 5

\section{Regional Setting and Flow Dynamics of the Snake River Plain Aquifer}

Conceptual Model Input: Aquifer

Addresses Need: 1 . Need to determine preferred flow zones in the aquifer for characterization at the regional and subregional scale.

2. Need methods for delineation of flow direction in the aquifer at a facility scale.

5. Need to analyze existing data and collect temperature logs on all aquifer and vadose zone wells to evaluate flow regimes.

Principal Investigator: Richard Paul Smith, Idaho National Engineering and Environmental Laboratory

Purpose: Groundwater modeling in the Snake River Aquifer suffers from poor and incomplete conceptual understanding of geometric relationships and geologic processes that affect aquifer flow in the subsurface environment. This research explores an improved understanding of recharge sources, geothermal input, and groundwater flow in the Snake River Aquifer.

Project Description: To achieve this purpose, this project will: (1) develop methodologies for use of additional naturally-occurring isotopes of Sulfur, Lead, and Neodymium to trace groundwater flow; (2) acquire additional aquifer temperature and chemistry data from existing wells in areas where data is sparse or inconclusive; (3) use novel analysis tools to evaluate the validity of groundwater flow nets currently used in contaminant transport modeling and to investigate temporal variations in head gradient using historic water level data from 50 years of observation; (4) incorporate the results of a regional geologic and geophysical mapping project on the eastern Snake River Plain; and (5) interpret the results in the context of regional and local geologic and geophysical setting to improve conceptual and numeric models. 
Research Project Number: 6

\section{Finding Where Water Moves Under Infiltration Ponds Using Remote Sensing Techniques}

Conceptual Model Input: Vadose Zone

Addresses Need: $\quad 3$. Need to improve the use of 3D tomography and other cross-hole geophysics for selected facilities to show changes in moisture.

7. Need measurement techniques to monitor ambient travel time through the vadose zone to the SRPA at selected facilities.

Principal Investigator: Gail Heath, Idaho National Engineering and Environmental Laboratory

Purpose: Cleanup involves the safe treatment, storage, and final disposal of radioactive wastes, surplus nuclear materials, and spent nuclear fuels that remain at the sites of the nation's nuclear weapons facilities and energy research and development sites. Long-term protection of the environment from these wastes requires an understanding of the processes that control contaminant fate and transport, and how changes in the vadose zone geochemical environment can alter that fate.

Project Description: Long-term stewardship of DOE lands requires an understanding of the fate of contaminants released to the vadose zone by past waste disposal practices. The rate at which contaminants move through the vadose zone depends on whether water moves downward along preferred flow paths or diffusely throughout the vadose zone. Electrical resistivity tomography can provide a three-dimensional image of the subsurface from which preferred flow paths, if they exist, can be readily identified. Images of subsurface electrical resistivity distribution will be used to identify the preferred conceptual model for flow in the vadose zone under an infiltration pond. By obtaining data on moisture content from other methods (water content sensors, neutron logs), resistivity can be calibrated to provide a three-dimensional data set on subsurface moisture. Research results will have applicability to INEEL operations, environmental remediation, and to other DOE facilities. 
Research Project Number: 7

\section{Calibration and Enhancement of Geophysical Imaging Tools in a Mesoscale Experimental Facility}

Conceptual Model Input: Aquifer

Addresses Need: $\quad 2$. Need methods for delineation of flow direction in the aquifer at a facility scale.

Principal Investigator: Roelof Jan Versteeg, Idaho National Engineering and Environmental Laboratory

Purpose: To advance the fundamental understanding required to solve contaminant transport and remediation issues, both on the INEEL site and at other DOE sites.

Project Description: One of the fundamental DOE science needs is the ability to understand and predict contaminant fate and transport. A key component in this is the ability to couple field geophysical data to hydrological, biological and geochemical processes. The object of this project is to develop the fundamental skills required to do this by conducting a series of controlled experiments in a large soil tank and integrating the resulting geophysical, geochemical and hydrological data into coupled models. The results of this research will be used by geophysicists, hydrologist, geochemists, and modelers. 
Research Project Number: 8

\section{Mesoscale Investigations of Vadose Zone Carbon Cycles}

Conceptual Model Input: Source Term and Vadose Zone

Addresses Need: 13. Need studies of chemical state of the waste form in the Subsurface Disposal Area and other sites.

Principal Investigators: Larry Hull, Kristine Baker, Craig Cooper, Don Fox, Mitch Plummer, and Dave Thompson (INEEL)

Purpose: The objective of this project is to provide more defensible predictions of radionuclide migration in the vadose zone where multiphase transport and variable gas-phase composition may impact radionuclide mobility.

Project Description: Inorganic carbon is selected as the integrating variable for multiphase and multi-component vadose zone processes because it serves as a coupling component among microbial productivity, solution $\mathrm{pH}$, control of mineral-solute interactions, gas-phase transport, and dissolved phase transport. Radionuclides being investigated are carbon-14 and uranium. Results of the investigation will apply to DOE waste disposal sites in the arid west, and are directly applicable to the Subsurface Disposal Area (SDA) at the INEEL. The experimental conditions have been selected to represent important components of the subsurface environment at the SDA including material composition, variable gas-phase composition, and unsaturated moisture conditions.

Carbon-14 and uranium are two significant components of the buried waste inventory with estimated high mobility. A mesoscale column ( $3 \mathrm{~m}$ high and $1 \mathrm{~m}$ in diameter) was packed with sediment representative of the SDA and instrumented to monitor moisture potential, solution chemistry, gas-phase chemistry, and temperature. Gas-phase tracer tests were conducted with sulfur hexafluoride to quantify appropriate transport parameters for pore gas. Dissolved-phase tracer tests were conducted with lithium bromide to quantify appropriate transport parameters for solutes. Constitutive relations for microbial activity as a function of moisture content were derived from measured microbial productivity. Sediment samples were collected to determine microbial and mineralogy composition. Using these parameters, computer models were used to predict the migration of carbon-14 and uranium in the column.

In August 2002, three liters of tracer solution containing tritium, carbon-14, and uranium were injected into the column approximately $60 \mathrm{~cm}$ below the sediment surface. Sampling showed that carbon-14 migrated rapidly in the gas phase. Uranium has not been detected in the solution samplers, but predictive models indicate that it will take several months for uranium migration to be detected. Results of this experiment allow the phase-transfer parameters for carbon-14 to be determined, which can be applied to predictive models of carbon-14 migration at the SDA. The results support the position that a significant fraction of the carbon-14 in buried waste will be transported to the surface in the gas phase and will not be transported to the aquifer. 
Research Project Number: 9

\section{Geomicrobiology of Subsurface Environments}

Conceptual Model Input: Aquifer and Vadose Zone

Addresses Need: 1 . Need to determine preferred flow zones in the aquifer for characterization at the regional and subregional scale.

Principal Investigators: F. Colwell, et al. (INEEL); A. Igoe (Albertson College); T. Magnuson, J. Taylor, and A. Ray (Idaho State Univ.); S. O'Connell (Western Carolina Univ.); B. Peyton (Washington State Univ.); K. Reardon (Montana State Univ.); F. Rosenzweig (Univ. of Montana); and M. Whiticar (Univ. of Victoria)

Purpose: The overall objective of this project is to enhance the understanding of biological properties in the subsurface to develop predictive knowledge of contaminant fate and transport. End point applications of the work include remediation of contaminated geologic media at DOE sites and facilities nationwide, and industrial sites throughout the world, as well as agriculture, mining, resource recovery (energy), aquifer contamination, and waste disposal.

Project Description: This research targets two knowledge gaps that have been identified with respect to DOE's subsurface contamination problems. These gaps relate to our current inability to:

(1) characterize physical, chemical, and biological properties of the subsurface, including approaches to understanding the properties of the geologic system and relating them to contaminant fate and transport; and (2) characterize highly heterogeneous systems. The basic research conducted within this project seeks to address needs arising from these knowledge gaps. Specifically, to improve the capabilities for characterizing the biological properties of the subsurface, including biological heterogeneity, at the scales that control contaminant fate and transport.

Microorganisms are the primary agents of geochemical change in the subsurface, and these changes mediate transport and degradation phenomena. The following research tasks are driven by critical deficiencies in the existing microbiological knowledge base that limit in situ remedial applications:

- Quantifying the impact of microbial partitioning between geological media and groundwater on biogeochemical transformations

- Quantifying the biological effects on wettability and inhibition because these physical parameters impact contaminant partitioning as well as the access and bioavailability of contaminants to transformation

- $\quad$ Establishing the connection between the structure and function of subsurface microbial communities and specific environmental conditions of the habitat

- Determining how co-contaminants impact biotransformation of metals and radionuclides.

These tasks are consistent with those of the INEEL's Subsurface Science Initiative, which has identified biogeochemical transformations as a key research focus. Furthermore, the tasks target real site problems within the DOE complex. 
Research Project Number: 10

\section{Geocentrifuge Research Laboratory Development}

Conceptual Model Input: Aquifer and Vadose Zone

Addresses Need: 7. Need measurement techniques to monitor ambient water travel time through the VZ to the SRPA at selected facilities.

Principal Investigator: Alan T. Stadler, Idaho National Engineering and Environmental Laboratory

Purpose: To develop an operational 2-m-radius geocentrifuge with associated procedures for its use, functional supporting laboratory capabilities, initiation of geocentrifuge research activities, and establishment of both internal and external outreach programs.

Project Description: The INEEL is developing a facility for geoenvironmental and geotechnical applications. The centerpiece of the facility is a 2-m-radius Actidyn Systemes Model C61-3 civil engineering centrifuge with a payload capacity of $500 \mathrm{~kg}$ at $100 \mathrm{~g}$. Data acquisition is accomplished through an on-board computer linked via a fiber optic rotary joint to a user computer located in the centrifuge control room.

The initial focus of this geocentrifuge research facility will be on subsurface transport studies and the performance of engineered caps and barriers. It will be available for use by national laboratory, university, and private sector investigators. The centrifuge is an exciting research capability that will allow hydrologic and biogeochemical investigations using intact blocks and cores of vadose zone materials and reconstructed models with idealized 2- and 3-dimensional (2-D and 3-D) physical and chemical heterogeneities. The geocentrifuge will allow researchers to study in a few hours or days the effects of decades of gravity-induced fluid movement.

This ESRA project initiates the development of this geocentrifuge research capability at the INEEL. Activities have included the commissioning of the two-meter-radius centrifuge and the establishment of the supporting laboratory areas. These areas include soil storage, sample preparation, the centrifuge control room, and office/meeting space for the geocentrifuge research staff and investigators. Commissioning has included centrifuge performance verification and the development of procedures for use of the device. The project activities were divided into three tasks: laboratory capability, research programs, and outreach. 


\section{Biocorrosion}

Conceptual Model Input: Source Term

Addresses Need: $\quad 12$. Need studies of physical waste form of contaminants in the Subsurface Disposal Area and other sites.

Principal Investigators: Patrick J. Pinhero, Ph.D. and Richard N. Wright, Ph.D. (INEEL)

Purpose: Detection and mitigation of microbially-influenced corrosion (MIC) in Spent Nuclear Fuel (SNF) storage, both wet and dry, is the ultimate goal of this task. Supporting goals are to: (a) verify that MIC is active and indeed a problem in SNF storage facilities, (b) identify and understand the fundamental corrosion mechanisms inherent to MIC, and (c) design and construct a deployable device that can be used to measure MIC activity in SNF storage environments. These goals are congruent with those of the DOE Office of Environmental Management (DOE-EM) to invest in research and development that can provide long-term, cost effective solutions for dealing with an increasing inventory of nuclear waste.

Project Description: MIC, as it relates to the storage of spent nuclear fuel, is a potential problem at the INEEL and other sites across the DOE complex. This project developed a novel fundamental science capability for pinpointing localized corrosion at its inception using conductive atomic force microscopy. Additional accomplishments include development of a database of Tafel-determined corrosion rates for a library of microbiological systems, development of electrochemical noise systems for real-time monitoring of INEEL service environments, and development of a corrosion inhibitor for aluminum alloys. Other accomplishments of this project included determining the radiation-tolerance of microbes, establishing new protocols with respect to microbiologically sterile system controls, and development of many new capabilities for studying localized corrosion. 
Research Project Number: 12

\section{Near-Surface Engineered Environmental Barrier Integrity}

Conceptual Model Input: Source Term and Vadose Zone

Addresses Need: $\quad$ 12. Need studies of physical waste form of contaminants in the Subsurface Disposal Area and other sites.

Principal Investigators: S. J. Piet, R. P. Breckenridge, and project team: J. Beller, D. Burns, L. Chambers, G Geesey, D. Glenn, J. Jacobson, T. Kaser, D. Kunerth, T. Luther, P. Martian, R. Martineau, G. Matthern, E. Mattson, T. McGonigle (Idaho State University); R. Podgorney, I. Porro, and J. Seymour (Montana State University); R. Soto, E. Steffler, A. Stormberg, G. Stormberg, R. Versteeg, and G. White (INEEL)

Purpose: To catalyze a Barrier Improvement Cycle making Remediation System Performance Management possible.

Project Summary: Society has and will continue to generate hazardous wastes, which pose risks that must be managed. Risk for exceptionally toxic, long-lived, and feared waste is controlled through deep burial, such as at Yucca Mountain. Some wastes are recycled, destroyed, or treated, while others are stored at or near the ground level (in someone's back yard). Most of these "back-yard" storage sites include a surface barrier (cap) to prevent downward water migration, but some hazards from these caps will persist indefinitely. Indeed, some caps, only years old, have not shown adequate performance. As society and regulators have demanded additional proof that caps are robust against more threats and for longer time periods, they have become increasingly complex and expensive. As has been found in other industries, increased complexity will eventually increase the difficulty in estimating performance, in monitoring system/component performance, and in repairing or upgrading barriers as risks are managed.

An approach is needed that will lead to simpler, less expensive, longer-lived, more manageable caps. The objective of this project, which started in April 2002, is to catalyze a Barrier Improvement Cycle (iterative learning and application), making Remediation System Performance Management (doing the right maintenance neither too early nor too late) possible. The knowledge and capabilities gained will help verify the adequacy of past remedial decisions, improve barrier management, and enable improved solutions for future decisions. We believe it will be possible to develop simpler, longer-lived, less expensive caps that are easier to monitor, manage, and repair.

The project plan is to: (a) improve the knowledge of degradation mechanisms in times shorter than service life, (b) improve modeling of barrier degradation dynamics, (c) develop sensor systems to identify early degradation, and (d) provide a better basis for developing and testing new barrier systems. This project combines selected exploratory studies (benchtop and field scale) with the coupled effects of accelerated aging testing at intermediate mesoscale, the testing of new monitoring concepts, and the modeling of dynamic systems. The emphasis on mesoscale (coupled) tests, accelerated effects testing, and dynamic modeling separates this project from other efforts, simultaneously building on that body of knowledge. The project is examining the performance of evapo-transpiration, capillary, and grout-based barriers. 
Research Project Number: 13

\section{Non-Ideal Solution Thermodynamics}

Conceptual Model Input: Source Term

Addresses Need: 13. Need studies of chemical state of the waste form in the Subsurface Disposal Area and other sites.

14. Need to determine what from the standpoint of geochemistry is influencing transport and retardation.

Principal Investigators: Randall LaViolette, Michael McIlwain, Dean Peterman, and Jill Scott (INEEL); Donald Schreiber (Western Michigan State)

Purpose: To develop a variety of approaches for estimating Pitzer parameters.

Project Description: Thermodynamic modeling of the behavior of complex waste solutions is fast becoming a powerful means of providing data for informed decision-making and selection of alternatives for management of chemical processes and products. Pitzer parameters are needed to describe high-level waste physical properties, component solubilities, and chemical reactivity. We are fabricating an isopiestic measurement apparatus to test the accuracy of various prediction approaches.

Molecular dynamics (MD) and quantum mechanics (QM) activities have included the testing of commercial algorithms for accuracy and validity for published test ionic solutions. QM calculations on nitrate and aluminum ions were performed to understand the hydration configuration around the species, obtain interaction potentials, and explore the potential of water displacement/competition. Depending on the number of species considered, MD simulations can require quite extensive modeling run times in order to correctly represent the system of interest. One way of reducing the computation time is to develop a simple interaction potential for water and all other atoms in the system. Another approach was to employ massively parallel codes for the MD simulation.

Multicomponent Pitzer parameter estimation is being pursued to augment direct modeling of the properties of high ionic strength solutions. The Pitzer ion-interaction model relies on experimentally determined Pitzer parameters, when available for single component systems. Progress to date indicates that ion size and acidity are valuable for predicting the shape of the desired trend.

Experimental measurement capability is being established to validate predictions being supplied by the modeling and empirical tasks. Water activities are determined in this isopiestic apparatus by measurement of mass transfer of water between samples. The current state of apparatus development is such that the project can now plan for testing and calibration. 
Research Project Number: 14

\section{Investigation of the Movement and Fate of Chlorinated Hydrocarbons}

Conceptual Model Input: Vadose Zone

Addresses Need: 7. Need measurement technique to monitor ambient water travel time through the VZ to the SRPA at selected facilities.

Principal Investigator: Robert James Lenhard, Idaho National Engineering and Environmental Laboratory

Purpose: This research will evaluate a conceptual model of carbon tetrachloride contamination of a site at the INEEL. The movement of $\mathrm{CCl}_{4}$ in the gas phase through simulated layers of sediments and basalt toward the water-saturated zone will be measured as well as microbial-assisted transformation of $\mathrm{CCl}_{4}$.

Project Description: The experimental data will be used to better understand and predict the subsurface fate of $\mathrm{CCl}_{4}$ at the disposal area, especially the potential for microbial transformation of $\mathrm{CCl}_{4}$. The data will also be used to test the predictive model that is being used to simulate the $\mathrm{CCl}_{4}$ contamination. The proposed work enhances understanding of contamination problems at DOE sites and predictive uncertainty of numerical models used to model subsurface contamination at DOE sites. It also has application to other DOE sites and directly addresses scientific needs cited by DOE. 
Research Project Number: 15

\section{Modeling of Flow and Colloid Behavior in Subsurface Fractures}

Conceptual Model Input: Vadose Zone and Source Term

Principal Investigator: Paul Meakin, Idaho National Engineering and Environmental Laboratory

Addresses Need: $\quad 6$. Need to know the geochemical characteristics of the neat field environment for actinides.

14. Need to determine what from the standpoint of geochemistry is influencing transport and retardation.

Purpose: This research is aimed at the development of some of the conceptual models and computer models that will be needed to interpret and guide subsurface process experiments.

Project Description: Recent observations indicate that some pollutants travel much further and/or faster than predicted, and that there are serious gaps in our understanding of subsurface processes. Laboratory scale and large mesoscale experiments are being designed at INEEL to develop the understanding that will be needed to remediate and manage polluted sites in the future. In particular, large mesoscale experiments will be needed to evaluate, and validate our understanding of the subsurface and our ability to predict the behavior of subsurface pollutants. Conceptual models and computer models will be needed to interpret and guide such experiments.

This project will result in improved modeling of flow and transport in the vadose zone. The program will also contribute to the development of a better understanding the behavior of waste forms and their near-field transport. Both flow in fractures and colloid- mediated transport have been implicated in the transport of radionuclides and other contaminants further and faster than expected. An improved understanding of these transport phenomena and the capability to reliably model them is needed to reduce remediation costs and more reliably predict the fates of pollutants. Both flow in fractures and the behavior of colloids in fractures are important in the oil and gas industry.

An improved understanding of single- and multi-phase flow in fractures and fracture networks is of fundamental importance in geoscience. The behavior of colloids in the subsurface is also of broad scientific interest. Improved models for flow in fractures would have an important impact on several areas of technology including environmental management and remediation, oil \& gas recovery, civil engineering and materials science. 


\section{Application of New Borehole Geophysical Methods for Stratigraphic Correlation and Identification of Non-Aqueous-Phase Contaminants}

Conceptual Model Input: Aquifer and Vadose Zone

Addresses Need: $\quad 10$. Need to perform vertical profiling of contaminant plume geometry to determine layering effects.

1. Need to determine preferred flow zones in the aquifer for characterization at the regional and subregional scale.

Principal Investigator: Russel Cleveland Hertzog, Idaho National Engineering and Environmental Laboratory

Purpose: This work will contribute to environmental quality by providing a more definitive way to correlate lava flow units in the subsurface, and by providing a heretofore unavailable way to identify non-aqueous contaminants in groundwater.

Project Description: This research will apply state-of-the-art research logging capabilities and develop new interpretation methodologies to address the difficult problems of stratigraphic correlation of lava flows and identification of non-aqueous phase organic contaminants in groundwater in the subsurface of the INEEL area. If successful, it will eventually result in deployment of an additional logging tool (Nuclear Magnetic Resonance), which has the potential to differentiate between groundwater and non-aqueous phase organic contaminants in the groundwater. It will provide expertise for interpretation of borehole logging results. It will provide drill-rig support for pulling and replacing pumps, and for setting and removing temporary plastic or fiberglass casing in wells selected for logging. 
Research Project Number: 17

\section{Computational Experiments of Hysteretic Chemical and Moisture Migration}

Conceptual Model Input: Vadose Zone

Principal Investigator: Annette Lynn Schafer, Idaho National Engineering and Environmental Laboratory

Addresses Need: 14. Need to determine what form the standpoint of geochemistry is influencing transport and retardation.

15. Need to develop better tracer tests to track flow through the interbeds in selected areas.

Purpose: To investigates the influence of repeated infiltration events on the transport of solutes in variably saturated porous media.

Project Description: Since the movement of water is history dependant, geochemical reactions should be history dependant. This research will: (1) address numerical and uncertainty limitations by introducing hysteretic data into a simulator, enabling Monte Carlo simulation of transient infiltration events, (2) use numerical experiments to assess the range of conditions under which these effects might influence transport predictions, and (3) use physical experiments to test the hysteretic relationships incorporated into the model.

Incorporating these data into predictive models will be approached through stochastic relationships describing the heterogeneity in hydraulic conductivity. The correlation between reactive surface area, capillary pressure, and relative hydraulic conductivity will be tested. The research proposed here addresses: (1) the utility of applying tracer technologies and analysis for determining chemical heterogeneity in stratified geologic media, (2) the need to estimate large-scale in situ geochemical behavior, and (3) the need to accurately predict the transport of reactive contaminants in geochemically heterogeneous media.

Vadose zone simulations have been primarily deterministic with limited attempts at including uncertainty. Uncertainty in hydrologic parameters (e.g., permeability and moisture characteristic curves) and boundary conditions (e.g., infiltration magnitude, timing, and spatial variability) affects the usability of the simulation results for making environmental decisions. 
Research Project Number: 18

\section{Characterization of Nonlinear Complex Resistivity Spectra During Biochemical Reduction of $\mathrm{Cr}+6$ to $\mathrm{Cr}+3$}

Conceptual Model Input: Aquifer and Vadose Zone

Addresses Need: $\quad 10$. Need to perform vertical profiling of contaminant plume geometry to determine layering effects (such as $\mathrm{Cr}^{+6}$ at the Test Reactor Area).

Principal Investigator: Gregory John Stormberg, Idaho National Engineering and Environmental Laboratory

Purpose: This research addresses the need for better methods to characterize and monitor the fate of contaminants undergoing biochemical transformations in the subsurface. Research is expected to allow us to establish a qualitative relationship between biochemical reactions and nonlinear complex resistivity parameters, and determine if such measurements can be used to track the course of microbiologically mediated reactions in situ.

Project Description: This research involves study of a geophysical method, nonlinear complex resistivity, and the potential for development of a minimally invasive or non-invasive technique for mapping and monitoring microbiologically mediated reactions in contaminated, heterogeneous, subsurface environments. The specific biological reaction of interest is the reduction $\mathrm{of}^{+6}$ to $\mathrm{Cr}^{+3}$ by indigenous chromate-reducing bacteria. 


\section{Multiscale Modeling of Multiphase (Unsaturated) Flow}

Conceptual Model Input: Aquifer and Vadose Zone

Addresses Need: 7. Need measurement technique to monitor ambient water travel time through the VZ to the SRPA at selected facilities.

Principal Investigator: Paul Meakin, Idaho National Engineering and Environmental Laboratory

Purpose: This research intends to describe subsurface heterogeneities in quantitative terms and incorporate this description into computer models. This ability will provide a key element in the prediction of subsurface contaminant fate and transport, and reduce modeling uncertainties. These important computational capabilities and methodologies will enable more accurate modeling of fieldscale contaminant behavior.

Project Description: A critical need in addressing contamination at DOE sites is to account for the complex spatial variability in hydrologic properties when modeling contaminant behavior at the field scale. Contaminant behavior in the subsurface depends on physical and chemical heterogeneities that span an enormous range of length scales, from the atomic scale to major geological units. Currently no geophysical measurement method or combination of methods can provide a detailed description of the subsurface over this range of length scales. This project explores using wavelet-based and statistical methods to better represent the effects of the complex spatial variability of hydrological properties on different scales in subsurface fate and transport models. 
Research Project Number: 20

\section{Modeling Solute Partitioning at Interfaces}

Conceptual Model Input: Vadose Zone

Addresses Need: 14. Need to determine what from the standpoint of geochemistry is influencing transport and retardation.

Principal Investigator: Randall Laviolette, Idaho National Engineering and Environmental Laboratory

Purpose: This research addresses the need for improved models to predict contaminant fate and transport. It bridges a knowledge gap that is important for modeling sorption of compounds beyond extremely simple solutes.

Project Description: Adsorption and desorption processes play major roles in subsurface contaminant fate and transport. Model descriptions of these processes, and their coupling with other biogeochemical processes, are required for remediation and monitoring strategies. In many cases, empirical descriptions of adsorption are inadequate for accurate predictions of chemical transport. Even the equilibrium assumption is inappropriate, depending on the time and flow regimes. This research investigates a more reliable and scientifically defensible approach employing kinetic and equilibrium models based on more realistic mass-action functions under near-to-equilibrium conditions. The effort will determine more realistic models for simple and multi-dentate surface complexation for a wide range of complex surfaces. This project should help resolve the debate regarding how to best model sorption of complex solutes and determine whether simple, currently deployed fate and transport models are adequate or must be modified.

DOE's Environmental mission requires accurate models for predicting the long-term fate and transport of actinides and other subsurface contaminants, both for designing waste repositories and managing waste at contamination sites. Valid conceptual and mathematical models for adsorption and desorption processes are an essential component to this endeavor. 
Research Project Number: 21

\section{Estimating the Climatic Sensitivity of Vadose Zone Infiltration Rates through Paleohydrologic Analyses}

Conceptual Model Input: Vadose Zone

Addresses Need: 15. Need to develop better tracer tests to track flow through the interbeds in selected areas.

Principal Investigator: Mitchell A. Plummer, Idaho National Engineering and Environmental Laboratory

Purpose: The research will provide preliminary data to evaluate the long-term impact of precipitation changes on the flux of water moving through the vadose zone. As a result, this study will improve understanding of the relationship between climate and recharge, thereby providing a means to assess the sensitivity of a particular waste site to future environmental changes.

Project Description: The downward flux of soil moisture is a critical parameter in estimating the potential for contaminant transport from hazardous and/or radioactive wastes in the vadose zone. These fluxes are derived through a complex set of processes from precipitation. At sites where very long-term transport predictions are necessary (e.g., radioactive disposal sites that must consider periods as long as tens of thousands of years), the potential for climate-driven changes in subsurface infiltration rates must be assessed. This project will explore a means for evaluating climatic sensitivity of vadose zone infiltration. The research approach involves estimation of paleotemperatures and paleoprecipitation rates through inverse modeling of glacial fluctuations, and reconstruction of subsurface infiltration changes through inverse modeling of subsurface soil moisture and solute movement.

Specifically, this project will yield a numerical model to predict past annual precipitation rates and a model to evaluate vadose zone fluxes. This work will also develop expertise in collecting supporting data for estimating vadose zone fluxes. 
Research Project Number: 22

\section{Advanced Borehole Seismic Sources for High-Resolution Subsurface Imaging and Characterization for Environmental Applications}

Conceptual Model Input: Vadose Zone

Addresses Need: $\quad 3$. Need to improve the use of 3D tomography and other cross-hole geophysics for selected facilities to show changes in moisture.

Principal Investigator: David Michael Weinberg, Idaho National Engineering and Environmental Laboratory

Purpose: To investigate and design several borehole seismic sources specific to environmental applications.

Project Description: Characterization of subsurface physical heterogeneities is the first necessary step toward building reasonable and defensible models of subsurface transport. The technical problems associated with "seeing" or imaging the subsurface lie within two general areas: physical properties of the earth materials through which one wants to image, and the resolution available based on the interrogation technique itself. Subsurface characterization can be performed in a multitude of geophysical ways, but as ever-finer vertical and horizontal resolution is required, acoustic (seismic) techniques have become the overall standard method, especially if detailed 3-dimensional imaging is needed. Substantial savings in characterization and long-term monitoring costs could be achieved by accurately being able to determine spatial variability of flow of contaminants over larger scales of the vadose zone. It is the intent of this research to investigate and design several borehole seismic sources specific to environmental applications. 
Research Project Number: 23

\section{Advanced Technology for Mapping Subsurface Water Conductivity}

Conceptual Model Input: Aquifer and Vadose Zone

Addresses Need: 1 . Need to determine preferred flow zones in the aquifer for characterization at the regional and subregional scale.

2. Need methods for delineation of flow direction in the aquifer at a facility scale.

Principal Investigator: Gail Lynn Heath, Idaho National Engineering and Environmental Laboratory

Purpose: The INEEL has extensive applied research capabilities in the area of sensor development. Through this project this capability will be directed toward developing in situ/ex situ environmental characterization capabilities. An affordable sensor architecture that can provide sufficient data to both test and drive predictive models is identified as one of the major needs and challenges of subsurface science research.

Project Description: This research explores a novel approach to distribution mapping of resistivity or conductivity in the subsurface. The feasibility will be tested through a system of permanently installed probes with electrodes at varying depths, deployed over the area of interest, and electronically controlled as to active pair and excitation frequency. A global positioning system coupled with an automated surface platform will measure the 3-axis vector surface magnetic field at each map point over the range of selected operational frequencies and electrode pair combinations. Automated data processing will generate conductivity maps during the progress of the survey with the fine details of the spatial magnetic data added as the 3-axis magnetic data are acquired from each map point. The data will be used to determine depth to groundwater and identification of contaminant plumes and contaminant migration through comparison with background and historical conductivity values. 
Research Project Number: 24

\section{Development of Enzymatic Biosensors for Environmental Applications}

Conceptual Model Input: Aquifer and Vadose Zone

Principal Investigator: Vicki Sue Thompson, Idaho National Engineering and Environmental Laboratory

Addresses Need: 7. Need a measurement technique to monitor ambient water travel time through the VZ to the SRPA at selected facilities.

Purpose: The development of biosensors for subsurface measurements will lead to the development of a new line of innovative, cost-effective measuring technologies that can be of direct use for basic research in understanding environmental biogeochemical processes, for monitoring of chemical species during remediation applications, and for long-term monitoring programs.

Project Description: Biosensors possess the advantages of selectivity, sensitivity, and rapid response time. Combined with improved polymer-based methods of stabilizing immobilized enzymes, the potential for constructing rugged and durable devices for field use is excellent. This research will investigate immobilized enzymes as biosensors for the determination of chemical species in the subsurface, using a urea sensor as a model. Such biosensors could be used for monitoring contaminant migration through direct measurement of the contaminant or by measurement of other species that affect contaminant migration. This work will provide the foundation for the development of a new line of innovative, costeffective monitoring technologies for subsurface investigations. 
Research Project Number: 25

\section{Kinetics and Mechanisms of Inter-Surface Transfer and Solid-Solution Partitioning of Surface-Complexed Metals in Colloidal Systems}

Conceptual Model Input: Aquifer and Vadose Zone

Principal Investigator: George Dean Redden, Idaho National Engineering and Environmental Laboratory

Addresses Need: $\quad$ 14. Need to determine what from the standpoint of geochemistry is influencing transport and retardation.

Purpose: The research will provide basic understanding of solute-colloid interactions that are necessary for modeling colloid-facilitated transport. It will also help to prepare the investigators for anticipated studies involving colloids at the meso-scale and field scale, and take advantage of in-house capabilities for synthesizing and using engineered colloids for novel applications in subsurface environments.

Project Description: Colloidal surface science is an exciting frontier topic in biogeochemistry. It holds promise for significant breakthroughs in our understanding of subsurface contaminant fate and transport, and our ability to utilize that knowledge for contaminant cleanup. This research will explore fundamental aspects of colloid-facilitated transport of contaminants in subsurface environments, and will explore the possible applications of engineered colloids for manipulating and treating contaminants in porous media. Colloidal particles have been implicated in the accelerated transport of heavy metals and radionuclides in subsurface environments. In addition, colloids are being considered in terms of a "nano-technology" with potentially valuable applications in the treatment and monitoring of subsurface contaminants. 


\section{Organic Co-Solvent and Co-Contaminant Effects on Sorption of Uranyl and Cesium to Metal Oxide Surfaces}

Conceptual Model Input: Vadose Zone

Principal Investigator: George Dean Redden, Idaho National Engineering and Environmental Laboratory

Addresses Need: $\quad$ 14. Need to determine what from the standpoint of geochemistry is influencing transport and retardation.

Purpose: To address some of the more significant questions regarding the treatment, and potential environmental impact, of radioactive complex waste mixtures.

Project Description: The production of nuclear fuels and weapons has generated a large inventory of radioactive wastes that are currently stored at several DOE facilities. These wastes are often complex mixtures of heavy metals, radionuclides, oils, organic solvents, and organic metal-complexing agents. DOE has placed a high priority on developing the methods and technology to treat and safely store the wastes and to mitigate areas of environmental contamination. The complexity of the waste mixtures poses some unique technical and scientific challenges due to the range of chemical components and unusual physical properties. In some cases, there is an absence of even the most basic information needed to devise chemical treatment procedures and develop predictive environmental transport modeling for risk assessment and site cleanup. This research will explore the effects of organic co-solvents on the chemical interactions between key components of the waste mixtures and metal oxide surfaces. 
Research Project Number: 27

\section{Natural and Synthetic Subsurface Colloids}

Conceptual Model Input: Aquifer and Vadose Zone

Principal Investigator: Glenn Allen Moore, Idaho National Engineering and Environmental Laboratory

Addresses Need: $\quad$ 14. Need to determine what from the standpoint of geochemistry is influencing transport and retardation.

Purpose: The Department of Energy is responsible for cleaning up the environmental legacy from over 50 years of nuclear weapons production. This is an enormous challenge, and requires the significant improvement of our knowledge of the processes affecting fate and transport of contaminants in the environment. This project will contribute to the fundamental understanding necessary to evaluate the impact of colloid-facilitated transport on contaminant fate in the subsurface at the INEEL. It will also contribute to the development of new approaches for colloid collection from subsurface zones, colloid characterization, and the development of innovative technologies for use in colloid investigations and in situ cleanup.

Project Description: To effectively model and/or perform meso-scale investigations of colloidfacilitated contaminant transport, one must first understand the nature of the colloid species present and their dynamic properties. The primary objective of this research is to investigate the natural colloids that are present in vadose zones, perched water zones, and the Eastern Snake River Plain Aquifer. This data will provide a significant knowledge base supporting subsurface computational modeling and experimental investigations. A second component of this project involves processing of synthetic colloids. Namely, engineered colloids that behave like the naturally occurring ones to provide a source of standardized colloids for bench scale and meso-scale experiments dealing with colloid transport. 


\section{Development of Techniques for In Situ Measurement of Groundwater Contaminant Source Strength}

Conceptual Model Input: Aquifer and Vadose Zone

Addresses Need: $\quad$ 14. Need to determine what from the standpoint of geochemistry is influencing transport and retardation.

Principal Investigator: Robert Charles Starr

Purpose: To develop a methodology for better characterizing subsurface contaminant sources to facilitate better predictions of contaminant plume evolution, selection of appropriate source remedial measures, and verification of source remediation activities. Accurate prediction of plume evolution is a key component of understanding environmental risks, and selecting and verifying the performance of subsurface remediation activities is a major portion of cleaning up the environmental legacy.

Project Description: The theory and methodology for in situ measurement of mass transfer coefficients in secondary sources of groundwater contaminants will be tested at both the meso and field scales. Secondary contaminant sources generate long-lived plumes of contaminated groundwater. Knowledge of the secondary source mass and of mass transfer coefficients is needed to make meaningful predictions of contaminant plume evolution, which is used in risk assessment and selection of remedial approaches, including natural attenuation. Successful aquifer remediation often requires that secondary sources be removed, converted into innocuous forms, or isolated from the groundwater system; a method for measuring in situ mass transfer coefficients could be used to evaluate the effectiveness of source remediation activities. These needs indicate that developing a method for measuring the mass transfer coefficients in a secondary source is important. This approach will be tested by experiments at the bench scale that will be used to measure mass transfer rates under different hydraulic conditions, and by meso scale experiments with sources of different geometry, mass, and type (e.g., organic liquid and sorbed contaminants). 
Research Project Number: 29

\section{Sorption of Heavy Metals and Radionuclides on Mineral Surfaces in the Presence of Organic Co-Contaminants}

Conceptual Model Input: Source Term and Vadose Zone

Addresses Need: $\quad$ 6. Need to know the geochemical characteristics (e.g., oxidation states) of the near field environment for actinides.

14. Need to determine what from the standpoint of geochemistry is influencing transport and retardation.

Principal Investigator: Dr. James O. Leckie, Stanford University

Purpose: At present, with the available experimental database, broad generalizations concerning the effect of organic ligand and chelating agents on metal or radionuclide mobility cannot be made. The quantitative predictions of partitioning that are necessary to estimate contaminant transport are not yet possible, and specific details of the chemical mechanisms are still hypothetical. In order to make reasonable transport predictions, an expanded database is needed for a range of priority heavy metal contaminants, common ligands, and representative mineral surfaces. Elucidating the mechanisms by which organic ligands affect metal partitioning at surfaces will provide information necessary for the design of effective treatment strategies.

Project Description: A review of the known inventory of chemical wastes at DOE facilities reveals that a large fraction of the waste is present as complex mixtures containing radionuclides, heavy metals, fuels, oils, organic solvents, and a variety of organic metal complexing agents. This situation is a result of a history of co-disposing wastes associated with chemical processing, metal surface cleaning, decontamination, and fabrication procedures used in the production of nuclear fuels and weapon components. The large inventory of complex and potentially unstable wastes must be stored until suitable treatment, confinement or disposal technologies have been developed. Unfortunately, in many cases the waste materials have been either discharged directly into open pits, or have since escaped from temporary containment facilities and now contaminate surrounding soils and groundwater.

The chemical complexity of these wastes present particularly challenging problems with respect to predicting subsurface migration of the radionuclides and heavy metals, and developing suitable remediation strategies. Among the organic compounds at DOE sites are a number of organic chelating agents that can form stable solution complexes with metals, radionuclides, and their oxy-ions. Examples include EDTA1, NTA2, and citric acid. It would be reasonable to predict that the formation of metal-organic complexes, especially those with stable multi-dentate structures, will influence the mobility of the metals and radionuclides in soils and groundwater. A general prediction that is consistent with the few available field studies would be that metal complexing organic ligands should increase metal mobility. This has already been demonstrated in a number of studies. However, recent work with uranium and citric acid and cadmium and citric acid on metal oxides has shown that, under particular chemical conditions, complexing agents can actually enhance metal adsorption. Mobility of ionic solutes in groundwater is a function of the extent of partitioning between the mobile (water) and immobile (soil, mineral) phases.

Organic ligands compete with reactive surface binding sites for metal solutes, or bind directly to surfaces thereby altering the type and availability of binding sites. In most field applications, increased mobility of soil and groundwater contaminants is not desirable since retrieval of the contaminants or isolating the 
public from hazardous conditions becomes more difficult as zones of contamination expand. However, in some cases, where remediation involves contaminant recovery, maximum mobility can be a distinct advantage. 
Research Project Number: 30

\title{
Research Program to Determine Redox Properties and Their Effects on Speciation and Mobility of Pu in DOE Wastes
}

\author{
Conceptual Model Input: Source Term and Vadose Zone \\ Addresses Need: $\quad 6$. Need to know the geochemical characteristics (e.g., oxidation states) of the \\ near field environment for actinides.
}

14. Need to determine what from the standpoint of geochemistry is influencing transport and retardation.

Principal Investigator: Dr. Gregory Choppin, Florida State University

Purpose: The main output from this project will be the data and the model to reliably predict the plutonium oxidation states, transformation reactions, and plutonium behavior in diverse geologic environments, and to allow the development of appropriate new technologies or evaluate the effectiveness of proposed technologies.

Project Description: Plutonium contamination is a major problem at many DOE sites. This research seeks to provide fundamental data and models for predicting plutonium speciation and environmental behavior which will allow evaluation of the many processes proposed for remediation of plutoniumcontaining DOE wastes. Basic to this prediction are: (1) the complete fundamental data on aqueous complexation, solubility reactions, and geochemical conditions under which different plutonium oxidation states transform from one to another; and (2) a model containing this fundamental data which can predict site-specific reactions.

We propose to summarize existing data and develop additional fundamental data to measure the oxidation state (or states) in a variety of solid/solution systems in the presence and absence of chemicals likely to be present in DOE wastes of environmental systems and which can promote redox transformations and complexation reactions. Specifically, we will: (1) determine stability constants of $\mathrm{Pu}(\mathrm{IV})$ with strong complexants such as EDTA and DTPA, (2) determine the geochemical conditions under which different reductants (e.g., $\mathrm{Fe}(0), \mathrm{Fe} 2+, \mathrm{Fe}(\mathrm{II})$-containing solids, and humics) can reduce $\mathrm{Pu}(\mathrm{VI})$ to $\mathrm{Pu}(\mathrm{III}) / \mathrm{Pu}(\mathrm{IV})$ and oxidants (e.g., $\mathrm{MnO}_{2}$ and radiolytic products) that can oxidize $\mathrm{Pu}(\mathrm{IV})$ to $\mathrm{Pu}(\mathrm{V}) / \mathrm{Pu}(\mathrm{VI})$, and (3) summarize fundamental data into a model and test the accuracy of this model in a limited set of conditions using plutonium contaminated sediments or sediments spiked with different oxidation states. 
Research Project Number: 31

\section{The Influence of Calcium Carbonate Grain Coatings on Contaminant Reactivity in Vadose Zone Sediments}

Conceptual Model Input: Vadose Zone

Principal Investigator: Dr. John M. Zachara, Pacific Northwest National Laboratory

Addresses Need: $\quad$ 14. Need to determine what from the standpoint of geochemistry is influencing transport and retardation.

Purpose: This project will explore the behavior of calcium carbonate grain coatings including how they form and dissolve (e.g., natural and waste fluid induced), their reactivity toward contaminants under water-saturated and unsaturated conditions, their impact on the reactivity of the mineral substrate, and their in-ground composition and minor element enrichment. The goal is to provide an improved understanding of contaminant sequestration/immobilization reactions that can be scaled to macroscopic reactive transport models used to forecast contaminant migration.

Project Description: Fundamental research is proposed to investigate the role of calcium carbonate grain coatings on the vadose zone chemical reactivity of key Hanford contaminants (i.e., Co-60, Sr-90, $\mathrm{CrO}_{4}$, Tc-99) Calcium carbonate is widely distributed through the Hanford vadose zone as a result of current and past geochemical processes, and exists as grain coatings and intergrain fill. It also results from the interaction of high level waste (e.g., high in $\mathrm{Na}$ and $\mathrm{OH}$ ) with $\mathrm{Ca}$-saturated subsurface sediments. While secondary iron-, aluminum-, and manganese-oxyhydroxide grain coatings are known to control the sorption chemistry of non-calcareous sediments for inorganic ions, no comparable understanding exists for carbonate grain coatings, which may be equally or more abundant in certain situations. We hypothesize that carbonate coatings enhance the sorption of carbonate compatible contaminants (e.g., Sr-90 and Tc-99) through a combination of adsorption and co-precipitation processes, but interfere with the reductive immobilization of the oxoanions $\mathrm{CrO}_{4}$ and $\mathrm{TcO}_{4}$ by passivating electron dense surfaces of $\mathrm{Fe} 2+-$ minerals such as magnetite and biotite in Hanford sediments.

The scientific focus will be on the influence of the coatings on: (1) surface coordination or coprecipitation reactions, and (2) electron transfer reactions that can result in the immobilization of redox-sensitive contaminants. Modern surface- and bulk-sensitive structural and imaging methods including X-ray absorption spectroscopy, scanning probe microscopy, photoelectron spectroscopies, and others will be applied in concert with judiciously designed model systems such as epitaxially grown surfaces of known crystallographic orientation and structure to provide a rigorous molecular and microscopic understanding of the controlling reactions of target contaminant ions with carbonate-coated mineral surfaces. Model system studies will be linked with parallel spectroscopic, microscopic, and macroscopic investigations of calcareous Hanford sediments, to provide basic scientific information for the remediation/closure of Hanford and other DOE sites. 
Research Project Number: 32

\title{
Spectroscopic and Microscopic Characterization of Contaminant Uptake and Retention by Carbonates in Soils and Vadose Zone Sediments
}

\author{
Conceptual Model Input: Vadose Zone
}

Addresses Need: $\quad 6$. Need to know the geochemical characteristics (e.g., oxidation states) of the near field environment for actinides.

14. Need to determine what from the standpoint of geochemistry is influencing transport and retardation.

Principal Investigator: Dr. Richard J. Reeder, State University of New York at Stony Brook

Purpose: The release and migration of toxic metals and radionuclides within the subsurface and vadose zones at various sites over the DOE Complex pose serious technological challenges for remediation. The design and implementation of cost-effective remediation strategies require knowledge of the factors that govern contaminant mobility and reactivity within their host materials. Calcium carbonate, resulting from pedogenic processes, is an important component of soils and vadose zone materials at the Hanford Site, where it coats grains and occurs as a massive caliche layer at depth. We propose a collaborative project to characterize the uptake and retention of contaminants $(\mathrm{Co}, \mathrm{Cs}, \mathrm{Pb}, \mathrm{Sr}, \mathrm{Cr}$, and $\mathrm{U})$ on calcium carbonate (calcite), with a focus on conditions and materials relevant to this site.

Project Description: The research plan calls for detailed microscopic and spectroscopic characterization of carbonate coatings and caliche from the Hanford Site, combined with an assessment of the heterogeneity of reactive surface sites that could influence contaminant uptake properties or long-term retention. This will rely on microscopic study as well as mineralogic and geochemical characterization. Spatially resolved X-ray fluorescence and X-ray absorption spectroscopy (micro-XRF/XAS) as well as X-ray photoelectron spectroscopy (XPS) will be used to map the distribution of contaminant reaction products after exposure to natural and model carbonate substrates.

These results will have direct application for assessing the reactive fraction of available surface area on carbonates from the affected site. Adsorption and desorption experiments for target contaminants on calcite will be conducted using radioisotope and high-precision gamma-counting methods to determine both the kinetics and extents of uptake from solutions over a $\mathrm{pH}$ range relevant to site conditions. Desorption will test the tendency for long-term retention of contaminants on calcite. Because existing studies suggest that adsorption onto calcite results in co-precipitation, which would have a major influence on potential re-release, it is essential to determine the chemical state of the adsorbed metals, i.e., its speciation.

Contaminant speciation will be determined in situ using X-ray absorption fine structure (XAFS) spectroscopy of "wet slurries" as a function of duration of adsorption and surface coverage. This elementspecific technique provides information on oxidation state, molecular formula and structure, and identity of ligands, and allows distinction between inner-sphere and outer-sphere type surface complexes as well as between co- precipitation and surface precipitation. Separate co-precipitation experiments with target contaminants will allow an assessment of the effectiveness of uptake during crystallization of calcite, which is favored in the soil and vadose zone as a result of periodic wetting and drying, and also in response to the highly alkaline waste fluids. XAFS spectroscopy will again be used to confirm speciation. 
The results of this comprehensive study will provide detailed information on contaminant speciation, physical and chemical properties of subsurface carbonate phases, and the reactions involving calcium carbonates that occur in the subsurface zone for a site relevant to DOE goals. These are essential components of models necessary for predicting contaminant mobility and for designing effective technologies for the recovery or immobilization of contaminants. 
Research Project Number: 33

\section{Technetium Attenuation in the Vadose Zone: Role of Mineral Interactions}

Conceptual Model Input: Vadose Zone

Addresses Need: $\quad 6$. Need to know the geochemical characteristics (e.g., oxidation states) of the near field environment for actinides.

14. Need to determine what from the standpoint of geochemistry is influencing transport and retardation.

Principal Investigator: Dr. Nancy J. Hess, Pacific Northwest National Laboratory

Purpose: The immobilization of Tc under oxic conditions requires surface-mediated reduction of Tc to low solubility Tc species that precipitate. Thermodynamic data for the Tc species and solubility limiting solids under these conditions are not available. Lack of fundamental data on these aspects seriously impairs the validity of risk assessment and the efficiency of remediation efforts. The proposed research will determine the mechanisms of surface-mediated reduction/precipitation reactions of Tc on Fe-containing mineral surfaces, the composition of these precipitates, and build a thermodynamic database for the solubility-limiting phases and aqueous species. These results can be directly utilized in contaminant transport modeling in the vadose zone and for the design of appropriate remedial strategies for Tc.

Project Description: Approximately $4.5 \times 10 \mathrm{~L}$ of liquid waste containing $930 \mathrm{Ci}$ of Tc-99 from uranium recovery processing were discharged directly to the ground at the Hanford Site from 1953 to 1958. As a result, the entire soil column beneath many of the disposal sites became saturated. Technetium is anticipated to be highly mobile and to readily migrate to groundwater. However, mass balance calculations indicate that more than $80 \%$ of the Tc-99 released to the subsurface environment at Hanford may not have entered the groundwater. It is hypothesized that Tc reduction through surface-mediated reactions with Fe II-containing minerals may have resulted in precipitation of low solubility Tc solids, effectively immobilizing Tc in the vadose zone and accounting for this discrepancy. Published sorption studies demonstrate that limited adsorption of Tc on Fe minerals occurs under oxic conditions. 
Research Project Number: 34

\section{Calcite Precipitation and Trace Metal Partitioning in Groundwater and the Vadose Zone: Remediation of Strontium-90 and Other Divalent Metals and Radionuclides in Arid Western Environments}

Conceptual Model Input: Vadose Zone and Aquifer

Addresses Need: $\quad$ 14. Need to determine what from the standpoint of geochemistry is influencing transport and retardation.

Principal Investigator: Dr. Frederick S. Colwell, Idaho National Engineering and Environmental Laboratory

Purpose: Radionuclide and metal contaminants are present in the vadose zone and groundwater throughout the U.S. Department of Energy (DOE) weapons complex. Demonstrating in situ immobilization of these contaminants in vadose zones or groundwater plumes is a cost-effective remediation strategy. However, the implementation of in situ remediation requires definition of the mechanism that controls sequestration of the contaminants. One such mechanism for metals and radionuclides is co-precipitation of these elements in authigenic calcite and calcite overgrowths. Calcite, can incorporate divalent metals such as strontium, cadmium, lead, and cobalt into its crystal structures for the formation of solid solutions. The rate at which trace metals are incorporated into calcite is a function of calcite precipitation kinetics, adsorption interactions between the calcite surface and the trace metal in solution, solid solution properties of the trace metal in calcite, and also the surfaces upon which the calcite is precipitating. The objectives of this research are to: (a) elucidate the mechanisms and rates of microbially-facilitated calcite precipitation and divalent cation adsorption/co-precipitation occurring in a natural aquifer and vadose zone perched water body as a result of the introduction of urea, and (b) assess the effects of spatial variability in aquifer host rock and the associated hydro/biogeochemical processes on calcite precipitation rates and mineral phases within an aquifer.

Project Description: These research objectives will be accomplished by conducting integrated laboratory and field research using sites which include a groundwater site at the Test Area North (TAN) and a perched water vadose zone site at Idaho Nuclear Technology and Engineering Center (INTEC), both located at the Idaho National Engineering and Environmental Laboratory (INEEL). The experimental focus will be on the in situ microbially-catalyzed hydrolysis of urea, which results in an increase in $\mathrm{pH}$, and precipitation of calcite. The parameters for the field experiments will be developed in laboratory microcosm systems with known urea-hydrolzing microorganisms in order to evaluate the relative importance of environmental factors on the precipitation of calcite and the sequestration of metals. Field studies will couple a nutrient diffuser technology containing urea and an electron donor with a high-resolution multi-level passive groundwater sampler to conduct in situ calcite precipitation experiments in the aquifer at TAN and later in the perched water vadose zone. Through in situ incubation, we expect to determine differences in the rates of calcite precipitation as a function of vertical heterogeneity in the basalt aquifer and the presence of urea in the diffusers. These experiments will involve the formation of calcite overgrowths onto mineral templates. The mass of the overgrowths as well as the trace metal concentrations and carbon and strontium isotopic composition will be determined using thermal ionization mass spectrometry (TIMS), secondary ion mass spectrometry (SIMS), and inductively coupled plasma-mass spectrometry (ICP-MS). By using different concentrations of urea in the diffusers and by incubating the device across strata that vary markedly in permeability, we anticipate results that will allow not only a determination of feasibility of the technology in such an aquifer but also an assessment of the hydrogeological conditions that are best suited for the manipulation of geochemical conditions to promote calcite precipitation. Using traditional culture-based based microbiology as well as 
molecular methods, we will also determine a microbiological community correlate of the calcite precipitation in the different geological strata as a means of verifying that urea-hydrolyzing microorganisms are responsible for the observed precipitation of calcite. 
Research Project Number: 35

\section{Chemical Speciation of Strontium, Americium, and Curium in High Level Waste: Predictive Modeling of Phase Partitioning During Tank Processing}

\section{Conceptual Model Input: Source Term}

Addresses Need: $\quad 6$. Need to know the geochemical characteristics (e.g., oxidation states) of the near field environment for actinides.

14. Need to determine what from the standpoint of geochemistry is influencing transport and retardation.

Principal Investigator: Dr. Andrew R. Felmy, Pacific Northwest National Laboratory

Purpose: To extend the work of an FY 1996 EMSP grant for examining the effects of organic chelate complexation of the speciation and solubility of $\mathrm{Sr}$ and trivalent actinides under strongly basic, high carbonate conditions, similar to those present in high-level waste tanks at U.S. Department of Energy storage sites.

Project Description: In the first three years of this research program a comprehensive experimental and modeling approach was implemented which focused on the displacement of Sr from organic chelators and the formation of important metal-chelate-hydroxide complexes for the trivalent actinides. This comprehensive approach involved coupled experimental solubility studies, spectroscopic measurements of solution speciation, molecular modeling studies which yielded information on species structure and energetics, and thermodynamic modeling efforts using the Pitzer thermodynamic model which is valid to high ionic strengths. Using this approach, research studies were completed on $\mathrm{Sr}$ and the trivalent actinide analog Eu(III) on four of the most important chelates in tank waste, as well as on the important inorganic ligands, hydroxide and carbonate. All of these research results were published in the open literature.

Although these studies have already proven useful in several waste tank applications, the complexity of many of the wastes, specifically with respect to ligand concentration and complexity of many of the wastes, shows that continued research is required in order to apply these results to a wide range of tank compositions. Based upon our results, we proposed: (1) extension to important chelates not previously studied, (2) studies of competing metal ions, and (3) specific studies using Am(III)/Cm(III). The chelate complex studies will directly extend our previous research on these chelates to citrate and oxalate. In addition, we propose to address the possible formation of mixed ligand-ligand complexes and chelate-carbonate solutions. The competing metal studies will address $\mathrm{Ni}, \mathrm{Al}, \mathrm{Mn}$, and Fe. These studies will extend our previous work on the competing metal $\mathrm{Ca}$. These fundamental data on chemical speciation and solubility will then be used to develop highly accurate thermodynamic models, which are valid to high ionic strength. Such thermodynamic models are widely used by scientists and engineers at Hanford and other DOE sites to help develop improved waste disposal technologies. 
Research Project Number: 36

\section{Understanding the Chemistry of the Actinides in High Level Waste Tank Systems: The Impact of Temperature on Hydrolysis and Complexation with Organics}

\section{Conceptual Model Input: Source Term}

Addresses Need: $\quad 6$. Need to know the geochemical characteristics (e.g., oxidation states) of the near field environment for actinides.

Principal Investigator: Dr. Sue B. Clark, Washington State University

Purpose: To provide a thermodynamic basis for describing actinide speciation over a range of tank-like conditions. These conditions include elevated temperature, elevated $\mathrm{OH}$ - concentrations, and in the presence of various organic ligands.

Project Description: The remediation of DOE's HLW tanks is an enormously challenging problem. The waste is highly radioactive resulting from the large quantities of plutonium, actinides, and fission products. The chemical matrices of the various HLW tanks are extremely harsh, with pHs in excess of 14, elevated temperatures due to radiolytic heating, and a wide array of organic ligands used in materials processing and their degradation products. To remove waste from the tanks, DOE must design strategies to characterize the material safely, separate the radioactivity (i.e., the fission products and actinides) from the large quantity of non-radioactive material, and immobilize the radioactive waste for geologic disposal.

The Tanks Focus Area (TFA) is currently using the Environmental Simulations Program (ESP) to simulate these chemical processes. The ESP relies on a thermodynamic database to make predictions on the chemical speciation of components in the waste, including the actinides. This requires that the chemistry of plutonium and the actinides in these systems be understood, and that relevant chemical equilibria be defined and stability constants and other thermodynamic parameters be quantified. Unfortunately, relatively little is known about the behavior of plutonium and the actinides in highly alkaline systems with elevated temperatures and where organics are present. A database that describes the chemical equilibria and the impact of temperature on them does not exist

In 1998, research was begun in this area under the EMSP program, and significant progress has been made. However, considerable work remains to accomplish the goal. The objectives of this research plan are to:

Provide an experimental basis for describing actinide speciation over ranges of $\mathrm{pH}$, temperature, and organic ligands relevant to HLW.

Use the information obtained from limited experimental work to develop a thermodynamic database predicting $\mathrm{Pu} /$ actinide speciation under wide ranges of conditions relevant to HLW. This will allow the extension of the ESP to simulate actinide chemistry in HLW and pretreatment processes.

The proposed work will be completed by a team of chemists and geochemists from Washington State University (WSU), University of Idaho (UI), Lawrence Berkeley National Lab (LBNL), and Pacific Northwest National Lab (PNNL). All of the collaborating partners have experience in actinide chemistry, solution chemistry, and thermodynamic modeling. The proposed research builds on the foundation of data generated in our current EMSP research program. The experimental work proposed will be completed by WSU, UI, and LBNL. We will work with Andy Felmy of PNNL to use the data we generate from our experimental work to create a thermodynamic database for the ESP and the TFA. 
Research Project Number: 37

\section{Coupled Flow and Reactivity in the Variably Saturated Porous Media}

Conceptual Model Input: Vadose Zone

Addresses Need: $\quad$ 6. Need to know the geochemical characteristics (e.g., oxidation states) of the near field environment for actinides.

14. Need to determine what from the standpoint of geochemistry is influencing transport and retardation.

Principal Investigator: Dr. Carl Palmer, Idaho National Engineering and Environmental Laboratory

Purpose: To develop new conceptual models for contaminant adsorption and transport in heterogeneous vadose zone media.

Project Description: Improved understanding of contaminant migration processes through the vadose zone is required for DOE to provide defensible computational models, better define long-term stewardship requirements for DOE sites, and help design effective barriers to vadose zone contaminant migrations. We propose research that results in improved conceptual models of contaminant migration in heterogeneous, variably saturated, porous media, particularly at low water contents where information is difficult to obtain using traditional methods. We hypothesize that the reactivity of variably saturated porous media depends on the moisture content of the medium and can be represented by a relatively simple function applicable over a range of scales, contaminants, and media. A key, novel aspect of the proposed research is using the new two-meter radius, geocentrifuge being installed at the Idaho National Engineering and Environmental Laboratory (INEEL). This geocentrifuge experimental approach has two distinct advantages over conventional methods. First, experimental data is collected over much shorter time periods, resulting in a more complete evaluation of various chemical conditions and materials. Second, the increased forces in the geocentrifuge allow experiments to be conducted over a wider range of moisture regimes as compared to conventional methods.

Although the results of the proposed research applies to all DOE sites, those with deep vadose zones in arid climates, such as the INEEL, Hanford, the Nevada Test Site, and Yucca Mountain, will benefit the most from the work. 
Research Project Number: 38

\section{Mechanisms of $\mathrm{CCl}_{4}$ Retention and Slow Release in Model Porous Solids and Sediments}

Conceptual Model Input: Vadose Zone

Addresses Need: 13 . Need studies of chemical state of the waste form in the Subsurface Disposal Area and other sites.

14. Need to determine what from the standpoint of geochemistry is influencing transport and retardation.

Principal Investigator: Dr. Robert G. Riley, Pacific Northwest National Laboratory

Purpose: To provide a better mechanistic description of the fundamental processes by which non-polar compounds are retained by sediments and subsequently released. We will focus our effort on the behavior of carbon tetrachloride $\left(\mathrm{CCl}_{4}\right)$ in sediments, as $\mathrm{CCl}_{4}$ is a contaminant of key concern at the Hanford Site and is not expected to degrade readily under the oxidizing conditions at the site. This objective will be reached through a combination of theory and experimentation with model systems and natural sediments.

Project Description: The transport and fate of non-polar hydrocarbons in soils and sediments depend in large part on the relative influence of sorptive and degradative processes. If the non-polar compound is not easily degraded, then, with time, diffusion into micropores, entrapment by internal cavities, and sorption to hydrophobic surfaces create a migration-resistant fraction (MRF). Although the diffusion/entrapment/sorption process has the positive attribute of retarding the transport of the non-polar compound, it also protects the compound from possible remediation by technologies based on rapid degradative processes. Eventually, the MRF serves as a slow-release source term once the original concentration gradient is reversed. Protection and slow release of contaminants by sediments frustrated many remediation attempts by significantly increasing the overall cost of cleanup and making it difficult to estimate natural attenuation rates.

Our unique approach encompasses three hypothesis-driven tasks. Task 1 will focus on sorption and release experiments with well-defined porous materials. An innovative system that circulates supercritical carbon dioxide will be used to artificially generate $\mathrm{CCl}_{4} \mathrm{MRF}$ in the porous media on a laboratory timescale. Assessment of the accumulation of the MRF and its slow-release behavior will be performed using a combination of analytical (gas chromatography, microbalance gravimetry) and spectroscopic (small-angle X-ray scattering, X-ray microscopy and tomography) measurements that will provide high-quality data about the spatial and temporal characteristics of the MRF. After the MRF behavior in the model porous media has been well defined, similar experiments will be conducted in Task 2 using natural sediment samples. Parallel release experiments will also be carried out using Hanford sediments that have been exposed to $\mathrm{CCl}_{4}$ for several years. Task 3 will use a combination of lattice-Boltzmann simulations and continuum-based models to develop a coherent, mechanistic description of the overall entrapment and release process. Models will initially be developed for the well-defined porous materials and will later be applied to the more complex systems investigated in Task 2 .

The success of the proposed work will provide the first mechanistic description of $\mathrm{CCl}_{4}$ retention and release by porous materials and sediments and will represent a significant improvement in understanding the factors controlling these processes. Incorporation of this information into numerical transport models will improve predictive accuracy and robustness. Moreover, the enhanced predictive capability arising from the proposed work is expected to have a large impact on current deliberations regarding active 
remediation versus monitored natural attenuation of the extensive $\mathrm{CCl}_{4}$ plume at the Hanford Site. Ready extension of this knowledge to other chlorinated hydrocarbon compounds contaminating Department of Energy sites as well as other organic contaminants would be expected. 
Research Project Number: 39

\section{Characterization of U(VI) Sorption-Desportion Processes and Model Upscaling}

\section{Conceptual Model Input: Source Term}

Addresses Need: $\quad$ 14. Need to determine what from the standpoint of geochemistry is influencing transport and retardation.

Principal Investigator: Dr. John M. Zachara, Pacific Northwest National Laboratory

Purpose: To characterize sorption and desorption processes of U(VI) on pristine and contaminated Hanford sediments over a range of sediment facies and materials properties.

Project Description: Uranium (VI) is a common subsurface contaminant on DOE lands because of its central role in the nuclear fuel cycle. U(VI) groundwater plumes exist at Hanford, Oak Ridge, Savannah River, and other DOE sites. At each of these locations, DOE, regulators, and stakeholders are attempting to identify the best corrective and remedial actions for these U(VI) plumes to protect human health and valuable environmental resources. Typically, the credibility of such assessments has been low because of inability to forecast in-ground U(VI) migration rates and redistribution. An insufficient scientific understanding of U(VI) geochemistry, and lack of knowledge of the various mineralogic, geochemical, and geophysical factors that control the rates and extent of $\mathrm{U}(\mathrm{VI})$ reactions in commonly heterogeneous subsurface environments are key impediments.

The sediments needed to characterize sorption and desorption processes of U(VI) will be obtained from vertical cores collected from outside and inside waste sites, and will include the important geologic formations and facies types in which U(VI) contaminant plumes exist. The physical and chemical properties of the sediments will be incrementally characterized with increasing sophistication until controlling properties are identified. Molecular speciation measurements of adsorbed and precipitated $\mathrm{U}(\mathrm{VI})$ will be made using X-ray absorption and laser induced fluorescence spectroscopy with the objective of developing speciation-based conceptual and numeric models of sorption/desorption. The implications of intragrain mass transfer and reaction will be investigated using U-spiked/contaminated materials varying in U-contact time up to 30 years or more.

Geochemical and mass transfer model parameters will be correlated with sediment physical, chemical, and mineralogic properties in an attempt to develop a site-wide model for U(VI) geochemical retardation. Simple, volume-based upscaling relationships will be established for both sorption and desorption processes. The developed models and upscaling relationships will be tested at a U(VI) vadose zone field injection experiment to be performed by others where sediment geochemical/geophysical properties and U-plume evolution can be sampled and studied at scales ranging from centimeters to tens of meters. The research will provide new insights on the mechanisms of U(VI) retardation at Hanford and approaches to upscale laboratory developed geochemical models for defensible field-scale predictions. 
Research Project Number: 40

\section{The Aqueous Thermodynamics and Complexation Reactions of Anionic Silica and Uranium Species to High Concentration}

Conceptual Model Input: Source Term and Vadose Zone

Addresses Need: $\quad$ 14. Need to determine what from the standpoint of geochemistry is influencing transport and retardation.

Principal Investigator: Dr. Andrew R. Felmy, Pacific Northwest National Laboratory

Purpose: To conduct a follow-on project to complete previous silica complexation studies and address thermodynamic data needs related to U(VI) complexation.

Project Description: High ionic strength, highly basic tank wastes containing several important radionuclides, including Sr-90, Tc-99, Co-60, as well as actinide elements (isotopes of U, Pu, and Am), are known to have leaked into the vadose zone at the Hanford Site. Determining the magnitude of these tank leaks, the extent of migration of the radionuclides, and their potential future mobility are some of the most daunting challenges facing Hanford and other DOE sites. Anionic silica species can represent a primary transport vector for radionuclides in the subsurface owing to the dissolution of silica and aluminosilicate minerals upon interactions with the basic Hanford tank wastes.

The following have already been done to address these issues:

- $\quad$ The first reliable high ionic strength thermodynamic model for polysilicate species (including monomers, dimers, trimers, etc.) at $25^{\circ} \mathrm{C}$ has been developed

- The effects of these silicate species on Sr solubility, complexation, and potential mobility have been evaluated

- $\quad$ New stability constants for $\mathrm{Sr}, \mathrm{Co}(\mathrm{II}), \mathrm{U}(\mathrm{VI})$, and Am(III) silica complexes have been developed

- A molecular model for determining the protonation state and structure of these complexes has been developed

- Initial data on Cm(III) polysilicate complexation and polysilicate anion interactions has been developed

- $\quad$ Previously unidentified enantiomeric forms of polysilicates species have been discovered.

In addition, computer code and a new thermodynamic database for modeling high ionic strength solutions to scientists working on the IP has been provided. This follow-on project proposes to complete the studies on silica complexation, expand efforts to address other key thermodynamic data needs related to U(VI) complexation at the Hanford Site, and continue collaboration with members of the Hanford Groundwater/Vadose Zone Integration Project (IP) program. 
Research Project Number: 41

\section{Characterization of Contaminant Transport Using Naturally-Occurring U-Series Disequilibria}

Conceptual Model Input: Vadose Zone and Aquifer

Addresses Need: $\quad 7$. Need measurement technique to monitor ambient water travel time through the VZ to the SRPA at selected facilities.

14. Need to determine what from the standpoint of geochemistry is influencing transport and retardation.

Principal Investigator: Dr. Michael T. Murrell, Los Alamos National Laboratory

Purpose: To form the database for a model code for computing: (1) fluid residence time (transport rates) in the basalt aquifers at various locations, (2) in situ adsorption and desorption rate constants as well as the retardation factors of various radionuclide wastes, and (3) rock dissolution rate and its relation to preferential flow and contaminant transport in the fractured rocks.

Project Description: The interactions of mixed wastes containing radionuclides with solid rock surface and the mobility of the radionuclides in aquifer systems depend not only on the chemistry of the nuclides and the physico-chemical effects of radioactive decay, but also on the site-specific hydrogeology. Thus, to characterize contaminant transport, it is best to crosscheck figures derived from any small-scale laboratory experiments over limited times with that obtained from field-oriented, natural analog studies. We propose such a study using the naturally-occurring $U$ and Th decay-series disequilibria. Research has shown that the parent/daughter disequilibrium patterns existing in groundwater systems can be modeled in terms of local nuclide mass balance to arrive at such information as the rock-water contact time (fluid flow) and rates of contaminant transport (taking into account the retardation effect due to nuclide/rock interaction contaminants at INEEL by grouping them into three categories, represented by isotopes of: (1) Th and $\mathrm{Pa},(2) \mathrm{U}$, and (3) Ra. Mass spectrometric measurements of these elements will be emphasized in order to minimize sample size requirements and to maximize precision. 
Research Project Number: 42

\section{Characterization of Contaminant Transport by Gravity, Capillarity and Barometric Pumping in Heterogeneous Vadose Regimes}

Conceptual Model Input: Vadose Zone

Addresses Need: $\quad 3$. Need to improve the use of 3D tomography and other cross-hole geophysics for selected facilities to show changes in moisture.

7. Need measurement technique to monitor ambient water travel time through the VZ to the SRPA at selected facilities.

8. Need to develop better methods for correction factors of measurement of water levels in a flat gradient environment.

15. Need to develop better tracer tests to track flow through the interbeds in selected areas.

Principal Investigator: Dr. Charles R. Carrigan, Lawrence Livermore National Laboratory

Purpose: To investigate the detailed nature of each stage of the transport of fractured and heterogeneous regimes in the vadose zones.

Project Description: Many releases of chemical solvents or DNAPLS occur at the surface causing the vadose layer to be the first part of a hydrologic system to interact with the contaminant. As the entry point of these chemicals into a groundwater system, the vadose zone can become a long-term source function for contamination that is metered by natural processes into the underlying saturated zone for further dispersal. However, a contaminant plume does not remain unaffected by the surrounding unsaturated soil. Heterogeneous vadose regimes, such as those containing fractures or other permeability heterogeneities, are the sites of complex interactions between the atmosphere and groundwater. When a volatile contaminant exists as free product or in dissolved form in the vadose environment, upward transport can occur with the contaminant ultimately being vented as a vapor into the atmosphere. It is known that partitioning of a liquid contaminant into the vapor phase can be a very effective means of decontamination. The subsequent transport of the vapor occurs naturally and can be enhanced, for example, by the anisotropy resulting from fractured-matrix-flow paths as well as by certain heterogeneity distributions. Several stages in the transport process are involved in going from a volatile, liquid state contaminant to a contaminant vapor vented at the surface.

In a three-year effort, we will investigate the detailed nature of each of these stages of transport in the vadose zones of fractured and heterogeneous regimes with: (1) the aid of existing data, (2) new field studies involving dissolved tracer gases, and (3) 3-D diagnostic computer simulations that provide a framework to interpret our observations. We will emphasize determining the impact of features specific to a site (i.e., the local geology and hydrology), on each stage of the transport process. In particular we want to better understand how the time scales for partitioning contaminants from the liquid to the vapor states and then transporting the vapor out of the vadose regime are dependent on the specific character of a site. Such timescale information will be important for determining the appropriate response to vadose zone contamination including the option of natural remediation (i.e., no response). This information can also be interpreted as a baseline performance criterion for proposed soil-venting schemes. Not least, this work will result in the development of new field methods, involving the injection and analysis of dissolved rare-isotope and chemical-compound tracers, that we anticipate applying to sites at Lawrence Livermore and to the thick, fractured basalt vadose regime at the Idaho National Engineering and Environmental Laboratory. 
Research Project Number: 43

\section{Aquifer Transport of Th, U, Ra, and Rn in Solution and on Colloids}

Conceptual Model Input: Aquifer

Addresses Need: $\quad 6$. Need to know the geochemical characteristics (e.g., oxidation states) of the near field environment for actinides.

14. Need to determine what from the standpoint of geochemistry is influencing transport and retardation.

Principal Investigator: Dr. G. J. Wasserburg, California Institute of Technology

Purpose: The purpose of this study is to investigate the behavior of naturally occurring $\mathrm{U}, \mathrm{Th}, \mathrm{Ra}$, and $\mathrm{Rn}$ isotopes in groundwater and to utilize these elements as natural analogues for waste radionuclides in predicting migration behavior in potentially impacted aquifers.

Project Description: This study will obtain information on the natural radionuclides provided to groundwater throughout an aquifer system that will be used to quantitatively constrain the transport in groundwater and removal to host formations of radionuclides that potentially may reach the recharge zones of these aquifers. Previous studies were largely based on analyses by counting techniques, which can provide precise data for only short-lived nuclides. Discussions regarding long-lived nuclides were based upon more limited data, especially for Th. Utilizing techniques developed in our laboratory for the measurement of long-lived Th and $\mathrm{U}$ isotopes by mass spectrometry, it is now possible to measure these low concentrations of Th in groundwaters.

Various recent investigations have focused on the role of colloids in the migration of radionuclides. Ultrafiltration techniques have been developed that can be used for the separation of colloids, and the conditions under which radionuclides are significantly associated with organic and inorganic colloids can be examined. While the data regarding the association of long-lived nuclides with colloids is limited, we have found that ultrafiltration techniques can be used to process large volumes of water, allowing measurement of short-lived and long-lived nuclides in ultrafiltered waters and colloid separates.

The goal of the proposed work is to investigate the fundamental controls on natural radionuclide migration in specific aquifers by integrating aquifer sample analyses, focused laboratory experiments, and field observations of two aquifer study sites. This will include analyses of particles and colloids as well as 'dissolved' species. The work will use standard decay counting methods for determining concentrations of the short-lived nuclides and high precision mass spectrometry to measure the long-lived nuclides. The project will focus on obtaining the following:

1. Measurements of radionuclide concentrations in groundwaters and changes in concentrations along groundwater flow lines as water chemistry evolves.

2. Measurements of the proportion of radionuclides transported by colloids and particles.

3. Laboratory measurements of the rate of recoil supply of radionuclides to groundwater.

4. Measurement of the distribution of parent elements within the aquifer rock to determine the controls on radionuclide recoil and dissolution inputs to groundwater. 
5. Calculation of radionuclide removal and retardation rates based upon input rates and groundwater evolutionary history.

6. Laboratory measurements of the rates of removal by adsorption of the radionuclides onto aquifer host rocks, and comparison of this data with calculated aquifer removal rates.

7. Model calculations and predictions of the transport behavior and rates of migration of waste radionuclides that potentially may reach the recharge zones of sandy and limestone aquifers. 
Research Project Number: 44

\section{Collaborative Research: Hydrogeological-Geophysical Methods for Subsurface Site Characterization}

Conceptual Model Input: Vadose Zone and Aquifer

Addresses Need: $\quad 2$. Need methods for delineation of flow direction in the aquifer at a facility scale.

3. Need to improve the use of 3D tomography and other cross-hole geophysics for selected facilities to show changes in moisture.

4. Need to better define the porosity and permeability in selected areas.

7. Need measurement technique to monitor ambient water travel time through the VZ to the SRPA at selected facilities.

Principal Investigator: Dr. Gary M. Mavko, Stanford University

Purpose: To develop the scientific basis and demonstrate methodologies for inexpensive high resolution imaging of natural heterogeneities and for relating these heterogeneities to the hydrogeologic parameters that control flow and contaminant transport

Project Description: This project focuses on three issues that are critical to Environmental Management of contaminated sites: reducing cost, reducing risk, and increasing the effectiveness of subsurface remediation schemes. The significance of this research is that it addresses the issue of site characterization, which is not only a very significant budget item in the site clean-up effort, but is also the key to the success of any clean-up effort. In effect, our objective is to develop methods for "imaging" hydrogeologic parameters. Our focus is to help establish the scientific basis for applying shallow geophysics to hydrogeological problems, through: (a) feasibility studies, (b) sediment-rock physics, (c) improvements in the procedures for co-interpretation of geophysical and hydrogeological data, and, ultimately, and (d) demonstration of a practical implementation of joint seismic and electromagnetic data for hydrogeologic characterization of DOE contaminated sites.

An essential task will be to identify limitations, pitfalls, and uncertainties of these co-interpretations (i.e., to quantify the risks in applying shallow geophysics to hydrogeological site characterization). The research combines theoretical modeling, field data processing, analysis of laboratory measurements, and integration techniques. Our approach is to use seismic and electromagnetic methods jointly to map the distribution of seismic velocity and attenuation, and electrical conductivity in the 3-D volume defined by a set of boreholes. In a rough sense both velocity and conductivity depend on porosity and, to a lesser extent, on permeability, clay content, saturation, and the nature of pore fluid. Laboratory studies have shown these relationships in great detail and we now are refining these results and utilizing them to interpret survey data in terms of maps of the distribution of the hydrogeologic properties. This is an interdisciplinary study, since it integrates the fields of hydrogeology and geostatistics, geophysics, and rock physics. The team of researchers brings to this project a large collective experience in performing theoretical, field, and lab work. This work is an extension of research being carried out in the Subsurface Science Program with the DOE Office of Health and Environmental Research, and it complements the research on High Resolution Geophysical Imaging for Subsurface Process Definition by E.L. Majer from Lawrence Berkeley National Laboratory. 
Research Project Number: 45

\section{The Use of Dielectric and NMR Measurements to Determine the Pore-Scale Location of Organic Contaminants}

\section{Conceptual Model Input: Source Term}

Addresses Need: $\quad 4$. Need to better define the porosity and permeability in selected areas.

6. Need to know the geochemical characteristics (e.g., oxidation states) of the near field environment for actinides.

Principal Investigator: Dr. Rosemary J. Knight, Stanford University

Purpose: To determine if dielectric and NMR measurements can be used to discriminate between a water-wet system in which water coats the solid surface, and a system in which an organic contaminant is absorbed to the solid.

Project Description: A critical step in achieving the cost-effective treatment of a contaminated region of the subsurface is the initial design stage. The design of an effective treatment scheme for a contaminated site requires knowledge of the in situ physical and chemical state of the contaminant. A first-order problem in characterizing the in situ state of non-aqueous phase contaminants is determining the pore-scale distribution and mobility of the contaminant. Of specific interest in this research is determining the wettability of the system, i.e., is the contaminant present as an immiscible non-wetting phase located in the central volume of the pore space, or does the contaminant exist as a wetting phase that is adsorbed to, or coating, the solid surface. We plan to investigate, through an extensive laboratory study, the concept that measurements of the dielectric constant and nuclear magnetic resonance (NMR) can be used to determine wettability and thus discriminate between these two cases.

Wettability is a critical factor in determining the pore-scale location of the immiscible fluids and the movement of the fluid phases. While studies of wettability have long been an important part of understanding and modeling multi-phase flow in hydrocarbon reservoirs, there has been relatively little attention paid to the role of wettability in contaminant transport and remediation, even when the contaminant is an oil. In fact, it is generally assumed in an oil-water-air system that water is the wetting phase. As reviewed in a recent paper, this is not true for many natural systems, and the assumption of a water-wet state can lead to grossly inaccurate predictions of capillary pressure-saturation relationships and the mobility of the contaminant. Determining wettability is thus a critical factor in site characterization. Our past research has clearly shown a link between the dielectric and NMR response of geological materials and the wettability of the material. This has introduced the intriguing possibility that the combined use of dielectric and NMR measurements can be used as a means of characterizing the wettability of a geological system.

For field applications, ground-penetrating radar (GPR) is a high frequency electromagnetic technique that can be used to measure the dielectric properties of the subsurface in the frequency range of $10 \mathrm{MHz}$ to $1 \mathrm{GHz}$. The current development of a geophysical technique referred to as very early time electromagnetics (VETEM) will provide a means of obtaining measurements of dielectric properties at lower frequencies, in the range of $10 \mathrm{kHz}$ to $150 \mathrm{MHz}$. Measurement of the in situ NMR response of materials in the subsurface can be made with NMR borehole systems, and by using a surface measurement system, recently developed and now commercially available. The interest in this research is the potential use of both GPR and/or VETEM, and NMR as a means of characterizing the in situ physical and chemical state of an organic contaminant in the subsurface. 
The objectives of the research do not involve any analysis of the field methods. The use of the field techniques provides information about the dielectric constant and the NMR relaxation time of the subsurface. Our focus is exclusively a laboratory study aimed at developing a fundamental understanding of the link these two parameters and the pore-scale location of a contaminant. 
Research Project Number: 46

\section{Seismic Surface-Wave Tomography of Waste Sites}

\section{Conceptual Model Input: Source Term}

Addresses Need: $\quad 3$. Need to improve the use of 3D tomography and other cross-hole geophysics for selected facilities to show changes in moisture.

Principal Investigator: Dr. Timothy L. Long, Georgia Institute of Technology

Purpose: To extend spectral analysis techniques to a tomographic inversion for group velocity, and develop computer programs that will allow analysis at near real time in the field. More importantly, we propose research on techniques that will include lateral variation in structures.

Project Description: Studies of the earth using surface waves are extensive. The early targets were crustal thickness and upper mantle structure because surface waves are well recorded on the early long period instrumentation and because the velocity contrast between the crust and mantle exhibits pronounced dispersion. When simple (as in flat layered) earth models are employed, the vertical variations in velocity associated with differing crustal structures can be obtained by using analytical techniques for computing dispersion relations. However, the more interesting variations in surface structure, those related to major geologic structures, represent lateral variations in material properties. Simple analytical solutions to the elastic wave equation do not exist for media with lateral heterogeneities and/or irregular geometries. Thus, for complex structures, interpretations have had to wait for practical numerical solutions and more advanced computational facilities. For these reasons, perhaps, the application of surface waves to shallow engineering problems has been slow.

Surface wave dispersion methods have been attempted in seismic reflection to constrain the corrections for time delays introduced by variations in near surface velocity structure. The difficulties and mixed results in defining these static corrections include variations in the ratio of $\mathrm{P}$ to $\mathrm{S}$ wave velocities, expressed as Poisson's ratio, and the significant differences in computational methods applied to surface wave dispersion and reflection data. In soils engineering, the spectral analysis of surface waves (SASW) has been developed for determining the pavement strength of road beds and liquefaction potential of soils. The SASW technique is based on surface measurements of phase velocity above a structure which is assumed to consist of flat layers.

The near surface can have a highly heterogeneous velocity structure. The velocity contrast between the soil layers and the unweathered rock can approach two orders of magnitude, when, in comparison, conventional reflection and refraction studies consider a $10 \%$ contrast very significant. Surface wave dispersion is sensitive to the depth and lateral variation in velocity contrasts of this high magnitude and thus are appropriate for examining the near surface. Typically, they are most sensitive to the shallowest layers and can complement refraction and reflection data which are more appropriate for deeper structures. In general, zones of soil and rock disturbances, which have widths similar to or greater than their depths, are ideal for detection by surface wave dispersion. These include trenches filled with debris, walled bunkers, and accumulations of liquid waste in depressed zones. 
Research Project Number: 47

\section{3-D Spectral IP Imaging: Non-Invasive Characterization of Contaminant Plumes}

Conceptual Model Input: Vadose Zone

Addresses Need: 3. Need to improve the use of 3D tomography and other cross-hole geophysics for selected facilities to show changes in moisture.

10. Need to perform vertical profiling of contaminant plume geometry to determine layering effects (Such as $\mathrm{Cr}^{6}$ at the Test Reactor Area).

Principal Investigator: Dr. F. Dale Morgan, Massachusetts Institute of Technology

Purpose: To develop a noninvasive tomographic imaging technique, based on the spectral inducedpolarization method, to characterize the in situ distribution of organic and inorganic groundwater contaminants.

Project Description: Recent advances in tomographic imaging, applied to dc resistivity data have made it possible and practical to obtain high-resolution 3-D images of sub-surface resistivity structures. However, imaging of contaminant plumes with the dc resistivity method is only feasible in cases where the level of contamination is relatively high. Alternatively, the spectral IP response of rocks and soils, which arises from the polarization of an electrochemical surface phase at grain-solution boundaries, is very sensitive to even small amounts of contaminants.

We plan to further develop our de resistivity tomographic imaging algorithms to obtain a 3-D inversion code for spectral IP data. The resulting 3-D map of the spectral IP response can be used to characterize the subsurface chemical conditions. Laboratory studies will be conducted with the goal of obtaining a quantitative interpretation of the derived IP spectra in terms of the contaminant type and concentration. Lastly, field studies will be conducted at well-characterized field sites to test the overall performance of this integrated imaging method and to test new developments in field instrumentation. If this remote sensing method proves successful it will greatly enhance our ability to detect, identify, and map the distribution of contaminants in the subsurface. This technology will provide tremendous cost savings in terms of the number of boreholes that are necessary to characterize a contaminated site, and it will be extremely useful in the characterization and monitoring of in situ chemistry for remediation efforts. 
Research Project Number: 48

\section{A Hybrid Hydrologic-Geophysical Inverse Technique for the Assessment and Monitoring of Leachates in the Vadose Zone}

Conceptual Model Input: Vadose Zone

Addresses Need: $\quad 3$. Need to improve the use of 3D tomography and other cross-hole geophysics for selected facilities to show changes in moisture.

Principal Investigator: Dr. James R. Brainard, Sandia National Laboratories - Albuquerque

Purpose: To develop and field test a new integrated Hybrid Hydrologic-Geophysical Inverse Technique (HHGIT) for characterization of the vadose zone at contaminated sites.

Project Description: This fundamentally new approach to site characterization and monitoring will provide detailed knowledge about hydrological properties, geological heterogeneity, and the extent and movement of contamination. HHGIT combines electrical resistivity tomography (ERT) to geophysically sense a three-dimensional volume, statistical information about fabric of geological formations, and sparse data on moisture and contaminant distributions. Combining these three types of information into a single inversion process will provide much better estimates of spatially varied hydraulic properties and three-dimensional contaminant distributions than could be obtained from interpreting the data types individually. Furthermore, HHGIT will be a geostatistically-based estimation technique; the estimates represent conditional mean hydraulic property fields and contaminant distributions.

This method will also quantify the uncertainty of the estimates as well as the estimates themselves. The knowledge of this uncertainty is necessary to determine the likelihood of success of remediation efforts and the risk posed by hazardous materials. Controlled field experiments will be conducted to provide critical data sets for evaluation of these methodologies, for better understanding of mechanisms controlling contaminant movement in the vadose zone, and for evaluation of the HHGIT method as a long-term monitoring strategy. 


\section{Joint Inversion of Geophysical Data for Site Characterization and Restoration Monitoring}

Conceptual Model Input: Vadose Zone and Aquifer

Addresses Need: $\quad 3$. Need to improve the use of 3D tomography and other cross-hole geophysics for selected facilities to show changes in moisture

4. Need to better define the porosity and permeability in selected areas.

Principal Investigator: Dr. Patricia A. Berge, Lawrence Livermore National Laboratory

Purpose: To develop a code for joint inversion of seismic and electrical data to improve underground imaging for site characterization and remediation monitoring.

Project Description: Geophysical data will be inverted to obtain direct estimates of porosity and saturation, rather than for seismic velocity and electrical resistivity. In the first year, laboratory measurements of elastic and electrical properties of sand-clay mixtures containing contaminants will be performed. Also, algorithms relating geophysical properties to porosity and saturation, using rock physics theories, geostatistical and empirical techniques, and available laboratory measurements will be developed. In the second year, the inversion code will be tested on available borehole log data to predict properties of cores. In the third year, a field experiment will be carried out and the seismic and electrical data will be inverted using the code. Work will be carried out by Principal Investigator (PI) P. A. Berge and co-PIs J. G. Berryman, J. J. Roberts, and M. J. Wilt. 
Research Project Number: 50

\section{Advanced High Resolution Seismic Imaging, Material Properties Estimation and Full Wavefield Inversion for the Shallow Subsurface}

Conceptual Model Input: Vadose Zone and Aquifer

Addresses Need: $\quad 3$. Need to improve the use of 3D tomography and other cross-hole geophysics for selected facilities to show changes in moisture.

Principal Investigator: Dr. Alan R. Levander, Rice University

Purpose: To develop and test an integrated suite of imaging and inverse techniques appropriate to the range of wave propagation regimes customarily recorded in shallow seismic surveys.

Project Description: These imaging and inverse techniques will address the extreme physical conditions found in the shallow environment, and thereby significantly advance the ability of shallow seismic investigations to produce high fidelity structural and material property maps of the subsurface. High resolution subsurface material properties maps are essential for characterizing the geometry of aquifers, aquicludes, and other fluid pathways, and therefore are essential for environmental remediation efforts.

We will apply these methods to a number of high-resolution profiles we have acquired and are proposing to acquire at sites with different near surface properties, including two active environmental remediation sites. The methods to be developed represent basic research in seismic imaging, and include advanced wavefield imaging using pre-critical to post-critical energy, velocity estimation and reflector focusing, and wavefield inversion techniques appropriate for imaging and estimating the material properties of the highly heterogeneous near surface environment. The research will build on the PI's previous research developing seismic imaging and inversion methods tailored for petroleum exploration and crustal investigations. At all stages of the data processing we propose to exploit the entire wavefields commonly recorded (and often overlapping in time, space, frequency, and phase velocity) but customarily processed and interpreted independently in high resolution surveys. 
Research Project Number: 51

\section{Enhancements to and Characterization of the Very Early Time Electromagnetic (VETEM) Prototype Instrument and Applications to Shallow Subsurface Imaging at Sites in the DOE Complex}

Conceptual Model Input: Vadose Zone

Addresses Need: 3. Need to improve the use of 3D tomography and other cross-hole geophysics for selected facilities to show changes in moisture.

12. Need studies of physical waste form of contaminants in the Subsurface Disposal Area and other sites.

Principal Investigator: Dr. David L. Wright, U.S. Geological Survey - Denver

Purpose: The U.S. Geological Survey and the University of Illinois propose to improve the state-of-the-art of electromagnetic imaging of the shallow (0 to $5 \mathrm{~m})$ subsurface in conductive media with potential applications to subsurface characterization, landfill stabilization, decontamination/ decommissioning, and waste characterization at sites in the DOE complex.

Project Description: The research objectives will be accomplished by a combination of hardware and software enhancements to the existing Very Early Time Electromagnetic (VETEM) prototype instrument, physical modeling experiments, numerical forward and inverse modeling, and field demonstrations. The existing system will be enhanced with additional antennas, additional transmitter options, probably one or more gradiometer configurations, and a modified receiver. The instrument enhancements will be guided by numerical forward, inverse, and antenna modeling. Fast forward and inverse modeling codes appropriate to the VETEM instrument will be developed in 1-D and, if possible, 2-D that will run on a PC for in-the-field interpretation, as well as more detailed post-processing models. 
Research Project Number: 52

\section{Seismic-Reflection and Ground-Penetrating Radar for Environmental Site Characterization}

Conceptual Model Input: Vadose Zone

Addresses Need: 1 . Need to determine preferred flow zones in the aquifer for characterization at the regional and subregional scale.

2. Need methods for delineation of flow direction in the aquifer at a facility scale.

3. Need to improve the use of 3D tomography and other cross-hole geophysics for selected facilities to show changes in moisture.

Principal Investigator: Dr. Don W. Steeples, University of Kansas

Purpose: The goals of the research are: (1) to examine the complementary site-characterization capabilities of modern, three-component, shallow-seismic reflection and ground-penetrating radar (GPR) methods at depths ranging between 2 and $8 \mathrm{~m}$, (2) to demonstrate the usefulness of the combined methods to characterize the three-dimensional shape of the cone of depression around a pumping well and monitor for anisotropic flow, and (3) to allow the site to function as an outdoor mesoscale laboratory to validate existing three-dimensional ground-penetrating radar and seismic-reflection computer models developed at the University of Kansas.

Project Description: This research seeks to show how shallow, high-resolution, three-component seismic-reflection techniques, in concert with GPR, might assist in characterizing hydrologic-transport parameters at environmentally sensitive sites. The high dynamic range and many channels typical of modern seismographs, along with advances in ground-penetrating radar technology, offer more opportunities than ever before to extract useful information from the subsurface. Both techniques are noninvasive and can be used in situ. Combined, they offer the prospect of improved near-surface imaging with minimal environmental impact. Furthermore, shallow, three-component seismology and GPR have not been used together to examine the same volume of shallow earth in this manner before.

Landfills, industrial plants, mine-waste dumps, and chemical spills are widespread in the United States, and have the potential to introduce significant levels of leachates into local and regional aquifers. Establishing the spatial extent of the contamination as well as identifying the transport-flow directions and fates of the contaminants is essential to developing safe, effective, and cost-sensitive remediation strategies. Yet tracing preferential permeability paths in sufficient detail to allow quantitative analysis is among the most challenging problems currently facing hydrologists. Some of the factors limiting the accuracy of hydrologic predictions are lateral heterogeneity, unexpected stratigraphic layering, fracturing, and flow anisotropy. Commonly, our knowledge of these controlling hydrologic factors is derived from conceptual knowledge of regional geology coupled with information derived from drilling. However, invasive processes such as drilling are time consuming, costly, and can exacerbate existing problems. A combined seismic/GPR imaging approach has the potential to offer a low-impact, cost-effective alternative at some sites.

To accomplish these goals, a 120-channel, 24-bit seismograph will be used to collect the seismic data, and a Pulse EKKO 1000 ground-penetrating radar equipped with a high-speed data-acquisition subsystem will be used to obtain the radar data. The test site to be used has produced P-wave seismic-reflection data of exceptional quality previously, obtained at depths as shallow as $2.6 \mathrm{~m}$. Ground-penetrating radar data 
collected recently at this location are of high quality as well. The test site has attributes that are particularly useful for this research, and, although itself uncontaminated, the location is well-suited to serve as a proxy site for existing contaminated areas. 
Research Project Number: 53

\section{High Frequency Electromagnetic Impedance Measurements for Characterization, Monitoring and Verification Efforts}

Conceptual Model Input: Vadose Zone

Addresses Need: $\quad$ 12. Need studies of physical waste form of contaminants in the Subsurface Disposal Area and other sites.

Principal Investigator: Dr. Ki-Ha Lee, Lawrence Berkeley National Laboratory

Purpose: To develop high-frequency impedance (HFI) methodology utilizing a window in the electromagnetic (EM) spectrum from $1.0 \mathrm{MHz}$ to $100 \mathrm{MHz}$.

Project Description: The window between ground penetrating radar (GPR) and low-frequency induction techniques has not been used to non-invasively investigate the upper few meters of the ground for environmental applications. Modeling and physical parameter studies confirm that impedance measurements at this frequency band can yield high-resolution mapping of the electrical conductivity as well as the permissivity. It is well known that impedance method is free of source coupling, so that the ensuing analysis tends to be much simpler.

The research plan consists of three tasks: (1) development of high frequency field measurement techniques, (2) plane wave impedance estimation, and (3) data processing, analysis, and interpretation. These tasks will be investigated in a three-phase approach, roughly corresponding to three years. The proof-concept will be determined with off-the-shelf test instrumentation and commercially available components, and the theoretical methods for impedance estimation, survey design, and sensitivity analysis will be fully developed, during Phase 1 . The proof-of-concept will provide the specifications necessary for assembling a prototype system, using off-the-shelf components and a modest engineering effort, in Phase 2. Phase 3 will include the development of a data analysis package and field testing of the prototype system in order to verify the concept and proper operational procedures in known, well-characterized environments. 
Research Project Number: 54

\section{Complex Electrical Resistivity for Monitoring DNAPL Contamination}

Conceptual Model Input: Vadose Zone and Aquifer

Addresses Need: $\quad$ 12. Need studies of physical waste form of contaminants in the Subsurface Disposal Area and other sites.

Principal Investigator: Dr. Stephen R. Brown, New England Research, Inc.

Purpose: To develop new practical complex resistivity field measurement techniques for pollution characterization and monitoring. For this purpose we will document the detectability of clay-organic interactions with geophysical measurements in the laboratory, develop further understanding of the underlying physical and chemical mechanisms, and then apply these observations to develop field techniques to monitor the remediation of organic pollutants.

Project Description: This proposed work is driven by the following simple hypothesis: as organic compounds are removed (e.g., biodegraded or extracted through engineered remediation) the complex resistivity will change according to the new chemical make-up of the soil/groundwater system. Thus complex resistivity measurements can be used as an effective monitoring tool to indicate the progress of remediation activities.

A field implementation of the complex resistivity technique targeted at pollutant characterization would provide a quick and inexpensive means of monitoring the progress of the breakdown of the pollutants in-situ without intervention and without disturbing the process. This technique would be implemented, for example, through the emplacement of standard 2-D arrays of contacting electrodes combined with complex resistivity measurement equipment, techniques, and data analysis methods. These data would be used to create spatial images of the pollution location and concentration in the subsurface. Successive images through time would be subtracted to monitor the remediation efforts.

To accomplish these goals, the following will be done: (1) perform laboratory studies to identify complex resistivity signatures of the most important components of dense hazardous phase liquids (DNAPLs);

(2) evaluate the signal and noise levels in the field; (3) identify distinguishing characteristics of complex resistivity contaminant signatures and develop algorithms to identify them; (4) perform parameter studies of complex resistivity signature changes among natural rocks, soils, fluid chemistry, and saturation levels; (5) evaluate the ability of standard electrical geophysics field equipment to measure these effects, and if standard equipment is unsuitable, develop prototype frequency-sweeping portable equipment with modern phase lock-in electronics to give field measurements the noise immunity required to reliably discern the low-level signals; (6) develop a broad-band pulse method for rapid data acquisition and scooping measurements; and (7) develop measurement techniques and software for complex resistivity imaging from arrays of surface electrodes. 
Research Project Number: 55

\section{Material Property Estimation for Direct Detection of DNAPL Using Integrated Ground- Penetrating Radar Velocity, Imaging, and Attribute Analysis}

Conceptual Model Input: Vadose Zone

Addresses Need: $\quad$ 12. Need studies of physical waste form of contaminants in the Subsurface Disposal Area and other sites.

Principal Investigator: Dr. John Bradford, Boise State University

Purpose: To test and develop a suite of methodologies for direct detection of pooled and residual DNAPLs from surface ground-penetrating radar (GPR) data.

Project Description: This is a new, quantitative approach to the analysis of GPR data in which we determine material properties remotely by quantifying signal characteristics such as propagation velocity and waveform attributes including amplitude, frequency content, and phase. With careful consideration of the physics governing electromagnetic (EM) wave propagation, these properties can be extracted from GPR data to characterize variations in electric properties. Many DNAPLs, including chlorinated solvents, have much lower dielectric permittivity and conductivity than water. A contrast in electric properties is induced when DNAPL displaces water in the sediment column resulting in an anomalous GPR attribute signature. The attribute signature can be exploited for remote DNAPL detection. In our approach, we focus on three aspects of reflected wave behavior - propagation velocity, frequency dependent attenuation, and amplitude variation with offset. Velocity analysis provides a direct estimate of dielectric permittivity, attenuation analysis is used to identify variation in conductivity, and AVO behavior is used to quantify the dielectric permittivity ratio at a reflecting boundary.

Attribute analysis is integrated with sophisticated signal processing methodologies, not commonly applied in GPR investigation, which dramatically improve image resolution and spatial accuracy. We have completed much of the preliminary work to include theoretical development, numerical and physical modeling studies, and initial development of attenuation and AVO attribute extraction algorithms. The next step in development of these methods is rigorous field testing under a variety of hydrogeologic conditions. To this end, the focus of our proposed work is field investigation. We have identified a number of sites suitable for controlled GPR investigation including the Hanford Site, and four facilities designated as National Environmental Technology Test Sites (Dover AFB, DE; McClelland AFB, CA; Port Hueneme, CA; Wurtsmith AFB, CA). We propose to conduct a series of controlled and uncontrolled GPR experiments over known NAPL source areas at these sites. An integral part of data analysis will be continued development of attribute extraction algorithms. These algorithms will include methods for automated attribute extraction and material property estimation based on the physics of EM wave propagation.

Previous GPR NAPL detection studies have relied on minimal data processing and qualitative interpretation of subsurface profiles. Our approach combines sophisticated processing methodology with quantitative attribute analysis and material property estimation. The proposed research will lead to more efficient processing, reliable, accurate interpretations, and detection of subtle variations that are difficult or impossible to identify through qualitative interpretation alone. Implementation of these methodologies will be a significant advance in GPR research and in meeting DOE's need for reliable in situ characterization of DNAPL contamination. 
Research Project Number: 56

\section{Effects of Fluid Distribution on Measured Geophysical Properties for Partially Saturated, Shallow Subsurface Conditions}

Conceptual Model Input: Vadose Zone

Addresses Need: $\quad 3$. Need to improve the use of 3D tomography and other cross-hole geophysics for selected facilities to show changes in moisture.

4. Need to better define the porosity and permeability in selected areas.

7. Need measurement technique to monitor ambient water travel time through the VZ to the SRPA at selected facilities.

Principal Investigator: Dr. Patricia A. Berge, Lawrence Livermore National Laboratory

Purpose: To develop relationships between laboratory-measured geophysical properties and porosity, saturation, and fluid distribution for partially saturated soils.

Project Description: Effective in situ remediation requires knowledge of subsurface porosity, permeability, and fluid saturation. Estimation of hydrogeologic properties using improved geophysical imaging and interpretation is faster, cheaper, and less invasive than drilling. Methods for interpretation of geophysical field data can be improved by using controlled laboratory experiments to measure geophysical properties as functions of saturation, pressure, and soil composition, and then using rock physics theories to relate these measurements to hydrogeologic properties and to generalize results to the field scale. Results will improve interpretation of geophysical data collected in the field for characterizing in situ soils in the subsurface and fill materials such as sands used in capillary barriers.

Controlled laboratory ultrasonic experiments will be conducted on partially saturated soil samples including sand, sand-clay mixtures, and soil samples from a DOE Environmental Management site such as Hanford in Washington State or the Idaho National Engineering and Environmental Laboratory (INEEL). X-ray computed microtomography will be used to image fluid distribution and soil composition in our samples. These data will be combined with available laboratory measurements of electrical properties for similar samples, such as laboratory measurements of the dielectric constant. We will use rock physics theories will be used to develop relationships between the laboratory measurements and porosity, saturation, and fluid distribution, to improve interpretation of geophysical field data such as cross-hole seismic and ground-penetrating radar measurements.

This work builds on our previous Environmental Management Science Program (EMSP) research and extends results to the vadose zone since we propose to measure properties of partially saturated samples. Results of this proposed work can be applied to improving interpretation of geophysical field measurements used to characterize the subsurface and monitor remediation in the vadose zone at contaminated sites such as Hanford or INEEL. Improved subsurface characterization is essential to the Environmental Management mission, particularly for the subsurface contamination and tanks focus areas, and has direct relevance to needs for remediation of carbon tetrachloride and hexavalent chromium in soils in the vadose zone at Hanford, and to needs for improved technologies for detection and delineation of burial ground contents and subsurface geological boundaries in burial ground sites and liquid waste disposal sites at Hanford. The research results also may be relevant to the need for delineating and verifying removal of dense, nonaqueous phase liquids (DNAPLs) at various sites; the need for improving understanding of contaminant transport in a fractured rock vadose zone at INEEL; and possible monitoring of capillary barrier performance at Hanford in the future. 
Research Project Number: 57

\section{The Use of Radar Methods to Determine Moisture Content in the Vadose Zone}

\section{Conceptual Model Input: Vadose Zone}

Addresses Need: $\quad 3$. Need to improve the use of 3D tomography and other cross-hole geophysics for selected facilities to show changes in moisture.

\section{Principal Investigator: Dr. Rosemary J. Knight, Stanford University}

Purpose: To further develop the usefulness of radar methods (ground-based and borehole) as a means of characterizing moisture content in the vadose zone.

Project Description: Moisture content is a critical parameter affecting both liquid-phase and vapor-phase contaminant transport in the vadose zone. This research will focus on two specific aspects of the link between radar images and moisture content. The first aspect or question addressed is: Can a measure of the dielectric constant of a volume of the subsurface be used to determine the moisture content of that volume? In addressing this first question, our focus is on determining the optimal way to transform a 3-D map of dielectric constants into a 3-D map of moisture content. This is clearly a critical step in the use of radar information, and is a step that requires significant improvements in rock physics.

Through theoretical modeling and laboratory and numerical experiments, we will first explore the errors that will result in determined moisture content if we use the standard rock physics relationships, which assume that moisture content is homogeneously distributed, for a subsurface region that is truly heterogeneous. In this part of our research we will develop a rigorous theoretical basis for predicting the uncertainty. For some applications involved with characterization of the vadose zone, it might be sufficient to determine the potential error or uncertainty in moisture content that will be introduced by use of the standard models; the uncertainty could be incorporated in models of contaminant transport. Having quantified the possible level of error, we will investigate ways in which the combined use of surface and borehole radar data can be used to reduce the error. Two specific ideas that will be investigated are determining the magnitude of anisotropy in dielectric measurements, and incorporating information about attenuation.

The second question we address is: Can the spatial distribution of radar reflections be used as a means of characterizing the spatial distribution of moisture content in the subsurface? This aspect of our research addresses the direct use of the radar image for quantifying the spatial heterogeneity of moisture content in the subsurface. This problem involves two separate issues. The first is the development of processing methods to improve the resolution of the radar image. This would provide a closer link between the moisture variation in the subsurface, the related dielectric variation, and the location, continuity and amplitude of reflections. The second issue is the development of improved methodologies for analyzing the radar image to quantify the observed spatial variability.

We propose to investigate the use of wavelet transforms as an improved means of quantifying the scale-dependent spatial variability of the subsurface. The use of wavelet transforms is a method ideally suited to analyzing systems in which there are many scales of structure or heterogeneity, as are present in natural geologic systems. The development of this methodology for the analysis of radar images may provide a new way to quantitatively characterize, at many different scales, the spatial heterogeneity of moisture content in the subsurface. The close link between imaged dielectric properties and moisture content strongly suggests that this is an ideal approach to obtaining estimates of in situ moisture content, a critical factor in addressing issues associated with contaminant transport in the vadose zone. The successful completion of this proposed research will allow for improved accuracy in extracting information about both the magnitude of moisture content and its spatial distribution in the vadose zone. 
Research Project Number: 58

\section{High Frequency Electromagnetic Impedance Imaging for Vadose Zone and Groundwater Characterization}

Conceptual Model Input: Vadose Zone and Aquifer

Addresses Need: $\quad 3$. Need to improve the use of 3D tomography and other cross-hole geophysics for selected facilities to show changes in moisture.

7.Need measurement technique to monitor ambient water travel time through the VZ to the SRPA at selected facilities.

Principal Investigator: Dr. Gregory A. Newman, Sandia National Laboratories - Albuquerque

Purpose: To address existing problems with the high frequency electromagnetic impedance method in the following way: (1) implement full non-linear 2-D/3-D inverse solutions that incorporate source coordinates and polarization characteristics, (2) use these solutions to study improvements in image resolution that can be obtained by making measurements in the near and mid-field regimes using multiple source fields, (3) collect data at the Hanford Reservation with recently developed earth impedance measurement systems, and (4) interpret the field data with the newly developed inversion capability as well as with additional and independent information such as well logs from boreholes.

Project Description: Accurate description of transport pathways on the gross scale, the location of contamination, and characterization of heterogeneity within the vadose zone, are now realized as vital for proper treatment, confinement and stabilization of subsurface contamination at DOE waste sites. Electromagnetic (EM) methods are ideal for these tasks since they are directly sensitive to the amount of fluid present within porous media, as well as the fluid composition. At many DOE sites it is necessary to employ lower frequency $(<1 \mathrm{MHZ})$ or diffusive electromagnetic fields because of the inability of ground-penetrating radar (GPR) to penetrate to sufficient depths. The high frequency electromagnetic impedance method, which operates in the diffusive frequency range (10 HZ to $1 \mathrm{MHZ}$ ) as well as the low end of the spectrum employed by GPR (1 MHZ-10 MHZ), is an ideal technique to delineate and map the aforementioned targets. The method has clearly shown potential to provide needed information on variations in subsurface saturation due to leaking storage tanks and perched water zones, as well as mapping geological structures related to the subsurface hydrological properties and heterogeneity within the vadose zone.

Although it exhibits certain advantages over other EM methods, the impedance method comes with a set of assumptions and practices that can limit its potential. The first is the desire to locate receivers in the far-field of the transmitter which allows the use of magnetotelluric (MT) inversion codes to interpret the data. Unfortunately, one does not precisely know when one is in the far-field of the transmitter, because this depends on the geology to be imaged. The second limiting factor is the scarcity of complete 2-D and 3-D inversion schemes necessary to properly invert the data. While approximate 2-D schemes are now emerging, rigorous 2-D and 3-D inversion codes are needed to bound the range of applicability of the approximate methods. The purpose of this research is to address these problems, as stated above.

The benefit of this research to the DOE would be a combined measurement/interpretation package for non-invasive, high-resolution characterization of larger transport pathways, certain types of contamination, and heterogeneity within the vadose zone at the Hanford Reservation as well as other DOE facilities. 
Research Project Number: 59

\section{A Hydrologic-Geophysical Method for Characterizing Flow and Transport Processes within the Vadose Zone}

Conceptual Model Input: Vadose Zone

Addresses Need: $\quad 3$. Need to improve the use of 3D tomography and other cross-hole geophysics for selected facilities to show changes in moisture.

7. Need measurement technique to monitor ambient water travel time through the VZ to the SRPA at selected facilities.

Principal Investigator: Dr. David L. Alumbaugh, University of Wisconsin at Madison

Purpose: To develop a mid-scale hydrologic test to analyze flow and transport within the vadose zone.

Project Description: Predictive models have often been employed to estimate fluid flow and contaminant transport rates within the vadose zone, that lies beneath many DOE hazardous waste sites. Unfortunately, these schemes have often failed to provide accurate results and have underestimated transport rates. Reasons for these inaccuracies include: (1) oversimplification of the earth model; (2) a misunderstanding of how formation heterogeneity at different scales affects flow and transport;

(3) problems associated with the measurement of hydraulic properties and upscaling these measurements to the model scale; (4) a lack of understanding how man-made structures such as unsealed wells and leaking tank farms affect flow and transport. The proposed mid-scale hydrologic test will employ state of the art numerical and experimental tools that have and are continuing to be developed under a previously funded EMSP proposal.

The benefits to the DOE of this work include much better conceptual models of flow and transport mechanisms within natural heterogeneous and disturbed vadose zone deposits; a database to compare predictive and performance assessment models describing unsaturated flow and transport; improvements on, and validations of, current state-of-the-art hydrologic modeling schemes; and a validated experimental method that could be applied to other DOE sites to determine site-specific flow and transport rates. The team of scientists from Sandia National Laboratories, the University of Arizona, the University of Wisconsin-Madison, and SteamTech Environmental Services brings a unique perspective to the project, combining expertise in vadose-zone hydrology as well as inverse theory and geophysical imaging.

The proposed experiment will be conducted at the Sandia/Tech Vadose Zone (STVZ) facility where an infiltration experiment is currently being conducted to characterize flow in unsaturated media. Subsurface hydrologic conditions are being monitored using hydrological sensors as well as the electrical resistivity tomography (ERT) and cross borehole ground penetrating radar (XBGPR) geophysical methods. As deployed, these two methods are complimentary in that the ERT produces full 3-D estimates of subsurface properties, while the XBGPR yields only 2-D images but at a higher resolution than the ERT, such that finer scale processes and heterogeneities can be detected and examined.

Once this infiltration has reached steady state, a hybrid hydrologic/geophysical inverse technique (HHGIT) will be employed to produce 3-D estimates of hydrologic parameter distribution at the site, as well as the error associated with those estimates. A state-of-the-art numerical transport scheme will then be employed to simulate and design transport experiments where a saline fluid is allowed to infiltrate into the subsurface at the STVZ site. The progress of field experiments will be monitored using the two geophysical methods. The resulting geophysical images will yield valuable information about transport 
processes within the vadose zone and the effect of disturbances such as unsealed wells on transport and flow in unsaturated conditions, and will provide a validation of both the numerical schemes employed here as well as other hydrologic modeling codes. 


\section{Automating Shallow Seismic Imaging}

Conceptual Model Input: Vadose Zone

Addresses Need: $\quad 3$. Need to improve the use of 3D tomography and other cross-hole geophysics for selected facilities to show changes in moisture.

Principal Investigator: Dr. Don W. Steeples, University of Kansas

Purpose: To develop and demonstrate the use of a cost-effective automated method of conducting shallow seismic surveys.

Project Description: This research is designed to develop ultrashallow seismic imaging into a cost-effective method that could be applicable to DOE facilities. The approach represents a significant departure from conventional seismic-survey field procedures. Initial testing suggests that large numbers of geophones can be placed automatically by a mechanical device, which could make the application of shallow seismic reflection (SSR) considerably faster and cheaper.

The imaging results obtained using the proposed automated seismic methods will be compared with results obtained using classical seismic techniques as well as GPR surveys, and, in the third year of the proposed research, demonstration surveys at one or more DOE facilities will be performed. The techniques proposed here are not limited to shallow seismic reflection methods, but would also be capable of collecting data for seismic-refraction and possibly for surface-wave studies. Although this research falls primarily into the field of seismology, some ground-penetrating radar (GPR) data will be collected at a very small additional incremental cost for comparison and quality control purposes. 
Research Project Number: 61

\section{High Frequency Electromagnetic Impedance Measurements for Characterization, Monitoring, and Verification Efforts}

Conceptual Model Input: Vadose Zone and Aquifer

Addresses Need: $\quad 3$. Need to improve the use of 3D tomography and other cross-hole geophysics for selected facilities to show changes in moisture.

12. Need studies of physical waste form of contaminants in the Subsurface Disposal Area and other sites.

Principal Investigator: Dr. Ki-Ha Lee, Lawrence Berkeley National Laboratory

Purpose: We propose to continue development of high-frequency impedance (HFI) methodology utilizing a window in the electromagnetic (EM) spectrum from $1.0 \mathrm{MHz}$ to $100 \mathrm{MHz}$.

Project Description: This window, located between GPR and low-frequency induction techniques, has not been used to non-invasively investigate the upper few meters of the ground for environmental applications. Modeling and physical parameter studies confirm that impedance measurements in this frequency band can yield high-resolution mapping of electrical conductivity as well as the permissivity of near surface formations. In principle the impedance method we propose is free of source coupling for plane waves, so that the ensuing data analysis tends to be much simpler.

The proposed research plan consists of three tasks: (1) continued development and completion of high-frequency field measurement techniques, (2) construction and delivery of a field-hardened prototype HFI system, and (3) data processing, analysis, and interpretation. The proof-of-concept for the HFI system has been demonstrated in the first phase of the research program (1997 through 2000). Construction of a mobile HFI field system can be accomplished using off-the-shelf instrumentation and commercially available components, but research will be continued to develop better high-frequency sensors using innovative designs. Development of an analysis package for processing and interpretation of high-frequency data is also an essential part of the proposed work. Towards the end of the project, the prototype system will be capable of real-time mapping of the electrical conductivity and permissivity using simultaneous inversion in one dimension. Feasibility for implementing higher-dimensional analysis package in field operation will be critically evaluated. 
Research Project Number: 62

\section{Induced Polarization with Electromagnetic Coupling: 3-D Spectral Imaging Theory and Field Tests}

Conceptual Model Input: Source Term and Vadose Zone

Addresses Need: $\quad 3$. Need to improve the use of 3D tomography and other cross-hole geophysics for selected facilities to show changes in moisture.

10. Need to perform vertical profiling of contaminant plume geometry to determine layering effects (Such as $\mathrm{Cr}^{6}$ at the Test Reactor Area).

Principal Investigator: Dr. F. Dale Morgan, Massachusetts Institute of Technology

Purpose: To address the EM coupling problem by directly including EM induction in the IP modeling inversion codes.

Project Description: The Earth Resources Laboratory (ERL) has made recent advances in applying the induced polarization (IP) method for detection and mapping of contaminant plumes. The ERL has developed 3-D complex resistivity and time-domain inversion codes, and performed modeling that shows that spectral induced polarization (SIP) requires a wide frequency range to be effective. Laboratory experiments have revealed that the greatest IP response to contaminants is at frequencies higher than $1 \mathrm{KHz}$. However, electromagnetic capability (EMC) limits the effective frequency range to below $100 \mathrm{~Hz}$, and present correction methods are inadequate. The project will address the EM coupling problem using a fundamentally new approach - directly include EM induction in the IP modeling inversion codes. In other words, the EMC will be treated as a data signal, with useful information about the conductivity structure, instead of as a useless noise signal.

A forward problem is to be developed which predicts both the IP and the EM part of the data from a model. An appropriate inverse algorithm will be developed for 3-D spectral IP field data. The new modeling will incorporate rather than eliminate EM inductive coupling, extending the effective frequency range of SIP to the region of greatest interest beyond $1 \mathrm{KHz}$. The new method will also increase the subsurface resolution of tomography as the EM component of the data is fused with IP, where the EM is sensitive to the conductivity structure. The project will also perform two field demonstrations of SIP and time domain IP at two sites.

The original DOE project (DE-FG0296ER4714) was a broad foundational study of spectral IP (SIP) for site characterization. The project encompassed laboratory studies of microgeometry and chemistry effect on IP, an investigation of EMC noise, and development of 3-D modeling and inversion codes. The project showed that EMC is the major limitation for field implementation of SIP and conventional correction methods are inadequate. The present project is more focused, with the aim of resolving the EMC problem to enable inversion of spectral data in the desired higher frequencies above $1 \mathrm{KHz}$. The approach is to couple IP and EM in the modeling and inversion based on Maxwell's questions. The objectives of the renewal project are:

- $\quad$ Extend the present 3-D codes to include coupled IP-EM modeling and inversion

- $\quad$ Demonstrate field applications of 3-D SIP and time domain IP at two DOE sites. 
Research Project Number: 63

\section{Advanced High-Resolution Seismic Imaging, Material Properties Estimation and Full Wavefield Inversion for the Shallow Subsurface}

Conceptual Model Input: Vadose Zone

Addresses Need: $\quad 3$. Need to improve the use of 3D tomography and other cross-hole geophysics for selected facilities to show changes in moisture

Principal Investigator: Dr. Alan R. Levander, Rice University

Purpose: To complete development and testing of an integrated suite of imaging and inverse techniques for 2-D and 3-D seismic data being developing for shallow high-resolution imaging.

Project Description: Seismic methods have the potential to fully depict the contours and connectivity of subsurface aquitards and other essential structures for design of groundwater remediation programs. Use of seismic imaging methods thus promises to reduce the level of uncertainty about contaminant pathways due to the necessary scarcity of test wells and the untestable assumptions of geostatistical interpolation methods. Seismic analysis development has included 2-D Kirchhoff inversion, 2-D depth focusing analysis, 2-D wavefield inversion, and 2-D and 3-D travel time tomography. This project will extend Kirchhoff inversion, depth focusing, and full waveform inversion methods to $3-\mathrm{D}$. Both conventional analysis methods as well as these advanced analysis methods will be applied to 3-D survey data that has been acquired as part of this project.

To date a number of high-resolution seismic surveys have been conducted, including one extremely successful 2-D experiment at the Operable Unit 2 Superfund site at Hill Air Force Base in Utah, and a test 3-D survey at Rice University. The survey is designed to make a 3-D map of a shallow paleo-channel along which DNAPLs are confined at the base of a shallow aquifer. 
Research Project Number: 64

\section{A Resolution Analysis of Two Geophysical Imaging Methods for Characterizing and Monitoring Hydrologic Conditions in the Vadose Zone}

Conceptual Model Input: Vadose Zone

Addresses Need: $\quad 3$. Need to improve the use of 3D tomography and other cross-hole geophysics for selected facilities to show changes in moisture.

10. Need to perform vertical profiling of contaminant plume geometry to determine layering effects (Such as $\mathrm{Cr}^{6}$ at the Test Reactor Area).

Principal Investigator: Dr. David L. Alumbaugh, University of Wisconsin at Madison

Purpose: To conduct an intensive numerical modeling effort that is aimed at helping to resolve some of the issues for electrical resistivity tomography (ERT) and crossborehole ground-penetrating radar (XBGPR) geophysical methods as applied to characterizing and monitoring vadose zone properties and processes.

Project Description: Geophysical methods are rapidly becoming popular within the DOE complex as possible tools for characterizing subsurface hydrologic properties, as well as monitoring flow and transport processes within the vadose zone at contaminated sites. The reason for incorporating geophysical imaging into site characterization, remediation monitoring, or as a long-term monitoring tool for a site closure plan is simple: these methods offer the possibility to non-destructively characterize subsurface conditions and processes from a limited number of boreholes and/or measurements made on the surface. To convert between geophysical and hydrological properties requires the application of petrophysical models. In general petrophysical models are approximate, empirical relations developed from the studies of core-sized (a few $\mathrm{cm}$ ) samples. However, geophysical images typically have resolutions on the order of fractions of meters or larger.

In the past, there has been little work done to quantify the effect of heterogeneity due to structures that are larger than core samples but still too small to be resolved individually by geophysical imaging. In addition, there has been little work done to quantify the resolution of the imaging schemes that address their ability to characterize spatial heterogeneity within the vadose zone, and produce accurate time-lapse images of flow and transport processes. It is important to consider the cumulative effect of errors in both the geophysical data collection and processing, and within petrophysical models themselves, if interpreters are to understand those features in the images that are real, those that are artifacts, and how much credence can be given to the results in terms accuracy and precision.

This research will consist of four primary tasks: (1) high definition, large-scale numerical modeling of a series of statistically related vadose zone flow and transport processes to yield porosity, moisture content, temperature, and solute concentrations at 5 to 10 -cm intervals throughout a 1000 to $4000 \mathrm{~m}^{3}$ volume hypothetical vadose zone; (2) application and analysis of petrophysical relationships that convert the output of the hydrologic models from task 1 into geophysical parameter fields; (3) generation of synthetic ERT and XBGPR data sets from the geophysical parameter fields generated in task 2, and addition of random measurement noise and biased error to the data; and (4) imaging of the synthetic data sets using standard geophysical processing and inversion techniques, and comparison of the results to the original hydrologic models. 
The results of this effort will not only be employed to analyze the resolution and accuracy of the two geophysical methods for imaging within the vadose zone, but also will be applied to better understand data collected. The benefits to the DOE Environmental Management Program include a thorough evaluation of how well two of the geophysical imaging methods (i.e., ERT and XBGPR) can truly resolve subsurface hydrological features and processes within the vadose zone, synthetic data sets for other researchers to use for testing and assessment, and an assessment of an interactive method for determining subsurface flow and transport properties within the vadose zone. 
Research Project Number: 65

\section{Improving Ground-Penetrating Radar Imaging in High Loss Environments by Coordinated System Development, Data Processing, Numerical Modeling, and Visualization Methods with Applications to Site Characterization}

Conceptual Model Input: Vadose Zone

Addresses Need: $\quad 3$. Need to improve the use of 3D tomography and other cross-hole geophysics for selected facilities to show changes in moisture.

Principal Investigator: Dr. David L. Wright, U.S. Geological Survey - Denver

Purpose: To extend the limits of performance of GPR in both the hardware domain and in the numerical computation domain.

Project Description: Ground-penetrating radar (GPR) is a geophysical tool with the potential to locate, identify, and measure subsurface heterogeneity features directly. Unfortunately, in many environments the method does not produce interpretable data. There are a number of unstated assumptions that are usually made with GPR. One is that the radiated pulse output from the antenna into the ground does not change significantly in shape or amplitude across a given profile. Another is that propagation through the ground occurs such that reflections from subsurface interfaces will be replicas of the radiated waveform. Under many earth conditions these assumptions may be violated, leading to reflection arrivals that are misinterpreted or uninterruptible.

Dispersion, which is frequency-dependent velocity, is caused by high electrical conductivity and/or high dielectric or magnetic relaxations, and results in waveform changes during propagation such that the reflected arrivals are not replicas of the radiated waveform. Scattering of energy by an abundance of randomly oriented interfaces can also cause misinterpreted waveform changes. Variations in the very near surface conditions around a ground-coupled antenna as it moves along a profile will change the shape of the radiated waveform it transmits into the subsurface. When these changes are unknown, they cause misinterpretations of far-field reflection events. Environments that result in these problems are also almost always associated with high signal attenuation. Although the laws of physics will always impose limits to what can be achieved, we do not think that all that can be done has been done to produce correctly interpreted GPR data acquired in challenging environments.

It is our contention that an approach such as the one we propose here can sharpen subsurface images and extend possible depths of investigation in ways that are not now available in the GPR community. Since GPR is such a powerful field tool with a unique subsurface characterization potential, an extension of the domain of applicability of GPR is a worthy research goal. The key features in our system include: (1) greater dynamic range through real time sampling and receiver gain improvements, (2) modified, fully characterized antennas with current sensors to allow dynamic measurement of the changing radiated waveform, (3) modified deconvolution and depth migration algorithms exploiting the new antenna output information, (4) development of automatic full waveform inversion made possible by the known radiated pulse shape, and (5) a modified visualization package for efficient subsurface interpretation. 


\section{Microbial Mineral Transformations at the Fe(II)/Fe(III) Redox Boundary for Solid Phase Capture of Strontium and Other Metal/Radionuclide Contaminants}

Conceptual Model Input: Vadose Zone

Addresses Need: $\quad$ 14. Need to determine what from the standpoint of geochemistry is influencing transport and retardation.

Principal Investigator: Dr. F. Grant Ferris, University of Toronto

Purpose: Conduct studies at the University of Alabama and the University of Toronto to determine microbiological and geochemical controls on carbonate mineral precipitation reactions that are caused by bacterial reduction of Fe(III) oxides, and identify contributions of their processes to the solid phase capture of strontium and other metal/radionuclide contaminants.

Project Description: The impact of microbial Fe(III) oxide reduction on $\mathrm{Sr}$ chemistry will be addressed in sequential manner, starting with batch aqueous suspension experiments. These will be followed by microcosm semicontinuous culture studies using saturated sands artificially coated with $\mathrm{Fe}(\mathrm{III})$ oxides and natural Fe(III) oxide-bearing sediments. Constant hydraulic head flow-through column experiments will ultimately be conducted to assess aqueous and solid phase distribution of strontium under simulated field conditions. 
Research Project Number: 67

\section{Influences of Flow Transients and Porous Medium Heterogeneity on Colloid-Associated Contaminants Transport in the Vadose Zone}

Conceptual Model Input: Vadose Zone and Aquifer

Addresses Need: 1 . Need to determine preferred flow zones in the aquifer for characterization at the regional and subregional scale.

14. Need to determine what from the standpoint of geochemistry is influencing transport and retardation.

Principal Investigator: Dr. Joseph Ryan, University of Colorado

Purpose: To examine the enhanced transport of radionuclides by mineral colloids within variably saturated media.

Project Description: Associations between contaminants and soil colloids have affected contaminant mobility in the vadose zone and the quality of underlying groundwater in several settings. Nevertheless, the factors governing colloid-facilitated contaminant transport in unsaturated porous media have not been rigorously explored nor formalized into a quantitative model. In particular, the roles of flow transients and porous medium heterogeneity in colloid transport and colloid-associated contaminant transport have not been adequately investigated to date.

Laboratory experiments will be conducted with porous medium micromodels to identify mechanisms that govern colloid mass transfer interactions (i.e., deposition and mobilization) at solid-water and air-water interfaces. It's hypothesized that thin film straining and solid-water interface reactions dominate the deposition of soil colloids under unsaturated conditions, while expansion of thin-water films and elevated shear forces in the vicinity of the mineral grains drive colloid mobilization during periods of transient flow. The kinetics of adsorption and desorption reactions between radionuclides (Cs-137 and Sr-90) and the mineral colloids (illite clay and silica) will be measured, and the relationships between radionuclide-colloid interactions and contaminant mobility will be elucidated in column experiments with unsaturated media. It is possible that the kinetics of contaminant desorption from colloids will determine the extent to which colloid-facilitated transport contributes to the overall transport of radionuclides. Special attention will be devoted to defining the influences of porewater-flow transients and structured heterogeneities (i.e., preferential flow paths) on the mobilization and subsequent migration of colloid-bound radionuclides. Experiments will be performed with columns containing well-defined heterogeneities and with intact cores collected from sites within the DOE complex.

Knowledge gleaned from each phase of the laboratory work will be used to develop a mathematical model appropriate for quantifying colloid-facilitated contaminant transport in variably saturated media. Tests of the mathematical model against data from the column experiments will yield functional relationships between model parameters governing colloid and radionuclide mass transfer and measure system properties. The significant environmental implications of colloid-facilitated transport in the vadose zone make experimental observations and development of a quantitative understanding of the phenomenon critically important. Our proposed work represents the first systematic approach to identifying the controls on colloid-associated transport through unsaturated, heterogeneous media under transient flow conditions. 


\section{Multiphase Flow in Complex Fracture Apertures Under a Wide Range of Flow Conditions}

Conceptual Model Input: Aquifer

Addresses Need: 1 . Need to determine preferred flow zones in the aquifer for characterization at the regional and subregional scale.

2. Need methods for delineation of flow direction in the aquifer at a facility scale.

Principal Investigator: Dr. Paul Meakin, Idaho National Engineering and Environmental Laboratory

Purpose: To fill important knowledge gaps and develop new conceptual models to understand how pollutants travel in the vadose zone.

Project Description: At several DOE sites and in other countries, pollutants have traveled in the vadose zone much further and faster than predicted. This reveals the inadequacies of both the computer models used to predict the transport of pollutants in the subsurface and the conceptual models on which they are founded. A closely coordinated experimental and computer modeling program has been planned to study multiphase flow in fracture apertures. The hypothesis that focusing flow onto preferred pathways (such as fracture apertures), intermittent flow conditions, and the colloid mediated transport of strongly adsorbed pollutants play an important role in rapidly transporting subsurface contamination will be tested.

Experiments and simulations using several modeling methods will be performed, both under a wide range of flow conditions in realistic, complex fracture apertures (computer-generated fracture apertures using fractal and nonfractal statistical models, well-characterized natural fractal apertures, and/or replicas of natural fracture apertures). The modeling program will be based on methods that are well suited to geometrically complex boundary conditions (realistic fracture aperture geometries) and complex moving interfaces. These methods include lattice-gas/lattice-Boltzmann models, invasion percolation models, molecular dynamics, and smoothed particle hydrodynamics. By using these various methods, we can evaluate different modeling approaches and use computer modeling to extrapolate and interpolate the experiments to a broader range of conditions. The experiments will e performed in a unique and versatile matched-index-of-refraction flow laboratory at INEEL. 
Research Project Number: 69

\section{Advanced Conceptual Models for Unsaturated and Two-Phase Flow in Fractured Rock}

Conceptual Model Input: Vadose Zone

Addresses Need: $\quad$ 1. Need to determine preferred flow zones in the aquifer for characterization at the regional and subregional scale.

2. Need methods for delineation of flow direction in the aquifer at a facility scale.

7. Need measurement technique to monitor ambient water travel time through the VZ to the SRPA at selected facilities.

Principal Investigator: Dr. Michael J. Nicholl, University of Idaho

Purpose: To develop advanced conceptual models for two-phase flow in fractured rock.

Project Description: The Department of Energy's Environmental Management Program is faced with two major issues involving two-phase flow in fractured rock: transport of dissolved contaminants in the Vadose Zone, and the fate of Dense Nonaqueous Phase Liquids (DNAPLS) below the water table.

Conceptual models currently used to address these problems do not correctly include the influence of the fractures, thus leading to erroneous predictions. Recent work has shown that it is crucial to understand the topology, or structure of the fluid phases (air/water or water/DNAPL) within the subsurface. It has also been shown that even under steady boundary conditions, the influence of fractures can lead to a complex and dynamic phase structure that controls system behavior, with or without the presence of a porous rock matrix. Complicated phase structures within the fracture network can facilitate rapid transport, and lead to a sparsely populated and widespread distribution of concentrated contaminants; these qualities are highly difficult to describe with current conceptual models. Our approach is founded on systematic experimentation. As preliminary experiments have shown that behavior at fracture intersections is key, we will begin by conducting systematic experimentation to identify and classify behavior at intersections.

Understanding gained at the scale of intersections will be used to augment a Modified Invasion

Percolation (MIP) model that has shown significant promise in predicting flow through fracture networks. Development of the MIP model will be iterative, in that we will use numerical simulations to design critical physical experiments at the network scale, which will challenge the model. The augmented, and fully tested MIP model will be exercised on realistic fracture networks for the purpose of understanding large-scale development of phase structure. Networks will be generated using algorithms conditioned to field data collected at DOE sites (e.g., INEEL, Nevada Test Site, Oak Ridge). Results of the large-scale network simulations will be abstracted so that critical features may be included in conceptual models used by the Environmental Management Program. 
Research Project Number: 70

\section{Molecular-Level Process Governing the Interaction of Contaminants with Iron and Manganese Oxides}

Conceptual Model Input: Source Term

Addresses Need: $\quad 9$. Need research on contaminant release from treated waste forms (grout and vitrified waste).

14. Need to determine what from the standpoint of geochemistry is influencing transport and retardation.

Principal Investigator: Dr. Scott A. Chambers, Pacific Northwest National Laboratory

Purpose: To identify products and to determine the kinetics and mechanisms of surface-catalyzed redox reactions of $\mathrm{Cr}(\mathrm{VI})$ and $\mathrm{Cr}(\mathrm{III})$, and the reductive dechlorination of $\mathrm{CCl}_{4}$ and TCE. The combination of theory and experiment will provide the base information needed to scale from the molecular level to the microscopic grain level minerals.

Project Description: Many of the inorganic and organic contaminants present in sediments at DOE sites can be altered or destroyed by reduction and oxidation (redox) reactions occurring at mineral surfaces. A fundamental understanding of such redox processes provided by molecular-level studies on structurally and compositionally well-defined mineral surfaces will lead to: (1) improved models of contaminant fate and transport in geochemical systems, and (2) optimized manipulation of these processes for remediation purposes. To contribute to this understanding, we will study, both experimentally and theoretically, redox processes involving three important contaminants (chromate ion $\mathrm{CrO}_{4}{ }^{-2}$, carbon tetrachloride $\mathrm{CCl}_{4}$, and trichloroethene $\mathrm{TCE}, \mathrm{ClHC}=\mathrm{CCl}_{2}$ ) on the following iron and manganese oxides: hematite $\left(\hat{a}-\mathrm{Fe}_{2} \mathrm{O}_{3}\right)$, magnetite $\left(\mathrm{Fe}_{3} \mathrm{O}_{4}\right)$, maghemite $\left(\left(\tilde{a}-\mathrm{Fe}_{2} \mathrm{O}_{3}\right)\right.$, and pyrolusite $\left(\hat{a}-\mathrm{MnO}_{2}\right)$. These oxides and their hydroxylated analogs commonly occur as coatings on minerals or as interfaces in the subsurface environment. Single-crystal surfaces of these oxides will be synthesized in a carefully controlled fashion by molecular beam epitaxy. These surfaces, as well as high surface area powdered samples of these oxides, will be used in spectroscopic and kinetic experiments in both aqueous and gas phases. 
Research Project Number: 71

\section{Modeling of Cation Binding in Hydrated 2:1 Clay Minerals}

Conceptual Model Input: Source Term and Vadose Zone

Addresses Need: $\quad 9$. Need research on contaminant release from treated waste forms (grout and vitrified waste).

14. Need to determine what from the standpoint of geochemistry is influencing transport and retardation.

Principal Investigator: Dr. David E. Smith, New Mexico State University

Purpose: To develop molecular models for cation binding to clays through the use of computer simulations.

Project Description: Hydrated 2:1 clay minerals are high-surface area, layered silicates that play a unique role in determining the fate of ionic pollutants in the environment. These minerals, including smectites and vermiculites, make up a major component of many soils. Ionic pollutants, including radioactive metal ions, may displace interlayer cations from the clay and bind, sometimes irreversibly, to the fixed-charge sites on the clay layer sheets. This binding in turn has a significant impact on pollutant transport through soils and clay-based containment materials, and on groundwater and soil remediation strategies. The molecular mechanisms whereby cations bind to 2:1 clay minerals are, unfortunately, not fully understood. The compositional variability of clays, particularly the magnitude and location of isomorphic substitution sites, has a significant impact on their binding properties. In addition, the complicated balance between hydration forces and ion-clay interactions is often difficult to quantify. These models will build our intuition into cation-clay binding phenomena while explicitly identifying the key elements in the interactions that account for observed binding behavior. This in turn will assist in predicting and understanding the distribution coefficients that are used to model pollutant transport through natural soils or containment materials. In addition, strategies for soil remediation will benefit from an improved fundamental understanding of the nature of the binding interactions. The studies we propose here should help to elucidate the molecular mechanisms of cation binding.

Issues involving the proper storage and isolation of spent fuel, high-level waste, and transuranic waste are also subjects of intense current research and development. Radioactive wastes are unique among pollutants in that they cannot be destroyed in the traditional sense-radioactive nuclei remain radioactive until they spontaneously decay (or are forced to decay in nuclear reactors). Many radioactive isotopes have half-lives of thousands or millions of years. As a result, long-term storage and isolation technologies must be developed before waste can be removed from temporary storage facilities now in operation.

Current strategies for long-term storage of nuclear waste involve geological repositories such as the Waste Isolation Pilot Plant in New Mexico and the proposed Yucca Mountain site in Nevada. One key feature of geological repositories is the use of containment and backfill materials that can provide a sealing and sorbing buffer to radionuclide transport. We propose specifically to investigate the molecular origin of cation binding and mobility in hydrated clay minerals using simulation techniques. Computer simulations assist directly in building molecular intuition into chemical systems and provide a bridge between experiment and theory. To date, no calculations of cation binding thermodynamics have been reported. 
Our simulations will be used to build a molecular-level understanding of cation binding, and to analyze theories for cation exchange in clays. Specific focus will be given to cesium $\left(\mathrm{Cs}^{+}\right)$, strontium $\left(\mathrm{Sr}^{2+}\right)$, and uranium(VI) $\left(\mathrm{UO}_{2}{ }^{2+}\right.$ and hydrolysis products) cations, in that order, and to smectite and vermiculite clays of varying composition. The ions are chosen because they are important ionic components of high-level waste $\left(\mathrm{Cs}^{+}\right.$and $\left.\mathrm{Sr}^{2+}\right)$ and spent fuel $\left(\mathrm{UO}^{2+}\right)$. 
Research Project Number: 72

\section{Chaotic-Dynamical Conceptual Model to Describe Fluid Flow and Contaminant Transport in a Fractured Vadose Zone}

Conceptual Model Input: Vadose Zone

Addresses Need: $\quad$ 2. Need methods for delineation of flow direction in the aquifer at a facility scale.

Principal Investigator: Dr. Boris A. Faybishenko, Lawrence Berkeley National Laboratory

Purpose: To examine flow and transport through a fractured vadose zone as a deterministic chaotic dynamical process, and develop a model of it in these terms.

Project Description: Understanding subsurface flow and transport processes is critical for effective assessment, decision-making, and remediation activities for contaminated sites. However, for fluid flow and contaminant transport through fractured vadose zones, traditional hydrogeological approaches are often found to be inadequate. In this project, flow and transport through a fractured vadose zone will be examined as a deterministic chaotic dynamical process, and a model of it will be developed in these.

The geometric model of fractured rock and the flow dynamics model needed to describe chaotic behavior will be examined separately, then the geometry and flow dynamics will be put together to develop a chaotic-dynamical model of flow and transport in a fractured vadose zone. The model will be used to predict the long-term bounds on fluid flow and transport behavior, known as the attractor of the system, and to examine the limits of short-term predictability within these bounds. This approach is especially well suited to the need for short-term predictions to support remediation decisions, and long-term bounding studies. Laboratory and field experiments designed to test the model will be conducted. In the field experiments, the time variation of water flux, moisture content, and hydraulic head at various locations will be measured, as well as the total inflow rate to the subsurface. Such variations reflect the changes in the geometry and physics of water flow that display chaotic behavior. An attempt will be made to reconstruct this behavior using the data obtained. 
Research Project Number: 73

\section{Radiation Effects on Sorption and Mobilization of Radionuclides During Transport Through the Geosphere}

Conceptual Model Input: Vadose Zone

Addresses Need: $\quad$ 14. Need to determine what from the standpoint of geochemistry is influencing transport and retardation.

Principal Investigator: Dr. Lu-Min Wang, University of Michigan

Purpose: To expand the study of radiation effects on the sorption and ion exchange capacities of clays and zeolites by applying newly designed experimental methods.

Project Description: Site restoration activities at DOE facilities and the permanent disposal of nuclear waste inevitably involve understanding the behavior of materials in a radiation field. Radionuclide decay and associated radiation effects lead to physical and chemical changes in important properties. During waste processing and site restoration, materials can be exposed to radiation fields that exceed $104 \mathrm{rad} / \mathrm{hr}$. The radiation exposure is due to the incorporation or sorption of long-lived actinides and fission products.

The effect of radioactive decay processes on waste processing materials and geologic materials are an important aspect of understanding the long-term fate and mobility of radionuclides in the geosphere.

During the past three years, we have evaluated radiation effects in selected near-field materials in accelerated laboratory experimental utilizing energetic electrons and ions and in situ transmission electron microscopy (TEM). Zeolites and layered silicates were irradiated. These materials were found to be highly susceptible to irradiation-induced solid-state amorphization. The critical doses for complete amorphization of these phases are as low as $<0.1$ displacement per atom (dpa) or $108 \mathrm{GY}$ in ionization energy deposition (i.e., the dose for a zeolite with $10 \mathrm{wt} . \%$ loading of Cs-137 in 400 years). Even partial amorphization will cause a dramatic reduction (up to 95\%) in ion-exchange and sorption/desorption capacities for radionuclides, such as Cs and Sr. Because the near-field or chemical processing materials, e.g., zeolites or crystalline silicotitanate (CST), will receive a substantial radiation dose after they have incorporated radionuclides, our results suggest that radiation may, in some cases, retard the release of sorbed or ion-exchanged radionuclides. These results have a direct bearing on repository performance assessments (e.g., the extent to which zeolites can retard the release of radionuclides) and on the technologies used to process high-level liquid waste (e.g., separation of Cs-137 from HLW using CST at the Savannah River Site).

The radionuclides to be studied include $\mathrm{Cs}, \mathrm{Sr}, \mathrm{U}$, and Se. Selected clay and zeolite samples will be irradiated with high-energy electrons, high-energy ions and neutrons to simulate the radiation effects from a variety of radioactive decay processes at an accelerated rate using a unique combination of irradiation facilities available at the University of Michigan. Ion exchange/sorption experiments will be conducted on samples irradiated to various doses to determine the impact of the radiation effects on the sorption capacity and retention of radionuclides. We also propose the use of novel ion implantation and surface analysis techniques, in order to identify atomic-scale effects of radiation damage associated with single or small clusters of radionuclides sorbed onto mineral surfaces. Clay and zeolite colloids have recently been reported to be responsible for the migration of $\mathrm{Pu}$ for distances greater than one kilometer at the Nevada Test Site. We plan to use high resolution and analytical electron microscopy to characterize the different types of colloids present at the Nevada Test Site and at Hanford (with samples provided by collaborators at Sandia National Laboratories and Lawrence Livermore National Laboratory). 
The results of this research will provide a fundamental understanding of retention or release of radionuclides from geologic materials (clays, zeolites and colloids) in radiation-fields. 
Research Project Number: 74

\section{Microbially Mediated Immobilization of Contaminants Through In Situ Biostimulation}

\section{Conceptual Model Input: Source Term}

Addresses Need: $\quad$ 14. Need to determine what from the standpoint of geochemistry is influencing transport and retardation.

Principal Investigator: Dr. Philip M. Jardine, Oak Ridge National Laboratory

Purpose: To provide an improved understanding and predictive capability of the mechanisms that allow metal-reducing bacteria to be effective in the bioremediation of redox sensitive toxic metals and radionuclides

Project Description: This study is motivated by the likelihood that subsurface metal-reducing bacteria can be stimulated to effectively alter the redox state of contaminants so that they are immobilized in situ for long time periods. The work described in this proposal will advance the technological and scientific needs associated with the long-term management of the enormous in-ground inventories of $\mathrm{Cr}, \mathrm{U}, \mathrm{Tc}$, and Co present at numerous DOE installations throughout the country.

The objectives of our project are: (1) develop an improved understanding and predictive capability of the rates and mechanisms controlling microbially mediated reduction of toxic metals, radionuclides, and metals in situ, (2) quantify the impacts of hydrological and geochemical processes on the effectiveness of indigenous microorganisms to transform and immobilize radionuclides and metals in situ, (3) provide an improved understanding of the importance of microbial consortia interactions in the bacterial immobilization of radionuclides and toxic metals, and (4) determine intrinsic bioreduction rate parameters to improve our generic predictive capability of in situ microbially mediated metal reduction.

Our approach involves a multiscale experimental and numerical endeavor that uses: (1) undisturbed cores and a well-characterized, highly instrumented field facility for assessing biostimulation remedial strategies involving $\mathrm{Cr}(\mathrm{VI}), \mathrm{U}(\mathrm{VI})$, and $\mathrm{Co}(\mathrm{III}) \mathrm{EDTA}$, (2) multiple tracer techniques designed to delineate the influence of coupled hydrological, geochemical, and microbial processes, (3) a novel microarray-based genomic technology for rapidly characterizing shifts in microbial community structure and activity, (4) sophisticated surface analysis techniques (x-ray absorption spectroscopy) for quantifying the distribution and chemical environment of the immobilized contaminants, and (5) next-generation, high-performance hydrobiogeochemistry modeling to assist the design and performance assessment of the proposed field scale experiment.

The experimental and numerical results from this research will provided knowledge and information in previously unexplored areas of in situ biostimulation for metal and radionuclide immobilization to support EM's mission of long-term isolation and in situ remediation of contaminated environments. By unraveling the fundamental mechanisms controlling the microbially mediated reduction and immobilization of contaminants in situ, we provide an enhanced opportunity for successfully implementing biostimulation strategies at numerous DOE installations that are plagued with legacy waste. Further, this proposal combines DOE's commitment to environmental restoration with its commitment to major user facilities (SSRL, high-performance computing) and academic education. 
Research Project Number: 75

\section{Semi-Passive Chemical Oxidation Schemes for the Long-Term Treatment of Contaminants}

\section{Conceptual Model Input: Source Term}

Addresses Need: $\quad 6$. Need to know the geochemical characteristics (e.g., oxidation states) of the near field environment for actinides.

14. Need to determine what from the standpoint of geochemistry is influencing transport and retardation.

Principal Investigator: Dr. Frank W. Schwartz, Ohio State University

Purpose: To develop a scientific basis for the use of semi-passive, wells-based, chemical oxidation systems for treating chlorinated ethylenes (e.g., PCE, TCE, DCE).

Project Description: Through the years, a variety of cleanup technologies have been proposed for groundwater at contaminated sites. In many cases, the size and complexity of sites make cleanups costly and technically difficult in terms of meeting cleanup goals. It is not surprising then that focus in cleanup strategies has shifted from costly, active approaches and aggressive treatments to much less costly and often long-term strategies. Thus, there has been an explosive growth of approaches like natural attenuation, capable of controlling problems at relatively low costs. We expect that in the United States as well as countries around the world, that interest in low cost technologies will continue to grow.

As a family, passive and semi-passive technologies are attractive because of the significant advantages in operating for long periods of time with relatively low operation and maintenance (O\&M) costs. One example is a reactive barrier system that uses zero-valent iron for treating dissolved plumes. Once the investment is made in the capital cost of the iron wall, operating costs are minimal. Another approach is the use of time-release compounds (oxygen-release compounds; hydrogen release compounds) to enhance natural biotransformation processes. Typically, biological stimulation uses lines of wells to deliver treatment chemicals to a DNAPL source area, locally, and along the dissolved plume. Compared to other technologies the cost of installing wells and periodically adding treatment chemicals is relatively attractive.

In situ chemical oxidation (ISCO) schemes involve the addition of a chemical oxidant, like potassium permanganate $(\mathrm{KMnO} 4)$, which destroys organic contaminants in a straightforward reaction. There are a variety of published and unpublished examples of ISCO schemes applied to cleanups of solvent spills. Most research demonstrations have been short term in nature, designed as proof-of-concept illustrations of the ability of oxidants to destroy compounds like TCE in the subsurface. Most of the industrial applications, involve fixed term, active treatments of a contaminated plume. Without source control, ISCO, like pump-and-treat or other technologies, is not a permanent remedy. We think that ISCO schemes have the potential to be developed as low cost, semi-passive: approaches for the long- term control and cleanup of contaminated sites.

This study aims to provide basic research on a new passive remediation concept with ISCO. In essence, solids will be added to wells for dissolution and slow release into groundwater. The first objective is to use laboratory measurements and computer simulations to develop a new passive well-delivery systems for the controlled release of $\mathrm{KMnO} 4$. A system is required to facilitate the slow release of $\mathrm{KMnO} 4$ into flowing groundwater in a manner that maximizes the lateral spreading, and minimizes the number of 
wells. We also propose to consider the role of well distribution in maximizing the performance of the system. The second objective is to use laboratory experiments to assess whether chemical mixtures or cyclic chemical renovation schemes are capable of providing both contaminant destruction and plugging control. The third objective is to evaluate the kinetics of interactions among treatment chemicals and the porous medium in order to optimize design. It is well known that natural, oxidizable compounds in aquifer materials utilize $\mathrm{KMnO}$. The design of the well-delivery system will require knowledge concerning the fate and transport of $\mathrm{KMnO} 4$. 
Research Project Number: 76

\section{Underground Corrosion after 32 Years: A Study of Fate and Transport}

Conceptual Model Input: Source Term

Addresses Need: 12 . Need studies of physical waste form of contaminants in the Subsurface Disposal Area and other sites.

Principal Investigator: Dr. Kay Adler Flitton, Idaho National Engineering and Environmental Laboratory

Purpose: To conduct an ambitious research project that completes the National Institute of Standards and Technology (NIST) corrosion study and thoroughly examines the soil and environment surrounding the specimens.

Project Description: In 1970, the NIST implemented the most ambitious and comprehensive long-term corrosion behavior test to date for stainless steels in soil environments. Thirty-two years have passed since scientists buried 6,324 specimens from stainless steel types, specialty alloys, composite configurations, and multiple material forms and treatment conditions at six distinctive soil-type sites throughout the country. Today, there are more than 190 specimens per site, exceeding a total of 1000 specimens that remain undisturbed, a buried treasure of subsurface scientific data. This project will take an interdisciplinary research approach that will correlate the complicated interrelationships among metal integrity, corrosion rates, corrosion mechanisms, soil properties, soil microbiology, plant and animal interaction with corrosion products, and fate and transport of metallic ions.

The results will provide much needed data on corrosion rates, underground material degradation, and the behavior of corrosion products in the near-field vadose zone. The data will improve the ability to predict the fate and transport of chemical and radiological contaminants at sites throughout the DOE complex. This project specifically addresses the EMSP solicitation (LAB-02-03) call for research related to subsurface contamination and transport processes in the vadose and saturated zones. This research opportunity also directly applies to environmental management operational corrosion issues, and longterm stewardship scientific needs for understanding the behavior of waste forms and their near-field contaminant transport. 
Research Project Number: 77

\section{Assessing the State and Distribution of Radionuclide Contamination in Concrete: An Experimental and Modeling Study of the Dynamics of Contamination}

Conceptual Model Input: Source Term

Addresses Need: $\quad 9$. Need research on contaminant release from treated waste forms (grout and vitrified waste).

Principal Investigator: Dr. Brian Viani, Lawrence Livermore National Laboratory

Purpose: To enhance our understanding of how radionuclides bind to concrete and to develop a more accurate predictive capability, which will allow various decontamination approaches to be evaluated.

Project Description: There are hundreds of cement structures in the DOE complex that are contaminated by radionuclides and other chemicals. A fundamental understanding of the factors governing contaminant interactions in concrete is necessary in order to evaluate and model contaminant transport and develop more efficient methods for decontamination and decommissioning (D\&D) efforts. This will be accomplished through a combination of laboratory-based experiments on radionuclide interactions with cementitious materials, along with state-of-the-art materials characterization and transport modeling techniques.

Transport studies, including flow-through and batch sorption tests, will be initiated using the radionuclides $\mathrm{Cs}, \mathrm{Tc}, \mathrm{U}$, and $\mathrm{Pu}$ and ordinary Portland cement with or without aggregates. In addition to standard radioanalytical and microscopic methods, X-ray absorption spectroscopy will be used to provide detailed, element-specific information on radionuclide speciation, including distribution, redox activity, and aging effects. Results from these experiments will be compared to characterization of actual aged concrete cores from contaminated DOE facilities. Transport modeling simulations will use the chemical parameters determined from the lab-based experiments and the materials characterization tasks to predict the depth of contaminant penetration and its chemical form and association in the concrete. Our simulations explicitly account for fracture flow and mineralogical heterogeneity and will be used to predict the effect of fractures and aggregate on the resulting radionuclide distribution. 
Research Project Number: 78

\section{Resolving the Impact of Biological Processes on DNAPL Transport in Unsaturated Porous Media through Nuclear Magnetic Resonance Relaxation Time Measurements}

Conceptual Model Input: Source Term and Vadose Zone

Addresses Need: 9. Need research on contaminant release from treated waste forms (grout and vitrified waste).

Principal Investigator: Dr. Russel Hertzog, Idaho National Engineering and Environmental Laboratory

Purpose: To investigate the capability and limitations of low-field nuclear magnetic resonance (NMR) relaxation decay-rate measurements for determining environmental properties affecting DNAPL solvent flow in the subsurface.

Project Description: Knowing how environmental properties affect dense non-aqueous phase liquid (DNAPL) solvent flow in the subsurface is essential for developing models of flow and transport in the vadose zone that are needed for designing remediation and long-term stewardship strategies. For example, one must know if solvents are flowing in water-wet or solvent-wet environments, the pore-size distribution of the region containing DNAPLs, and the understanding of how physical and biological properties of porous media influence water and DNAPL distribution under saturated and unsaturated conditions.

The oil and gas industry uses NMR measurements in deep subsurface formations to determine porosity and hydrocarbon content and to estimate formation permeability. These determinations rely on NMR's ability to distinguish between water and hydrocarbons in the pore space and to obtain the distribution of pore sizes from relaxation decay-rate distributions. The potential of NMR decay rate distributions for characterizing DNAPL fluids in the subsurface and understanding their flow mechanisms has not been exploited. Near-surface unsaturated vadose zone environments provide unique challenges for using NMR. These challenges will be addressed through systematic laboratory experiments and a program of research to extend and adapt current field NMR measurements to near-surface environmental problems. 
Research Project Number: 79

\section{Differential Group-Velocity Detection of Fluid Paths}

Conceptual Model Input: Vadose Zone and Aquifer

Addresses Need: 1 . Need to determine preferred flow zones in the aquifer for characterization at the regional and subregional scale.

2. Need methods for delineation of flow direction in the aquifer at a facility scale.

Principal Investigator: Dr. Timothy L. Long, Georgia Institute of Technology

Purpose: To develop and test a new technology to aid in the selection and design of remediation options in shallow aquifers.

Project Description: The objective of this technology is to map the primary fluid pathways in shallow soils. Perturbations in the shear wave velocity of the soil would be measured by gauging changes in seismic response either induced by natural processes, (e.g., rainfall) or induced actively by pumping and withdrawing fluids. The observed changes in surface-wave velocity will then be used to map areas where fluids modified the fluid pressure and, hence, the shear-wave velocity. The proposed technique should identify areas reached by the fluids under normal or induced flow patterns. The proposed technique takes advantage of the abilities of signal-processing techniques to detect small differences in propagation. The differences will indicate flow paths relative to a reference structure that need only approximate the actual structure. In effect, an inversion of the perturbation of surface wave velocity is proposed instead of the inversion of surface wave dispersion for structure.

Perturbations in phase velocity can be measured in detail by computing the Fourier transform of the difference of normalized traces. It is expected that the differential measurements will provide significantly better precision than is possible with the direct estimation of the structure from a dispersion curve. During the first year, data reduction techniques will be tested on theoretical and field data. During the second year, one or more field tests of the technique would be carried out. The perturbations in the velocity structure will indicate where, in a time sequence, the pumped fluids have influenced the shear-wave velocity. Areas experiencing the greatest pressure and material properties changes would indicate primary flow paths and zones that are most likely amenable to remediation by extraction or flushing. A time sequence of tests could monitor the dispersion and movement of the induced perturbations. The technique could be used prior to remediation to detect flow paths and, hence, help design an optimal remediation process. It could be used during remediation to detect and determine which zones are reached by the remediation. 
Research Project Number: 80

\section{A Resolution Analysis of Two Geophysical Imaging Methods for Characterizing and Monitoring Hydrologic Conditions in the Vadose Zone}

Conceptual Model Input: Vadose Zone

Addresses Need: $\quad 3$. Need to improve the use of 3D tomography and other cross-hole geophysics for selected facilities to show changes in moisture.

Principal Investigator: Dr. David L. Alumbaugh, University of Wisconsin at Madison

Purpose: To conduct an intensive numerical modeling effort that is aimed at helping to resolve some of the issues for electrical resistivity tomography (ERT) and crossborehole ground-penetrating radar (XBGPR) geophysical methods as applied to characterizing and monitoring vadose zone properties and processes.

Project Description: Geophysical methods are rapidly becoming popular within the DOE complex as possible tools for characterizing subsurface hydrologic properties, as well as monitoring flow and transport processes within the vadose zone at contaminated sites. The reason for incorporating geophysical imaging into site characterization, remediation monitoring, or as a long-term monitoring tool for a site closure plan is simple: these methods offer the possibility to non-destructively characterize subsurface conditions and processes from a limited number of boreholes and/or measurements made on the surface. To convert between geophysical and hydrological properties requires the application of petrophysical models. In general petrophysical models are approximate, empirical relations developed from the studies of core-sized (a few $\mathrm{cm}$ ) samples. However, geophysical images typically have resolutions on the order of fractions of meters or larger.

In the past, there has been little work done to quantify the effect of heterogeneity due to structures that are larger than core samples but still too small to be resolved individually by geophysical imaging. In addition, there has been little work done to quantify the resolution of the imaging schemes that address their ability to characterize spatial heterogeneity within the vadose zone, and produce accurate time-lapse images of flow and transport processes. It is important to consider the cumulative effect of errors in both the geophysical data collection and processing, and within petrophysical models themselves, if interpreters are to understand those features in the images that are real, those that are artifacts, and how much credence can be given to the results in terms accuracy and precision.

This research will consist of four primary tasks: (1) high definition, large-scale numerical modeling of a series of statistically related vadose zone flow and transport processes to yield porosity, moisture content, temperature, and solute concentrations at 5 to $10 \mathrm{~cm}$ intervals throughout a 1000 to $4000 \mathrm{~m}^{3}$ volume hypothetical vadose zone; (2) application and analysis of petrophysical relationships that convert the output of the hydrologic models from task 1 into geophysical parameter fields; (3) generation of synthetic ERT and XBGPR data sets from the geophysical parameter fields generated in task 2, and addition of random measurement noise and biased error to the data; and (4) imaging of the synthetic data sets using standard geophysical processing and inversion techniques, and comparison of the results to the original hydrologic models.

The results of this effort will not only be employed to analyze the resolution and accuracy of the two geophysical methods for imaging within the vadose zone, but also will be applied to better understand data collected. The benefits to the DOE's Environmental Management Program include a thorough evaluation of how well two of the geophysical imaging methods (i.e., ERT and XBGPR) can truly resolve 
subsurface hydrological features and processes within the vadose zone, synthetic data sets for other researchers to use for testing and assessment, and an assessment of an interactive method for determining subsurface flow and transport properties within the vadose zone. 
Research Project Number: 81

\section{Multiphase Flow in Complex Fracture Apertures Under a Wide Range of Flow Conditions}

Conceptual Model Input: Vadose Zone and Aquifer

Addresses Need: $\quad 7$. Need measurement technique to monitor ambient water travel time through the VZ to the SRPA at selected facilities.

Principal Investigator: Dr. Paul Meakin, Idaho National Engineering and Environmental Laboratory

Purpose: To fill important knowledge gaps and develop new conceptual models to understand how pollutants travel in the vadose zone.

Project Description: At several DOE sites and in other countries, pollutants have traveled in the vadose zone much further and faster than predicted. This reveals the inadequacies of both the computer models used to predict the transport of pollutants in the subsurface and the conceptual models on which they are founded. A closely coordinated experimental and computer modeling program has been planned to study multiphase flow in fracture apertures. The hypothesis that focusing flow onto preferred pathways (such as fracture apertures), intermittent flow conditions, and the colloid mediated transport of strongly adsorbed pollutants play an important role in rapidly transporting subsurface contamination will be tested.

Experiments and simulations using several modeling methods will be performed, both under a wide range of flow conditions in realistic, complex fracture apertures (computer-generated fracture apertures using fractal and nonfractal statistical models, well-characterized natural fractal apertures, and/or replicas of natural fracture apertures). The modeling program will be based on methods that are well suited to geometrically complex boundary conditions (realistic fracture aperture geometries) and complex moving interfaces. These methods include lattice-gas/lattice-Boltzmann models, invasion percolation models, molecular dynamics, and smoothed particle hydrodynamics. By using these various methods, we can evaluate different modeling approaches and use computer modeling to extrapolate and interpolate the experiments to a broader range of conditions. The experiments will e performed in a unique and versatile matched-index-of-refraction flow laboratory at INEEL. 
Research Project Number: 82

\section{Advanced Conceptual Models for Unsaturated and Two-Phase Flow in Fractured Rock}

Conceptual Model Input: Vadose Zone

Addresses Need: $\quad 7$. Need measurement technique to monitor ambient water travel time through the VZ to the SRPA at selected facilities.

Principal Investigator: Dr. Michael J. Nicholl, University of Idaho

Purpose: To develop advanced conceptual models for two-phase flow in fractured rock.

Project Description: The Department of Energy's Environmental Management Program is faced with two major issues involving two-phase flow in fractured rock: transport of dissolved contaminants in the Vadose Zone, and the fate of Dense Nonaqueous Phase Liquids (DNAPLS) below the water table.

Conceptual models currently used to address these problems do not correctly include the influence of the fractures, thus leading to erroneous predictions. Recent work has shown that it is crucial to understand the topology, or structure of the fluid phases (air/water or water/DNAPL) within the subsurface. It has also been shown that even under steady boundary conditions, the influence of fractures can lead to a complex and dynamic phase structure that controls system behavior, with or without the presence of a porous rock matrix. Complicated phase structures within the fracture network can facilitate rapid transport, and lead to a sparsely populated and widespread distribution of concentrated contaminants; these qualities are highly difficult to describe with current conceptual models. Our approach is founded on systematic experimentation. As preliminary experiments have shown that behavior at fracture intersections is key, we will begin by conducting systematic experimentation to identify and classify behavior at intersections.

Understanding gained at the scale of intersections will be used to augment a Modified Invasion

Percolation (MIP) model that has shown significant promise in predicting flow through fracture networks. Development of the MIP model will be iterative, in that we will use numerical simulations to design critical physical experiments at the network scale, which will challenge the model. The augmented, and fully tested MIP model will be exercised on realistic fracture networks for the purpose of understanding large-scale development of phase structure. Networks will be generated using algorithms conditioned to field data collected at DOE sites (e.g., INEEL, Nevada Test Site, Oak Ridge). Results of the large-scale network simulations will be abstracted so that critical features may be included in conceptual models used by the Environmental Management Program. 
Research Project Number: 83

\section{Manipulating Subsurface Colloids to Enhance Cleanups of DOE Waste Sites}

\section{Conceptual Model Input: Source Term}

Addresses Need: $\quad$ 14. Need to determine what from the standpoint of geochemistry is influencing transport and retardation.

Principal Investigator: Dr. Philip M. Gschwend, Massachusetts Institute of Technology

Purpose: To improve the basic understanding of the processes involved in detaching colloids from geological media as a result of planned or unplanned changes in the groundwater solution chemistry.

Project Description: Colloidal phases, such as submicrometer iron oxyhydroxides, aluminosilicate clays, and humic macromolecules, are important subsurface sorbents for the low-solubility chemicals in DOE wastes. Recent research has demonstrated that such colloid-sized media may be mobilized in groundwater under certain conditions and thereby may enhance the belowground transport of sorbed contaminants. This colloid-facilitated transport may be problematic if it results in unwanted spreading of groundwater contaminants, but it may be beneficial if it can be controlled and used in efforts to remove low-solubility chemicals from the subsurface. At the present, we do not know the basic mechanisms responsible for holding colloids immobile in aquifers. Further, we are lacking fundamental understandings of the processes involved in detaching colloids from these geological media as a result of planned or unplanned changes in the groundwater solution chemistry.

This research project seeks to improve these basic understandings in a manner which should improve DOE's ability to control and remediate the existing legacy of waste sites. First, the particle:particle associations holding colloids immobile in several characteristic aquifer sands will be observed directly. These aquifer solids will be recovered from: (1) a geological sequence of iron oxyhydroxide-coated beach deposit aquifers extending inland from the coast of South Carolina, and (2) a north-south sample series from representative deposits located in Connecticut (glacial outwash), New Jersey (northern coastal plain), as well as South Carolina (southern coastal plain). Next, our ability to mobilize colloids from these sands will be tested in the laboratory using aqueous solutions of appropriate composition (e.g., low $\mathrm{pH}$, low ionic strength, surfactant amended) suggested by our observations of particle:particle attachments. The solid-solution interactions that limit our ability to impose particular solution conditions will also be investigated. Finally, the colloids at a chromium-contaminated field site (the glacial outwash site in Connecticut noted above) will be purposefully mobilized to ascertain the importance of field properties such as heterogeneous flow paths. 


\section{Colloid Transport and Retention in Fractured Deposits}

Conceptual Model Input: Vadose Zone and Aquifer

Addresses Need: $\quad$ 14. Need to determine what from the standpoint of geochemistry is influencing transport and retardation.

Principal Investigator: Dr. John F. McCarthy, Oak Ridge National Laboratory

Purpose: To assess the relative influence of chemical and physical factors expected to influence colloid transport in fractured materials, and investigate strategies for predictive simulation at the field scale.

Project Description: A series of field-scale and laboratory-scale experiments, using both natural undisturbed samples and simple one-dimension artificial fractures, are proposed to investigate the influence of physical and chemical factors on the transport of colloids in fractured materials (weathered shale saprolite and unweathered shale). The experimental results will be assessed using a computer model (COLFRAC) developed to simulate colloid transport in fractured materials. The experimental methods each operate at different physical/geological scales and can be used with different degrees of experimental control. This allows testing of hypotheses in a relatively simple setting in the laboratory where individual chemical or colloidal characteristics can be varied, and then the results compared with field-scale experiments where the influence of realistic geologic heterogeneity can be incorporated.

Understanding the processes that control colloid behavior will increase confidence with which colloid-facilitated contaminant transport can be predicted and assessed at various contaminated DOE sites. An added benefit is the expectation that this work will yield novel techniques to either immobilize colloid-bound contaminants in situ, or mobilize colloids for enhancing remedial techniques such as pump-and-treat and bioremediation. 
Research Project Number: 85

\section{Plutonium Speciation, Solubilization, and Migration in Soils}

Conceptual Model Input: Source Term, Vadose Zone, and Aquifer

Addresses Need: $\quad$ 14.Need to determine what from the standpoint of geochemistry is influencing transport and retardation.

Principal Investigator: Dr. Mary P. Neu, Los Alamos National Laboratory

Purpose: Provide data for control and prediction of Pu release, metal chemistry in groundwaters and soils, thermodynamic modeling, site decontamination, and risk assessment.

Project Description: The DOE is currently conducting cleanup activities at its nuclear weapons development sites, many of which have accumulated plutonium $(\mathrm{Pu})$ in soils for 50 years. There is scientific uncertainty about the levels of risk to human health posed by this accumulation and whether $\mathrm{Pu}$ is migrating from federal reserves onto public lands. To properly control Pu migration in soils, to better evaluate the public risk, and to design effective remediation strategies, a fundamental understanding of $\mathrm{Pu}$ speciation, transport, and release mechanisms is critically needed. Key elements of this research are:

- $\quad$ Determination of Pu oxidation state(s) and speciation in pond sediments and select soil samples. It is widely believed that $\mathrm{Pu}$ in soils at Rocky Flats Environmental Technology Site (RFETS) is not mobile, yet detention ponds are needed to meet effluent water quality standards. The speciation of $\mathrm{Pu}$ in these soils will be valid for other sites and will increase our understanding of actinide environmental chemistry.

- $\quad$ The Pu concentrations in settling ponds show seasonal variation that correlate very well with $\mathrm{Mn}$ concentrations. Actual pond sediment samples collected on a seasonal basis will be used to evaluate the impact of mineral redox cycling on Pu solubility and mobility. Laboratory studies using synthetic $\mathrm{Mn} / \mathrm{Fe}$ minerals and $\mathrm{Pu}$ species will be performed in parallel to determine the interaction mechanisms between $\mathrm{Pu}$ and these minerals, and the potential change in $\mathrm{Pu}$ mobility due to redox cycling.

- $\quad$ Thermal Ionization Mass Spectrometry (TIMS) analysis to establish plutonium concentrations and distributions, and $\mathrm{Pu}-240 / \mathrm{Pu}-239$ ratios in soils at RFETS, to better understand $\mathrm{Pu}$ pathways from contamination sources and to provide a critical basis to assess public risk from actinide migration. Concentrations and isotopic ratios of $\mathrm{Pu}$ in pond sediments as a function of depth will gauge changes in the Pu chemistry with time.

- Chemical systems important in Pu environmental behavior will be studied, providing critical thermodynamic data, as well as structural and chemical models for environmental samples. The $\mathrm{Pu}$ (III, IV, and V) species to be investigated will include: $\mathrm{Pu}(\mathrm{CO} 3)+, \mathrm{Pu}(\mathrm{OH}) \mathrm{x} 3-\mathrm{x}$, colloidal $\mathrm{Pu}(\mathrm{IV})$ hydroxide, $\mathrm{Pu}(\mathrm{OH}) \mathrm{x}(\mathrm{CO} 3) y 4-\mathrm{x}-2 \mathrm{y}, \mathrm{PuO} 2+$ and $\mathrm{PuO} 2 \mathrm{CO} 3-$. 
Research Project Number: 86

\section{Colloid-Facilitated Transport of Radionuclides Through the Vadose Zone}

Conceptual Model Input: Vadose Zone

Principal Investigator: Dr. Markus Flury, Washington State University

Addresses Need: $\quad$ 14. Need to determine what from the standpoint of geochemistry is influencing transport and retardation.

Purpose: To provide conclusive evidence that indicates under what conditions, if any, colloidfacilitated transport can be expected at the Hanford site, and what the quantitative magnitude of this transport process will be.

Project Description: Radioactive and hazardous waste stored in the underground tanks at the Hanford site has leaked or is suspected to have leaked into the vadose zone. Radionuclides, which are normally considered to be strongly sorbed (e.g., $\mathrm{Pu}$ and $\mathrm{Cs}$ ), have been detected at greater depth than predicted based on current theories of vadose zone contaminant transport. There is strong indication that contaminants can be transported via colloids. Such colloid-facilitated transport is likely to occur at the Hanford site, where contaminants leaking from the storage tanks are released directly to the vadose zone.

At Hanford, the potential for in situ formation of colloids as leaking tank waste enters the vadose zone is high. Tank waste supernatants are known to consist of solutions with high $\mathrm{pH}$, ionic strength, and aluminate concentrations. When such alkaline solutions contact soils and sediments around the tanks, it is likely that soluble silica-rich allophane, feldspathoids, and zeolite-like materials are formed. These negatively charged colloids are capable of adsorbing or coprecipitating with contaminant cations and moving through soil and sediment matrices.

The objectives of this project are to study three major processes responsible for colloid-facilitated transport: (1) formation and mobilization of colloids, (2) association of contaminants with colloidal particles, and (3) co-transport of colloids and contaminants in the vadose zone, specifically considering chemical and geochemical conditions at the Hanford site. The radionuclide Cs is selected as a model contaminant. Soil or sediment samples representative of the porous material under waste storage tanks will be collected at the Hanford site. Formation of colloids will be studied in batch systems by reacting solutions typical for tank waste with vadose zone materials and with solutions expected at equilibrium with soil material. Colloids will be separated and characterized in terms of size, structure, composition, and surface charge characteristics. The interactions of Cs with colloidal particles isolated from the previous step will be investigated with batch sorption experiments and spectroscopic techniques. Transport and co-transport of colloids and the radionuclide Cs will then be studied with a series of laboratory column experiments using repacked Hanford sand material. Experiments will be carried out under unsaturated, steady-state as well as transient water flow to study the effect of water content on colloid transport. Magnetic Resonance Imaging will be used to visualize colloidal movement inside the porous medium. Sorption studies and column outflow data will be analyzed with numerical models to elucidate the relevant mechanisms responsible for contaminant sorption as well as colloid and radionuclide transport.

Sorption and reaction models will be combined with transport models to quantitatively describe the column experiments. The results of the proposed research will lead to a better understanding of colloid-formation, colloid-contaminant-soil interactions, colloid migration, and colloid-facilitated transport in the vadose zone. The experiments proposed use conditions specific to the Hanford site, and the results are therefore directly applicable to clean-up strategies and procedures for Hanford contamination problems. 
Research Project Number: 87

\section{Field-Scale In Situ Measurements of Vadose Zone Flow and Transport Using Multiple Tracers at INEEL Vadose Zone Research Park (VZRP)}

Conceptual Model Input: Vadose Zone

Addresses Need: $\quad 15$. Need to develop better tracer tests to track flow through the interbeds in selected areas.

Principal Investigator: Dr. Robert C. Roback, Los Alamos National Laboratory

Purpose: To obtain a better understanding of vadose zone flow and transport processes at the field scale and establish defensible links between laboratory- and field-derived transport parameters for conservative and reactive elements in the vadose zone. The study site is the Vadose Zone Research Park (VZRP), located at Idaho National Engineering and Environmental Laboratory (INEEL).

Project Description: Processes that influence flow and transport of contaminates through the vadose zone remain poorly understood, despite the fact that the vast majority of contaminated sites nationally and globally are in the vadose zones. As a result, large uncertainties in contaminant transport rates typically exist for many sites. Realistic, field scale transport data are needed to lower these uncertainties and provide greater defensibility in DOE decisions on remedial actions and site closures.

INEEL has a thick vadose zone and is the site of numerous surface and shallow buried waste storage sites, some of which are known to have leaked contaminants to the vadose zone. Most of these contaminated sites are within 101 yards of the study site and share a common geologic and hydrologic setting. The research park provides a three-dimensional instrumentation array strategically surrounding a new infiltration pond slated for initial use in the upcoming year, and the Big Lost River, an intermittent stream proximal to the infiltration ponds.

This study will leverage cost and effort to establish the VZRP, as well as past experience gained from colloid and tracer transport studies conducted for Yucca Mountain Project (YMP)/Nevada Test Site (NTS), to develop a well-constrained data set that is highly relevant to contaminant transport in the vadose zone. It will provide important data to help understand contaminant transport both locally and globally. The proposed research will utilize planned filling of the infiltration ponds as well as flow in the Big Lost River to study the effects of fluid flux, water chemistry and degree of saturation on contaminant transport in the vadose zone, and physical and chemical interactions between the vadose and saturated zones. Our research plan has four major objectives: (1) to determine the transport of conservative and reactive solute tracers and colloid tracers through the vadose zone, local perched water zones, and into the aquifer at VZRP; (2) to examine isotopic variations of $\mathrm{U}$ and $\mathrm{Sr}$, and compare these to introduced sorbing and non-sorbing tracers; (3) to develop and calibrate a conceptual flow and transport model for the site, and (4) to provide the opportunity to examine the effects of flow and geochemical transients on tracer transport. 
Research Project Number: 88

\section{High Resolution Definition of Subsurface Heterogeneity for Understanding the Biodynamics of Natural Field Systems: Advancing the Ability for Scaling to Field Conditions}

Conceptual Model Input: Vadose Zone and Aquifer

Addresses Need: 3. Need to improve the use of 3D tomography and other cross-hole geophysics for selected facilities to show changes in moisture.

7. Need measurement technique to monitor ambient water travel time through the VZ to the SRPA at selected facilities.

Principal Investigator: Dr. Ernest L. Majer, Lawrence Berkeley National Laboratory

Purpose: This research is an integrated physical (geophysical and hydrologic) and microbial study using innovative geophysical imaging and microbial characterization methods to identify key scales of physical heterogeneities that affect the biodynamics of natural subsurface environments.

Project Description: Data from controlled laboratory and in situ experiments at the INEEL TAN site will be used to determine the dominant physical characteristics (lithologic, structural, and hydrologic) that can be imaged in situ and correlated with the microbial properties. Emphasis will be placed on identifying fundamental scales of variation of physical parameters that control transport behavior relative to predicting subsurface microbial dynamics. A key hypothesis addressed is that nutrient flux and transport properties are key factors in controlling microbial dynamics.

The outcome will be an improved understanding of the relationship between physical and microbial heterogeneity, thus facilitating the design of bioremediation strategies in similar environments. The work described here is an extension of current basic research on natural heterogeneity within the DOE/OHER Subsurface Science Program (SSP), and is intended to be one of the building blocks of an integrated and collaborative approach with an INEEL/PNL effort aimed at understanding the effect of physical heterogeneity on transport properties and biodynamics in natural systems. 


\section{Heterogeneity and Scaling in Geologic Media: Applications to Transport in the Vadose and Saturated Zones}

Conceptual Model Input: Vadose Zone and Aquifer

Addresses Need: $\quad 15$. Need to develop better tracer tests to track flow through the interbeds in selected areas.

Principal Investigator: Dr. Stephen R. Brown, New England Research, Inc.

Purpose: To perform a comprehensive study of heterogeneity and scaling of the structure of geologic media from sub-millimeter (pore) scale to the meter scale.

Project Description: The study will focus on measurement of the structure through geophysical methods, synthesis and description through mathematical models, and the implications for flow and transport in the vadose and saturated zones. The primary focus will be on soil and sedimentary materials, but will consider some aspects of fracture geometery in rocks and soils. The following work will be performed to accomplish these goals: (1) perform multi-scale measurements of heterogeneity and scaling of physical properties in the laboratory and at the backyard field scale, (2) describe and synthesize the data and develop mathematical models, and (3) perform parameter studies to explore these models in the context of transport in the vadose and saturated zones. In the course of this project we will develop a substantial data set for each of the samples we study. The data set will include extensive physical properties measurements, imagery, source information, and characterization. We will assemble the appropriate data for each sample together with sufficient auxiliary documentation to characterize both the sample and the data in the collection, and make the results freely available.

The DOE national laboratories have extensive environmental remediation and operations centers as well as research teams specializing in environmental problems. These organizations are concerned largely with pollution prevention, safe disposal of hazardous materials, polluted site identification and characterization, and cleanup of polluted sites. These organizations, and the private-industry subcontractors they hire, require state-of-the-art tools and techniques for characterization and monitoring. Our research will contribute to the effort by providing descriptions of heterogeneities and scaling properties in the vadose and saturated zones with particular emphasis on flow and transport. This work will also provide an important link between some geophysical measurements and fluid transport characteristics. 
Research Project Number: 90

\section{Copy Non-destructive Assay with Accelerator-Based X-ray Fluorescence for Subsurface Science}

Conceptual Model Input: Source Term and Vadose Zone

Addresses Need: $\quad$ 6. Need to know the geochemical characteristics (e.g., oxidation states) of the near field environment for actinides.

9. Need research on contaminant release from treated waste forms (grout and vitrified waste).

Principal Investigators: Doug Wells, Frank Harmon, John Kwolfie, Farida Selim (Idaho State University); Siddhartha Duttagupta (Boise State University); Tim Roney, T. White, J. L. Jones (INEEL)

Purpose: To develop a low-cost accelerator-based X-ray fluorescence technique to assay and image model soil columns, containers of hazardous or radioactive material, and in situ soil bore holes.

Project Description: Most of the problems associated with subsurface science at INEEL and other sites are related to either: (1) nondestructive means of measuring hazardous and radioactive wastes, or (2) measuring, modeling, and remediating the flow of hazardous or radioactive wastes through the vadose zone and aquifer. 


\section{Analysis of Stratigraphic Architecture at INEEL with Implications for the Subsurface Transport of Fluids}

Conceptual Model Input: Aquifer

Addresses Need: 1 . Need to determine preferred flow zones in the aquifer for characterization at the regional and subregional scale.

Principal Investigators: David Rodgers and Catherine Helm-Clark (Idaho State University), and Richard Smith (INEEL)

Purpose: To compile and critique data sets related to the subsurface distribution of materials and identify where new analyses are needed to resolve correlation problems. The results will be incorporated into models of groundwater flow.

Project Description: The architecture of the layers of the Eastern Snake River Plain aquifer exerts a strong influence on groundwater flow paths, because porosity and permeability vary considerably within and between the layers. 
Research Project Number: 92

\section{Developing Analytical Methods to Determine the Chemistry of Plutonium and Other Actinide Association with INEEL Subsurface Materials}

Conceptual Model Input: Source Term and Vadose Zone

Addresses Need: $\quad$ 6. Need to know the geochemcial characteristics (e.g., oxidation states) of the near field environment for actinides.

14. Need to determine what from the standpoint of geochemistry is influencing transport and retardation.

Principal Investigators: Sue B. Clark (Washington State University) and Dean Peterman (INEEL)

Purpose: To develop analytical methods (e.g., synchrotron x-ray microprobe analysis) to provide a significant level of understanding of actinide sorption in INEEL soils and sediments.

Project Description: Fundamental understanding of the geochemistry controlling the transport of plutonium and other radioactive species at INEEL disposal sites is required. 
Research Project Number: 93

\section{Sorption of Cesium in Natural Sediments}

Conceptual Model Input: Source Term and Vadose Zone

Addresses Need: $\quad 6$. Need to know the geochemcial characteristics (e.g., oxidation states) of the near field environment for actinides.

14. Need to determine what from the standpoint of geochemistry is influencing transport and retardation.

Principal Investigators: James B. Harsh, M. Flury, Laura Hanson (Washington State University); Melinda Hamilton and Carl Palmer (INEEL)

Purpose: This study will provide a comprehensive database on cesium-sediment interactions, leading to improvement of reactive sorption and transport models.

Project Description: Cesium is a major contributor to the inventory of radioactivity at Department of Energy sites, and as such is a key contaminant to be considered in clean-up strategies. 
Research Project Number: 94

\section{Characterization of Inorganic Precipitates Formed on Iron Oxide Mineral Surfaces During Colonization by Dissimilatory Iron-Reducing and Sulfate-Reducing Bacteria}

Conceptual Model Input: Source Term and Vadose Zone

Addresses Need: $\quad$ 6. Need to know the geochemcial characteristics (e.g., oxidation states) of the near field environment for actinides.

14. Need to determine what from the standpoint of geochemistry is influencing transport and retardation.

Principal Investigators: Gill Geesey and Catherine Reardon (Montana State University); Deborah Newby and Daphne Stoner (INEEL)

Purpose: To develop methods to prevent further migration of radioactive contaminants.

Project Description: The movement of groundwater through buried waste is generally the major mechanism for transporting hazardous waste beyond its original boundaries. 


\section{Collaborative Research on Direct Microbial Reduction of Mobile Metal lons}

Conceptual Model Input: Source Term, Vadose Zone, and Aquifer

Addresses Need: $\quad$ 6. Need to know the geochemcial characteristics (e.g., oxidation states) of the near field environment for actinides.

14. Need to determine what from the standpoint of geochemistry is influencing transport and retardation.

Principal Investigators: Brent Peyton and Sridhar Viamajala (Washington State University); Al Cunningham and Robin Gerlach (Montana State University); William Apel (INEEL)

Purpose: The research at each institution represents individual pieces of subsurface microbial metal immobilization that must be integrated with INEEL research to develop an effective treatment technology for the remediation of contaminated groundwater.

Project Description: This project will focus on the reducible metal contaminants, uranium and chromium, both of which are of interest to the Department of Energy. 


\section{Collaborative Research on Siderophore Mediated Transport of Uranium in Subsurface Environments}

Conceptual Model Input: Source Term and Vadose Zone

Addresses Need: $\quad$ 6. Need to know the geochemcial characteristics (e.g., oxidation states) of the near field environment for actinides.

14. Need to determine what from the standpoint of geochemistry is influencing transport and retardation.

Principal Investigators: Jim Petersen (Washington State University) and William Apel (INEEL)

Purpose: To investigate the effect of siderophores on metal and radionuclide mobility by studying the effects of salinity and $\mathrm{pH}$ on siderophore production and metal-contaminant siderophore complex stability.

Project Description: Siderophores are low-molecular-weight organic compounds that are released by many bacteria to chelate and solubilize iron. They also bind other metals, including divalent metal cations and actinides, forming stable complexes. They have been implicated as a mechanism of cell-to-cell communication in bacterial biofilm communities, possibly influencing subsurface metal/radionuclide transport and mobility. 
Research Project Number: 97

\section{Isolation and Characterization of Psychrophilic Chromium-Reducing Microorganisms and Enzymes from a Contaminated Aquifer}

Conceptual Model Input: Source Term and Vadose Zone

Addresses Need: $\quad$ 6. Need to know the geochemcial characteristics (e.g., oxidation states) of the near field environment for actinides.

10. Need to perform vertical profiling of contaminant plume geometry to determine layering effects (Such as $\mathrm{Cr}^{6}$ at the Test Reactor Area).

14. Need to determine what from the standpoint of geochemistry is influencing transport and retardation.

Principal Investigators: Peter Sheridan (Idaho State University) and William Apel (INEEL)

Purpose: This project will ascertain the phylogenetic diversity of chromate-reducing bacteria, will close, sequence, and analyze the genes encoding the reductase enzymes, and will elucidate the role of gene transfer in the environment and the extent of gene duplication of reductases.

Project Description: The use of various heavy metals in industrial processes has led to the contamination of a number of environments, necessitating substantial clean-up efforts. Chromium in the $\mathrm{Cr}(\mathrm{VI})$ and $\mathrm{Cr}(\mathrm{III})$ forms are found at several DOE sites. Microbially-mediated reduction of $\mathrm{Cr}(\mathrm{VI})$ to $\mathrm{Cr}(\mathrm{III})$ can be accomplished with mesophiles, but a significant number of chromium-containing environments are in low-temperature regions. Little work has been done to study reduction by psychrophilic (cold temperature-loving) microorganisms. 
Ongoing Research Project Number: 98

\section{Hydrologic Research}

Conceptual Model Input: Aquifer and Vadose Zone

Addresses Need: 1 . Need to determine preferred flow zones in the aquifer for characterization at the regional and subregional scale.

2. Need methods for delineation of flow direction in the aquifer at a facility scale.

6. Need to know the geochemical characteristics (e.g., oxidation states) of the near field environment for actinides.

\section{Principal Investigators: USGS}

Purpose: To collect data to describe the hydrologic and geochemical conditions and to evaluate effects of waste disposal and other activities at the INEEL on the geohydrologic system.

Project Description: Much of the data will be used to prepare interpretive reports. Recently, the USGS opened the National Water Information System (NWIS) web site to the public. This system permits public electronic access and retrieval of USGS water data, including INEEL groundwater and water quality data. The website address is http://water.usgs.gov/nwis/.

The following data will be collected in FY 2003:

1. About 270 water samples will be collected from approximately 170 deep and shallow wells and analyzed for selected chemical and radiochemical constituents to aid in the definition of contaminant plumes and water chemistry. Water samples will be analyzed by the DOE's Radiological and Environmental Sciences Laboratory (RESL), and by the USGS's National Water Quality Laboratory (NWQL) in Denver, Colorado.

2. If flow occurs in the Big Lost River and other selected streams, water samples will be collected periodically and submitted to the RESL and NWQL Laboratories for radionuclide and chemical analyses to determine the effect that surface-water flow has on the chemistry of ground water beneath the INEEL.

3. About 800 depth-to-water measurements in approximately 200 wells and numerous auger holes will be made during FY 2003 to denote changes in storage and hydraulic gradient in the Snake River Plain aquifer and perched-water systems. Operation of six continuous recorders will detect short-term water-level fluctuations and identify recharge events.

4. A historical and statistical analysis of the USGS hydrologic monitoring networks was initiated several years ago. This continuing analysis is designed to support the needs of the USGS modeling program and to evaluate redundancy of measurements. Also, periodic updates of the USGS QA/QC Program are made as a result of this analysis.

Concern has increased in recent years regarding well security issues as they relate to the protection of the environment and the integrity of the ground-water data set. USGS will continue with security modification of wells as required. 


\section{Ongoing Research Project Number: 99}

\section{Aquifer Recharge}

Conceptual Model Input: Aquifer and Vadose Zone

Addresses Need: 1 . Need to determine preferred flow zones in the aquifer for characterization at the regional and subregional scale.

7. Need measurement technique to monitor ambient water travel time through the VZ to the SRPA at selected facilities.

\section{Principal Investigators: USGS}

Purpose: To provide the data necessary for numerical simulation of the groundwater flow system to describe the quantity and distribution of recharge to the aquifer.

Project Description: Recharge can greatly affect the direction of ground-water movement and the configuration of contaminant plumes related to waste disposal. Streamflow records since 1904 at gages on the Big Lost River below Mackay Reservoir were analyzed in 1990 to define the volumes of water that episodically recharge the aquifer. This includes the amounts of water that were diverted into the spreading areas, the infiltration rates along the channel of the river, and the amount that is recharged at the playas. Other sources of episodic recharge, such as diversions onto the INEEL from the Mud Lake area, are being identified and will be quantified to the extent possible. Streamflow records are published in a series of annual reports entitled "Water Resources Data, Idaho." The episodic recharge is incorporated as part of the transient numerical modeling efforts.

In the past, the amount of recharge from the infiltration of rainfall, snowmelt, and streamflow has been assumed to be negligible except along the channel of the Big Lost River and within the INEEL spreading areas. In order to evaluate the validity of this assumption, a small drainage-basin gaging station network study was conducted over the last several years

In late June 1999, the USGS introduced a polyaromatic tracer (1,5 naphthalene disulfonate) into spreading areas A and B near the RWMC. Monitoring results indicate that water from the spreading areas can move laterally in the unsaturated zone to the subsurface disposal area (SDA) at the RWMC in a relatively short period of time (months). Test results also indicate that, at least locally, vertical movement of water through the unsaturated zone to the water table beneath the spreading areas is very rapid — on the order of a week. Because of the proximity of the spreading areas to the SDA and the large quantities of water that have been and may be diverted into these spreading basins, the influence of the spreading areas on contaminant transport at the SDA needs to be evaluated.

A Large-Scale Tracer Test, with multiple tracers in the Big Lost River and spreading areas A and B, is planned for a future date when the timing and quantity of flow in the Big Lost River and the INEEL Spreading Areas are sufficient. 


\section{Ongoing Research Project Number: 100}

\section{Geologic Framework}

Conceptual Model Input: Aquifer and Vadose Zone

Addresses Need: 1 . Need to determine preferred flow zones in the aquifer for characterization at the regional and subregional scale.

2. Need methods for delineation of flow direction in the aquifer at a facility scale.

\section{Principal Investigators: USGS}

Purpose: To use collective data and geophysical logs to quantitatively correlate selected basalt-flow groups, and begin a proposed 5-year effort to construct a three-dimensional hydrogeologic framework model of the INEEL and vicinity in support of the INEEL Long-Term Stewardship Plan.

Project Description: Two new geologic studies will be initiated in FY 2003. The first study will further examine the alteration minerals that are abundant in basalt below the base of the aquifer and better characterize the water-rock interactions that formed these minerals. Cores from five locations are known to contain these minerals. These cores and cores from three additional boreholes suspected of penetrating basalt containing abundant alteration minerals will form the basis of this study. Results of this study combined with stratigraphic data, basalt accumulation rates, and borehole temperature logs may provide an additional quantitative method to predict the depth to the base of the aquifer in large areas of the INEEL where deep coreholes are unavailable for direct determinations of this important hydrogeologic and model boundary. The second will be a study of the geochemistry of selected basalt flows from coreholes USGS 127, 128, and 129, located between the INTEC and RWMC. About 50 samples will be analyzed for petrography and major and trace-element chemical composition to supplement previously acquired paleomagnetic data. These collective data and geophysical logs will be used to quantitatively correlate selected basalt-flow groups, particularly the F and I groups of hydrogeologic units 1 and 2, between these coreholes and other previously studied coreholes at the INTEC and RWMC. In addition, a borehole flowmeter tool will be used to collect water circulation patterns in selected wells, and these patterns will be correlated with stratigraphy to test the validity of model derived particle-tracking results in and near known waste plumes in this part of the INEEL.

Differences in the polarity and inclination of remanent magnetization present in the rocks comprising the Snake River Plain aquifer at the INEEL offer the most reliable and cost effective means of differentiating the basalt flows. Cores from five boreholes were used to better define the basalt flows of hydrogeologic units 1 and 2 in the vicinity of the INTEC and CFA. Cores from USGS 128 (770 ft), ICPP-SCI-V-213 $(560 \mathrm{ft}), \mathrm{CPP}-185(500 \mathrm{ft}), \mathrm{CPP}-186(500 \mathrm{ft})$, and USGS $129(770 \mathrm{ft})$ were analyzed for their polarity and inclination. Results from approximately 900 samples from the combined 3,100 ft of core from these wells were compared to previously studied cores.

FY 2003 also will mark the beginning of a proposed 5-year effort to construct a three-dimensional hydrogeologic framework model of the INEEL and vicinity in support of the INEEL Long-Term Stewardship Plan. This model will be constructed using EarthVision software, a tool that provides visualization, data integration, and data analysis capabilities needed for a comprehensive approach to understanding and managing post-remediation issues at the INEEL. The first step in implementing EarthVision is to construct a 3-D geologic framework model. It is estimated that it will take approximately two years to construct the geologic framework model using geologic maps and lithologic and geophysical data from hundreds of boreholes. The geologic framework model will then be evaluated 
to determine the feasibility of undertaking 3 years of additional work for full scope implementation of EarthVision that will include integration and analysis of "nongeologic" data such as hydrologic, thermal, geochemical, and contaminant data. 


\section{Geochemistry - Rock Water Interactions}

Conceptual Model Input: Aquifer and Vadose Zone

Addresses Need: 1 . Need to determine preferred flow zones in the aquifer for characterization at the regional and subregional scale.

2. Need methods for delineation of flow direction in the aquifer at a facility scale.

4. Need to better define the porosity and permeability in selected areas.

7. Need measurement technique to monitor ambient water travel time through the VZ to the SRPA at selected facilities.

\section{Principal Investigators: USGS}

Purpose: To understand the chemistry of groundwater and the transport of solutes in the system.

Project Description: The northern part of the INEEL is situated in a closed topographical depression where rapidly infiltrating surface water mixes with groundwater derived from several tributary valleys, from groundwater moving into the area from the northeast, and possibly with water upwelling from the deep groundwater system. The water from each of these sources has a different chemistry that is related to the unique water-rock interactions that have taken place throughout its travel history. When these waters mix, the chemistry of water in the Snake River Plain aquifer at the INEEL is impacted. As this water moves in the Snake River Plain aquifer at and downgradient from the INEEL, the water is further impacted by the characteristics of the groundwater flow system, and by the effects of waste disposal.

In order to understand the chemistry of groundwater and the transport of solutes in the system, the following tasks are identified:

1. Develop reaction-path models of groundwater in the tributary valleys that recharge the Snake River Plain aquifer. The results of these studies will be used to develop a mixing model at and near the INEEL.

2. Develop a local meteoric water line derived from atmospheric precipitation data. The definition of the stable isotopic composition of hydrogen and oxygen in precipitation provides a baseline for comparing similar data derived from groundwater, surface-water, and solid-phase samples collected at the INEEL and vicinity. These comparisons provide a tool for identifying physical and chemical processes that affect the geochemistry of the Snake River Plain aquifer system and for identifying sources of recharge to the system

3. Develop a mixing model using chloride, a conservative ion, to evaluate the internal consistency of the USGS conceptual and steady-state models of groundwater flow at and near the INEEL. Recharge waters with known water-chemistry will be proportionately mixed with water from the Snake River Plain aquifer to determine if the assumptions regarding the magnitude of volumetric fluxes and directions of flow in the conceptual and steady-state flow models are reasonable. The conceptual model of flow in the Snake River Plain aquifer at the INEEL indicates strong structural and stratigraphic controls on migration of contaminants. Independent lines of evidence are essential to verify these controls. Evaluation of the internal consistency of flow and transport models will be 
conducted using independent lines of evidence (other than chloride) such as temperature, specific conductance, isotopes, trace elements, and other constituents. 


\section{Hydraulic Properties}

Conceptual Model Input: Aquifer and Vadose Zone

Addresses Need: 1 . Need to determine preferred flow zones in the aquifer for characterization at the regional and subregional scale.

2. Need methods for delineation of flow direction in the aquifer at a facility scale.

4. Need to better define the porosity and permeability in selected areas.

7. Need measurement technique to monitor ambient water travel time through the VZ to the SRPA at selected facilities.

15. Need to develop better tracer tests to track flow through the interbeds in selected areas.

\section{Principal Investigators: USGS}

Purpose: To quantify unsaturated-zone hydraulic properties and to use laboratory-measured properties to develop a model to predict hydraulic properties from particle-size distributions for INEEL sediments.

Project Description: Hydraulic properties of the Snake River Plain aquifer govern the velocity of ground-water movement and the migration of contaminants in the aquifer. In previous years, tests were conducted to provide information on aquifer transmissivity, and the hydraulic conductivity of rock units that make up the aquifer. As new wells are drilled, or as pumps are installed in existing wells, additional tests will be conducted to further document the spatial and vertical distribution of the hydraulic properties of the aquifer. Because hydraulic properties also control the movement of contaminants in the unsaturated zone and because little information on these hydraulic properties is available, during FY 2003 most of the USGS resources for this work element will be used for quantification of unsaturated-zone hydraulic properties.

In late FY 1998, a study was initiated to develop a methodology for the field determination of the hydraulic properties of the sedimentary interbeds. In outyears, we anticipate that the results of this study will be used to systematically evaluate the hydraulic properties of the sedimentary interbeds wherever new boreholes are drilled that penetrate these hydrogeologic units. Besides developing methodology and equipment for hydraulic and tracer borehole tests, this research will be directed toward developing a model to predict hydraulic properties from particle size distributions for INEEL sediments with the objective of creating a tool for inexpensive determination of unsaturated-zone hydraulic properties throughout the Snake River Plain.

An investigation of hydraulic properties of the sedimentary interbeds near the RWMC began in late FY 1998 and recently has been expanded to include the INTEC. One objective of this study is to obtain high-quality unsaturated hydraulic property measurements on interbed core samples using the steady-state centrifuge method, which provides accurate hydraulic conductivity measurements over a large range of water contents. Laboratory measurements have been completed on interbed samples from corehole SCI-V-215 adjacent to the new INTEC percolation ponds, and from multiple coreholes between the Big Lost River and the INTEC ponds. 
A major objective of the interbed investigation is to use laboratory-measured properties for developing a model to predict hydraulic properties from particle-size distributions for INEEL sediments. This will create a tool for inexpensive determination of unsaturated-zone hydraulic properties throughout the Snake River Plain. A database has been assembled using available hydraulic and bulk property data from the USGS, INEEL contractors, and local universities. The data are being evaluated statistically, looking for strong correlations between individual hydraulic properties, such as saturated hydraulic conductivity, saturated water content, air-entry potential, and the shape parameter for the water retention curve, and bulk properties (textural class percentages and the geometric mean and standard deviation of particle sizes). Multiple linear regression formulas will be developed that can be easily implemented for future estimation of hydraulic properties without the need for direct measurement. The model will be tested against data included in the original regression analysis and other data as it becomes available. Future hydraulic property measurements on interbed core samples will be used to corroborate the model results. 


\section{Groundwater Flow and Contaminant Transport Models}

Conceptual Model Input: Aquifer and Vadose Zone

Addresses Need: 1 . Need to determine preferred flow zones in the aquifer for characterization at the regional and subregional scale.

2. Need methods for delineation of flow direction in the aquifer at a facility scale.

7. Need measurement technique to monitor ambient water travel time through the VZ to the SRPA at selected facilities.

\section{Principal Investigators: USGS}

Purpose: To use the groundwater flow and contaminant transport models to evaluate the sensitivity of transient conditions on contaminant movement in the Snake River Plain aquifer and provide the platform for development of a transport model for the INEEL subregion.

Project Description: A two-dimensional numerical solute-transport model of the Snake River Plain aquifer at the INEEL is described in a report that was published in 1974. Recent data indicate that the waste products have not moved as far as was predicted by the numerical model constructed in 1974 . Generally, contaminant concentrations are smaller than those predicted by the model. However, during 1983, 1985, and 1986, tritium was detected in samples from wells along INEEL's southern boundary in concentrations similar to those that were predicted for 1980 .

To identify boundary conditions for a regional numerical model of ground-water flow at the INEEL, a 1980 three-dimensional flow model of the eastern Snake River Plain was revisited in 1993. In early 1995, an advective transport study was completed that: (1) described the compartments in the aquifer that function as intermediate- and regional-flow systems, (2) described pathlines for flow originating at or near the water table, and (3) quantified travel times for water in the aquifer as a result of advective transport. This work is needed to recalibrate or construct sub-regional hydraulic and transport models of the aquifer at the INEEL. The intermediate- and regional-flow compartments, and pathline and traveltime analyses are crucial to identifying the boundary conditions for models of the aquifer at the INEEL.

In late 1995, construction of a 3-dimensional hydraulic model was initiated. This hydraulic model is needed to model advective and solute transport. As part of this study, a draft conceptual model of flow in the Snake River Plain aquifer in the INEEL subregion was prepared and reviewed internally. 
Ongoing Research Project Number: 104

\section{SDA Probing}

Conceptual Model Input: Vadose Zone and Source Term

Addresses Need: $\quad 6$. Need to know the geochemical characteristics (e.g., oxidation states) of the near field environment for actinides.

9. Need research on contaminant release from treated waste forms (grout and vitrified waste).

11. Need development and testing of the in situ geochemical probe to measure $\mathrm{EH}, \mathrm{Ph}$, and ORP for selected ions in vadose zone studies.

13. Need studies of chemical state of the waste form in the Subsurface Disposal Area and other sites.

14. Need to determine what from the standpoint of geochemistry is influencing transport and retardation.

Principal Investigators: T.J. Meyer, Idaho National Engineering and Environmental Laboratory

Purpose: To provide in situ information about the buried waste at the SDA. This will include the radioactive content of the waste and will help to delineate areas greater than 100 microcuries per gram.

Project Description: This project has performed probing at the SDA utilizing Type A probes. Future work will consist of using Type B probes in the SDA. 


\section{Pit 9 Retrieval RWMC 7-10}

Conceptual Model Input: Aquifer, Vadose Zone, and Source Term

Addresses Need: $\quad 6$. Need to know the geochemical characteristics (e.g., oxidation states) of the near field environment for actinides.

9. Need research on contaminant release from treated waste forms (grout and vitrified waste).

12. Need studies of physical waste form of contaminants in the Subsurface Disposal Area and other sites.

13. Need studies of chemical state of the waste form in the Subsurface Disposal Area and other sites.

Principal Investigators: Larry Hull and Gary Groenewold, Idaho National Engineering and Environmental Laboratory

Purpose: To demonstrate retrieval from Pit 9-GEM 7-10 Project, and perform geochemical investigation of the materials retrieved and surrounding soils.

Project Description: This project will analyze retrieved material for radiological and chemical content including excavated soils encountered during retrieval. Results will be utilized to evaluate the success of the retrieval, valance oxidation states, retardation, and source term release mechanisms. 


\section{Development of SDA Tracer Testing}

Conceptual Model Input: Aquifer and Vadose Zone

Addresses Need: 1 . Need to determine preferred flow zones in the aquifer for characterization at the regional and subregional scale.

2. Need methods for delineation of flow direction in the aquifer at a facility scale.

7. Need measurement technique to monitor ambient water travel time through the VZ to the SRPA at selected facilities.

15. Need to develop better tracer tests to track flow through the interbeds in selected areas.

Principal Investigators: Gail Olsen

Purpose: To develop a tracer test to test the possible impacts to the SDA due to infiltration from the spreading areas.

Project Description: There is a need to quantify potential infiltration from the Big Lost River spreading areas as impacts are being seen at the SDA due to water in the spreading areas. This project will develop a tracer test and will evaluate the tracers to be placed in the spreading areas, the methodology for monitoring the tracers, and a surface injected tracer in a single SDA well.

The expected results from this project are to be able to trace lateral transport back to the source in the spreading area, develop flow information in the aquifer, and determine travel time from the ground surface through the vadose zone to the aquifer. 
Ongoing Research Project Number: 107

\section{Grouting Studies}

Conceptual Model Input: Vadose Zone and Source Term

Addresses Need: $\quad 9$. Need research on contaminant release from treated waste forms (grout and vitrified waste).

Principal Investigators: Brandt Meagher, Idaho National Engineering and Environmental Laboratory

Purpose: To perform bench scale testing for grouting in order to be able to predict effectiveness of various grout materials for possible use in grouting buried waste sites. The project also is designed to look at in situ thermal desorption of grout materials.

Project Description: The expected results from these studies will be the ability to predict appropriate contaminant release rates from grouted materials in order to evaluate long-term effectiveness of grouting buried waste. 


\section{Development of a Comprehensive Groundwater Sample Results Database}

Conceptual Model Input: Aquifer, Vadose Zone, and Source Term

Addresses Need: The database would be utilized in addressing all 15 R\&D needs

Principal Investigators: Thomas R. Wood, Idaho National Engineering and Environmental Laboratory

Purpose: To compile groundwater analytical data into a single electronic database.

Project Description: In order to adequately model, assess, and track the groundwater monitoring and groundwater impacts on a site-wide basis, a comprehensive groundwater sample results database is needed to provide all the information necessary to adequately evaluate the groundwater information collected. Compiling groundwater analytical data into a single electronic database will allow for data from Environmental Restoration Information System (ERIS), USGS, individual waste area group (WAG) databases, ANL-West data and other sources as available to be included for evaluation. 


\section{Evaluate Groundwater Data}

Conceptual Model Input: Aquifer and Vadose Zone

Addresses Need: 1 . Need to determine preferred flow zones in the aquifer for characterization at the regional and subregional scale.

2. Need methods for delineation of flow direction in the aquifer at a facility scale.

10. Need to perform vertical profiling of contaminant plume geometry to determine layering effects (Such as $\mathrm{Cr}^{6}$ at the Test Reactor Area).

Principal Investigators: Thomas R. Wood, Idaho National Engineering and Environmental Laboratory

Purpose: To evaluate groundwater data on a continuing basis.

Project Description: To achieve the purpose of this project, the following will be done: (1) evaluate the current monitoring network of 23 wells by trending data on hand; (2) interact with WAGs to generate contaminant specific plume maps, look for holes in monitoring network; (3) evaluate groundwater data to identify if existing analytical data can demonstrate compliance with maximum constraint levels (MCLs) or other risk-based concentrations as appropriate, and provide recommendations for improving the data set through post-ROD monitoring; (4) prepare a long-term groundwater monitoring plan based on trending of the well data and holes for plume in the monitoring network; and (5) prepare site-wide water table map on an annual basis. 
Ongoing Research Project Number: 110

\section{Evaluate Potentially Co-mingled Plumes}

Conceptual Model Input: Aquifer

Addresses Need: 1 . Need to determine preferred flow zones in the aquifer for characterization at the regional and subregional scale. (Aquifer \& Vadose Zone)

2. Need methods for delineation of flow direction in the aquifer at a facility scale.

10. Need to perform vertical profiling of contaminant plume geometry to determine layering effects (Such as $\mathrm{Cr}^{6}$ at the Test Reactor Area).

Principal Investigators: Thomas R. Wood, Idaho National Engineering and Environmental Laboratory

Purpose: To identify and plot areas where co-mingling of groundwater plumes may be taking place.

Project Description: This task will use current data from the database and data provided by the individual WAGs in an attempt to identify and plot areas where co-mingling of groundwater plumes may be taking place. The residual groundwater contaminants will be evaluated until 2095 to ensure compliance with MCLs or other risk-based concentrations as appropriate, throughout the INEEL. This task will interact with WAGs to assemble existing plumes on single maps (by contaminant). Identify and document vertical aquifer profiling data on hand from WAGs.

Vertical profile sampling of new wells will be conducted to evaluate the vertical extent of a contaminant plume in order to better evaluate the potential for co-mingling plumes. Vertical profile sampling conducted by individual WAGs will also be used, if available. The available data will be evaluated to determine the need for additional vertical profile sampling or for multiple well completion zones or nested well sets. The plans for these wells will be discussed with the Agencies.

A site-wide map with predicted plume geometries for 100-year compliance will be generated, as will a plan or report for assessing the validity of concern for co-mingled plumes at INEEL scale. 


\section{Evaluate Groundwater Quality}

Conceptual Model Input: Aquifer, Vadose Zone, and Source Term

Addresses Need: $\quad$ 6. Need to know the geochemical characteristics (e.g., oxidation states) of the near field environment for actinides.

14. Need to determine what from the standpoint of geochemistry is influencing transport and retardation.

Principal Investigators: Thomas R. Wood, Idaho National Engineering and Environmental Laboratory

Purpose: To evaluate groundwater quality for current compliance with MCLs or other risk-based concentrations

Project Description: The site-wide groundwater will be evaluated to assess compliance with the groundwater MCLs, or other risk-based concentrations as appropriate, at the downgradient and perimeter boundary wells using current data. WAG 10 's primary responsibility will be to interact with the other WAGs to monitor success of the individual WAGs remedial action to control groundwater contamination.

If groundwater is found to be impacted above MCLs or other acceptable risk-based concentrations after the individual WAG groundwater monitoring is turned over to WAG 10, the remedial methods selected for the WAG in their original record of decision (ROD) would be reinstated after notification of the problem to, and with the concurrence of, the Agencies. If a new impact or new site is identified that becomes the responsibility of WAG 10 , a decision process and evaluation of alternatives will be prepared for review and concurrence by the Agencies. 


\section{Ongoing Research Project Number: 112}

\section{Revise Sitewide Groundwater Model}

Conceptual Model Input: Aquifer

Addresses Need: 1 . Need to determine preferred flow zones in the aquifer for characterization at the regional and subregional scale. (Aquifer \& Vadose Zone)

2. Need methods for delineation of flow direction in the aquifer at a facility scale.

Principal Investigators: Thomas R. Wood, Idaho National Engineering and Environmental Laboratory

Purpose: To estimate groundwater flow pathlines and velocities on the sub-regional scale.

Project Description: The WAG 10 modeling will complement the modeling studies of the individual facility-specific WAGs but is not intended to reproduce their risk assessment calculations. Rather, WAG 10-08 will focus on updating the new WAG 10 scale advective velocity field through integration of new information developed from regional, sub-regional, facility-specific WAG, and other studies. Work elements included in this study include:

- $\quad$ Finish INEEL-wide 3-D stratigraphic model

- $\quad$ Perform calibrated steady-state model (7/30/03) particle-tracking of WAG 10 model (1994 data set)

- $\quad$ Evaluate and interpret middle 1823 data set (1600 ft deep corehole) including temperature logs and correlate to INEEL scale flow paths 2003)

- Use new data (water levels, geochemistry, trace isotope, thermal profile, middle 1823 data and other) to update. Make available to other WAGs INEEL-wide advective flow fields (both horizontal and vertical)

- Update, modify, support other WAG modeling efforts, and incorporate transport as appropriate into model.

The advective flow velocity field will be used to estimate groundwater flow pathlines and velocities on the sub-regional scale, integrate smaller scale flow systems, obtain an INEEL scale groundwater flow balance, assure flow consistency in the other WAG models, and provide support for the other WAG models groundwater flow boundary conditions. 
Ongoing Research Project Number: 113

\section{Risk Evaluation for Groundwater}

Conceptual Model Input: Aquifer

Addresses Need: 1 . Need to determine preferred flow zones in the aquifer for characterization at the regional and subregional scale

2. Need methods for delineation of flow direction in the aquifer at a facility scale.

6. Need to know the geochemical characteristics (e.g., oxidation states) of the near field environment for actinides.

10. Need to perform vertical profiling of contaminant plume geometry to determine layering effects (Such as $\mathrm{Cr}^{6}$ at the Test Reactor Area).

14. Need to determine what from the standpoint of geochemistry is influencing transport and retardation.

Principal Investigators: Thomas R. Wood, Idaho National Engineering and Environmental Laboratory

Purpose: To model all the contaminant sources and provide comprehensive risk results.

Project Description: The process for site-wide groundwater risk assessment will be to identify contaminants and plumes of potential concern, their locations, including any overlapping portions, and contaminant peak times from the comprehensive groundwater risk assessments previously conducted at each facility. This includes identifying any changes in contaminant concentrations from remedial efforts performed by each WAG and incorporating all other groundwater modeling efforts. Criteria for screening of contaminants and plumes from the site-wide evaluation will be outlined. Screening will be performed if appropriate risk-based criteria can be developed. The results of previous plume evaluations will be combined with newly collected data. Although the risks posed by most individual contaminant source have been evaluated, the individual evaluations are not necessarily consistent (with respect to conceptual models and assumptions) and, therefore, the risks cannot necessarily be accumulated to provide a cumulative risk. A process is being developed to model all the sources and provide comprehensive risk results. The process will use consistent conceptual models and modeling assumptions, as well as contaminant transport computational tools that have been used in past risk evaluations.

Results of the modeling will include such things as the location of plumes and locations of the intersecting plumes (crossover areas) of contaminants of concern and their resulting concentrations in time. At each of these locations, areas with maximum concentrations, it will be assumed that a groundwater drinking well is present for residential exposure. The pathways of concern will include ingestion of groundwater and homegrown produce (as a conservative measure). Contaminants of concern will be analyzed using the most recent standard risk assessment methodologies for home grown produce outlined by EPA in 1999, and MCLs or other appropriate risk-based concentrations for drinking water. This assessment will address risk from multiple plumes and contaminants of concern across space and time. 
Ongoing Research Project Number: 114

\section{TRA WAG-2 Perched Water Study}

Conceptual Model Input: Aquifer and Vadose Zone

Addresses Need: $\quad 6$. Need to know the geochemical characteristics (e.g., oxidation states) of the near field environment for actinides.

10. Need to perform vertical profiling of contaminant plume geometry to determine layering effects (Such as $\mathrm{Cr}^{6}$ at the Test Reactor Area).

14. Need to determine what from the standpoint of geochemistry is influencing transport and retardation.

Principal Investigators: Thomas R. Wood, Idaho National Engineering and Environmental Laboratory

Purpose: To investigate and track the movement and concentration of $\mathrm{Cr}$, Tritium, and Sr-90 in perched water and aquifer from the potential source at Test Reactor Area (TRA).

Project Description: The study will provide the data necessary to track the source of Cr, Tritium, and Sr-90 at TRA that is being monitored in the perched water wells. This data will be used to predict risk from the concentration of $\mathrm{CR}$ remaining after degradation. This is correlated to pre-ROD modeling showing that $\mathrm{Cr}$ would be below MCL in 2017. Also, the study will provide an investigation of the sources of perched water at TRA. 


\section{Tank Farm Closure Performance Assessment and Composite Analysis}

Conceptual Model Input: Aquifer, Vadose Zone, and Source Term

Addresses Need: $\quad$ 6. Need to know the geochemical characteristics (e.g., oxidation states) of the near field environment for actinides.

7. Need measurement technique to monitor ambient water travel time through the VZ to the SRPA at selected facilities.

14. Need to determine what from the standpoint of geochemistry is influencing transport and retardation.

15. Need to develop better tracer tests to track flow through the interbeds in selected areas.

Principal Investigators: Portage Environmental

Purpose: To evaluate the long-term performance of closure options considered for the Tank Farm Facility at INTEC in terms of potential radiological impacts to the groundwater.

Project Description: Impacts to the groundwater were measured in terms of the all pathway radiological dose and adherence to federal maximum contaminant limits. This project evaluates the potential impacts to groundwater from residual radioactive contamination left in waste storage tanks and the soil surrounding at the Idaho Nuclear Technology Center (INTEC). Several computer models were used to simulate: (1) failure of the stainless steel waste storage tanks, (2) release of radionuclides from the stainless steel tanks and into the surrounding soil, (3) leaching of radionuclides in contaminated soil surrounding the tanks, and (4) radionuclide transport in the unsaturated zone and aquifer.

This project is a direct application of the conceptual models now in use at the site for the source, vadose zone, and aquifer. 
Ongoing Research Project Number: 116

\section{INTEC CERCLA Disposal Facility (ICDF) Performance Assessment}

Conceptual Model Input: Aquifer, Vadose Zone, and Source Term

Addresses Need: 1 . Need to determine preferred flow zones in the aquifer for characterization at the regional and subregional scale.

7. Need measurement technique to monitor ambient water travel time through the VZ to the SRPA at selected facilities.

14. Need to determine what from the standpoint of geochemistry is influencing transport and retardation.

Principal Investigators: James M. McCarthy, Arthur S. Rood, Karen N. Keck (INEEL)

Purpose: To evaluate the long-term performance of the ICDF in terms of potential impacts to the groundwater. Impacts are measured in terms of the all pathway radiological dose and adherence to federal maximum contaminant limits.

Project Description: This project uses expected low-level radioactive waste disposal inventories and engineered cover designs, and couples them with mathematical and computer models to simulate the release and transport of radionuclides from the INEEL CERCLA Disposal Facility (ICDF) in future times. Its primary output is estimates of radiological impacts to the groundwater. The analysis is prospective in nature and must follow the guidance provided by DOE in DOE O 435.1. This guidance stipulates that long-term performance of the facility must be evaluated along with composite impacts from all facilities in the vicinity of the proposed disposal facility. This second analysis is termed a composite analysis. Initial engineering studies of the cover and vadose zone transport were performed using a finite difference model (STOMP) by an outside contractor. A far simpler model was calibrated to its output (GWSCREEN) and used to simulate the projected radionuclide inventories that are to be disposed in the ICDF.

This project is a direct application of the conceptual models now in use at the site for the source, vadose zone, and aquifer. 


\section{INTEC WAG-3 Tracer Studies}

Conceptual Model Input: Aquifer and Vadose Zone

Addresses Need: 11. Need development and testing of the in situ geochemical probe to measure Eh, $\mathrm{pH}$, and ORP for selected ions in vadose zone studies.

14. Need to determine what from the standpoint of geochemistry is influencing transport and retardation.

15. Need to develop better tracer tests to track flow through the interbeds in selected areas.

Principal Investigators: Erick Neher, PI and MSE (INEEL)

Purpose: Review INTEC WAG-3 tracer studies and evaluate the results.

Project Description: During Phase I of the study, batch test studies were performed of various fluorescent tracer dyes to find which tracer would work best in the subsurface sediments at INTEC. Approximately 1,500 batch tests were performed to show conservative studies. The purpose of the study was to determine the influence of specific INTEC recharge sources for the perched water systems and to establish baseline conditions in terms of contaminant concentrations and moisture levels in the vadose zone before service wastewater discharge was diverted from the former percolation ponds at INTEC to the new percolation ponds.

The tracer tests from Phase I were inconclusive due to the high sorption rates of tracer dye on alluvium and interbed material, but the tests did provide clues and estimates of water velocities concerning the movement of recharge water. The new field data (water level, isotope, and geochemical), coupled with historical data, suggest that the two principal water systems at INTEC are isolated and do not influence each other. 
Ongoing Research Project Number: 118

WAG-3 Vadose Zone Isotope Geochemistry

Conceptual Model Input: Vadose Zone

Addresses Need: $\quad 7$. Need measurement technique to monitor ambient water travel time through the VZ to the SRPA at selected facilities.

14. Need to determine what from the standpoint of geochemistry is influencing transport and retardation. (Aquifer, Vadose Zone, \& Source Term)

15. Need to develop better tracer tests to track flow through the interbeds in selected areas.

Principal Investigators: Erick Neher (INEEL) and Mark Conrad (LBNL)

Purpose: To sample all available perched water wells at INTEC for $\mathrm{H}, \mathrm{O}, \mathrm{Sr}, \mathrm{C}, \mathrm{N}, \mathrm{U}$, and stable isotopes.

Project Description: The expected results of the study were to be able to identify and differentiate sources of vadose zone and perched water recharge. The study was also designed to identify transport rates through the vadose zone. The isotope geochemistry can also be used to distinguish transport, general geochemistry, and contaminant geochemistry in the vadose zone and in perched water bodies. 
Ongoing Research Project Number: 119

\section{INTEC Geochemical Systems Study}

Conceptual Model Input: Vadose Zone

Addresses Need: $\quad 7$. Need measurement technique to monitor ambient water travel time through the $\mathrm{VZ}$ to the SRPA at selected facilities.

14. Need to determine what from the standpoint of geochemistry is influencing transport and retardation. (Aquifer, Vadose Zone, \& Source Term)

15. Need to develop better tracer tests to track flow through the interbeds in selected areas.

Principal Investigators: Erick Neher, PI (INEEL)

Purpose: To evaluate the full perched water/facility discharge system at INTEC

Project Description: The study will utilize stable isotopes, $\mathrm{H}, \mathrm{O}$, and nitrates to evaluate the full perched water/facility discharge system at INTEC for:

- $\quad$ Facility Discharges

- $\quad$ Effects of Precipitation

- Influence of infiltration from the Big Lost River.

The work will be performed by sampling discharge points and perched water monitoring wells for four quarters. The study is expected to provide an enhanced understanding of facility discharges, precipitation, and the influence of the Big Lost River on flow and transport in the subsurface. 